\title{
An Empirical Study of the Retums on Defaulted Debt and the Disc ount Rate for Loss-Given-Default
}

Draft: May 2009

J.E.L. Classific ation Codes: G33, G34, C25, C 15, C 52.

Keywords: Recoveries, Defa ult, Loss Given Default, Recoveries, Credit Risk, Basel, Distressed Debt 


\begin{abstract}
Prudential management of credit risk a nd supervisory requirements call for the accurate measurement of loss conditional upon defa ult (LGD). In the case of banks, in order to a chieve Advanced Intemal Ratings Based (AIRB) compliance under the Basel II minimum regulatory capital framework, loss a rising from counterparty default must be estimated. However, the discount rate to be applied to post-default cash flows is a largely unsettled issue, a mongst both practitioners and bank supervisors. In this study we survey various methodologies extant in the literature for detemining an appropriate discount rate. We propose an approach in which the discount rate is conditional upon the level or undiversifiable risk inherent in the recovery cash flows associated with defa ulted facilities. We present a stylized theoretic al framework for understanding such an approach. This is followed by an empiric al exerc ise that utilizes a comprehensive and commercially available database of workout recoveries, in which we analyze the retums on marketable bonds and loans, having market prices at default and at the resolution of the default event. We propose altemative empinical measures of the recovery risk inherent in post-default cash-flows: the annualized simple retum on defaulted debt (RDD) and the most likely disc ount rate (MLDR); and disc ount rates implied from a structural model of credit risk incorporating systematic recovery risk, a genera lization of the a symptotic single risk factor (ASRF) framework (Gordy, 2003). We find our empinically derived estimates to be signific antly higher than what has been found in the previous literature, a s well as what is used in industry, mean (MLE estimate of) RDD (MLDR) of $29.2 \%$ (21.3\%); this compares to benchmarks such as the $15 \%$ reported by Araten (2004), the $200 \mathrm{bps}$ over the risk-free rate suggested by Machlachlan (2004), or rates in the range of 10-15\% derived from model-based estimations (one or two factor structural credit models in conjunction with an assumption on the systematic risk factor). Principal find ings a re that retums on defaulted debt, which can be interpreted as an ap propriate discount rate for workout recoveries, vary significantly according to certa in different factors. There is some evidence that discount rate metric s a re elevated for loans having better collateral qua lity rank or better protected tranches within the capital structure; and for obligors rated higher at origination, more financially levered or having higher Cumulative Abnomal Retums (CARs) on equity just prior to default. However, the disc ount rate is increasing in market implied loss severity at default. We also find evidence that LGD discount rates vary pro-cyclically, as they inc rease with industry default rates, but there tends to be some a synchrono usity in this relationship; further, they a re inversely related to short-term interest rates. However, for other demographic s the results are inc onclusive, such as the industry group of the obligor. Finally, we conduct an a nalysis of the impact of the disc ounting method upon the distribution of estimated LGD and regulatory capital. We find that a regression model based discounting, for a sub-sample of the MULGD database, results in a capital charge 73 bps greater than discounting at a constant punitive rate of $25 \%$, and 113 bps larger than discounting at the contractual coupon rate (where the capital charge ranges in 7-8\%). This conservativeness of the risksensitive RDD model, as well as the evidence that the risk in recovery cash flows conta in a signific ant non-diversifiable component, supports the appropriateness of this framework for regula tory capital calculations.
\end{abstract}




\section{Introduction and Summary}

Fina ncial institutions world wide a re grappling with implementation of the a dvanced intemal ratings-based (IRB) a pproach under the Ba sel II minimum regulatory capital framework. Indeed, for many of such institutions this has momphed into a critical a c tivity, often involving a concentration of resources and focus. There are many controversies and unresolved issues, but among one of the most misunderstood and little studied aspects of this surrounds the proper discount factor to be applied to recoveries on defaulted debt, an ingredient in the calculation of the key Basel parameter economic loss-given-default (LGD). In the case of banks that qua lify to measure LGD from their own reference datasets, this is defined as the present value reduction in loan value as a proportion of the exposure-at-default (EAD).

As workout periods for defa ulted loans may be extended over many years, it is necessary to discount cash flows to a common period, the most natural being the time at which the event of default occurs ${ }^{1}$. Ba nking supervisors, practitioners and academic s a like have not been able to agree upon the interest rate to be applied on recovery cash-flows post default, in order to a rive at an estima te of the true economic loss attributable to a defaulted loan. While for some portfolios this estimate can be derived from observing the market price of defaulted debt, in the case of the vast majority of most banks' loan portfolios, the nonma rketa bility of the instruments in question necessita tes an actua rial approach that uses a punitive (or risk-adjusted) disc ount rate. ${ }^{2}$

There exist a rguments, potentially supported by certa in economic models, that to the extent there may be opportunity costsassociated with hold ing defaulted debt, the discount rate (or, equiva lently in this context, the required return on the defaulted instrument) used to risk adjust workout recoveries should be commensurate with this by including an appropriate risk premium. Indeed, this has been the practice of workout specialists since farbefore the advent of Basel II, as projected recoveries have tra ditionally been discounted at a punitive rate in order to calculate the expected present value of recoveries for the purpose of managing the workout process. This interpretation of the discount rate for workout rec overies has been the one ad opted for purposes of Basel, and indeed is stated as such in official guidance issued on the to ic $^{3}$ of LGD as well as in the final Rule 4 .

\footnotetext{
${ }^{1}$ This implies that the calculation of LGD is dependent upon how default is defined, which under the final Basel rule (OCC et al, 2008) includes events such as formal bankruptcy of the firm, out-of-court restructuring or renegotiation of debt at an economic loss, as well as payment a rrears in excess of 90 days.

${ }^{2}$ There are two generally accepted methods for estimating LGD within the tra ditional a pproach to credit risk management and also under the Basel paradigm. First, one can observe the market prices of defaulted loans at or near default, which implic itly embeds the market perception of recovery risk (Altman et al, 2005). Altematively, and probably most relevant for most banks hold ing non-public debt, workout recoveries to come a re disc ounted at an "a ppropriate", risk adjusted discount rate (Araten et al, 2003).

However, even in the case where portfolios consist of traded debt, such exhibits extreme illiquid ity conditional upon distress that makes the fomer impractic al. In fact, the latter a pproach has become standard and is closest to the mandated Basel II IRB formulation. ${ }^{3}$ Early guidance on the topic states: "When recovery streamsare uncertain and involve risk that cannot be diversified a way, net present value calculations must reflect the time
} 
However, there is wide disagreement on how to think about this, as most of the arguments have approached the issue from a theoretical point of view, and practitioners have tended to a dopt this perspective. This strikes us as strange, as common sense, tra ditional workout practice and even supervisory guidance a rgue for risk a djustment of some kind. While there a re a n a ray of choic es that have been proposed, we can divide these arguments into three broad categories. A provocative view, from our standpoint, argues that the discount rate should be taken simply from the risk-free tem structure. Indeed, under paradigms of modem finance such as the Arbitrage Pricing Theory (APT), such risk premia should not exist and the only appropriate discount rate is risk-free. However, it may be argued that preconditions for this to hold may not obta in, such as the capability to replic a te cash-flows associated with defaulted exposures ${ }^{5}$. Moreover, it is possible that this choice may create an inconsistency between the rate used in quantifying economic LGD, and that used to discount a ntic ipated workout recoveries, which ra ises "use test" questions. The second a rgument proposes some kind of opportunity cost of funds, examples being a weighted average cost of capital (WACC), cost of equity capital or some other cost of funds. The theory here is that the bank should account for the opportunity cost of replacing the defaulted loan in its portfolio. Finally, the approach most in line with either workout practice or supenisory guidance recommends using a comparable risky rate of retum of some kind. These could include the contract rate at the time of distress (Keisman et al 2001), a rate of retum on a distressed index, a rate demanded by vulture investors or simply an a ppropriately estimated or otherwise imputed punitive rate (Araten et al (2003), Maclachlan (2004) or Davis (2004)).

However, in spite of the intuition and theoretic al arguments, in estimating LGD from bank's historic al reference data-sets (or other sources) for either risk management or Basel purposes, it is ra rely the case that the discount rate is differentiated by the potential recovery risk of the post-default associated cash flows. The implication for a financial institution undertaking compliance with the advanced IRB a pproach is the potential of not assigning enough regulatory c apital to instruments with high recovery risk, and vice versa, a ssessing too high a charge for those instruments with less recovery risk. However, it has been argued that the cross-sectional variation in recovery cash flows swamps the effect of a differentiated discount rate (Ca rey and Gordy, 2007). This has not been demonstrated empiric ally. In the cases where empiric al a nalysis has shown that overall average LGD is not sensitive to changes in the single discount rate used (Araten et al, 2003, Araten 2004), such a nalysis has not looked to va ry the rate by

value of money and a risk premium appropriate to the undiversifiable risk." (Basel Committee for Banking Supervision, 2005)

${ }^{4}$ The Basel II Final Rule in the U.S. (OCC et al, 2008) states (Page 450): "Where positive or negative cash flows on a wholesale exposure to a defaulted obligor or a defaulted retail exposure ... occur after the date of default, the economic loss must reflect the net present value of cash flowsas of the default date using a discount rate appropriate to the risk of the defaulted exposure."

${ }^{5}$ A commonly heard and misleading characterization of this view is that the argument hinges on the observation that in qua ntifying or estimating economic LGD from historical databa ses of recovery cash flows, such cash flows a re alrea dy risk a djusted. However, that need not be the case, as the prevailing version of the APT rests upon hedgibility, as opposed to the diversifia bility of risk in other frameworks such as the Capital Asset Pric ing Model (CAPM). 
segment, nor to study either the effect on the entire distribution of LGD or on economic capital of different discounting methodologies.

In this study, we perform a comprehensive a na lysis of empiric ally derived discount rates for LGD, by a nalyzing the relationship between market and emergence prices of defaulted debt. Thiscan be thought of as analogous to examining the relationship between the value of defaulted assets and that of their associated workout recoveries. We examine altema tive methodologies for estimating such empinic ally derived discount rates. We then propose a model for assigning a proper, risk-adjusted discount rate to defaulted instruments. From this, we quantify the effect of $d$ iscounting on the distribution of economic LGD, and on estimated regulatory capital, for a hypothetic al portfolio.

The data -set that we utilize, Moody's Ultimate Loss-Given-Defa ult (MULGD) database, contains the market prices of defaulted bonds and loans near the time of default, and the prices of these instruments (or of the bundle of instruments received in settlement of default) at the resolution of default. We have such data for 550 obligors and 1368 bonds and loans in the period 1987-2007. We develop altemative estimation methodologies to derive the discount rates. First, we examine the distributional properties of the individual annualized rates of retum on defaulted debt ("retum on defaulted debt" - RDD), a cross different segmentations in the dataset (e.g., default type, fa cility type, time period, seniority, collateral, original rating, industry). We then compa re this to various a ltematives. First, as proposed by Brady et al (2006), an approach that involves solving for a discount rate within a homogenous segment that has the highest likelihood of being the prevalent rate of retum in the market at the time of default ("most likely disc ount rate" - MLDR). Second, we examine the tec hnique of Machlachlan (2003), who develops a risk premium over the risk-free rate that is derived from a structural credit or a market based model.

In any of these approaches, we interpret such an estimate as the expected rate of retum that should reflect the unc ertainty of the recovery cash flows associated with the defaulted bond orloan. We can imagine that a rational investor prices the defaulted instrument after default in accordance with expected future cash flows, or the price of the asset at emergence from bankruptcy (or otherwise the resolution of the default event), which is a kin to a workout cash-flow in the setting of a private bank loan. The correct pricing of a defaulted loan requires that an investor estima tes potential future rec overies, as well as the timing of them, and then discounts the expected cash-flows using the proper disc ount rate, which presumably includes the required LGD risk premium. A general approach to estimating the latter is through the former, and while expected future recoveries a re not observable, it may be argued that if pric ing is rational then such realized cash flows should on average coincide with their expectations. However, this may only hold for a reasonably large, and in tems of recovery risk, homogenous segment of defaulted instruments. We can approach this in two ways: first, by studying rates of retum on defaulted instruments from default to emergence, either by looking at averages over such homogenous segments, or through multiva ria te regression; altema tively, under the assumption of homogeneous segmentations and a certain the rate of information diffusion through the resolution process, we can solve for the discount rate that equates the discounted average rea lized recoveries to the average market price (Brady et al, 2003). In this exerc ise, we empinic ally identify 
the critic al deteminants of the estimated disc ount rates for worko ut rec overies, a s well as provide theoretic al expla nations and practic al insights for the results.

Our principle results a re as follows. We find our empiric a lly derived estimates of the appropriate discount rate for workout recoveries, both the RDD and the MLDR, to be signific a ntly higher than what has been found in the previous litera ture, a s well as what is used commonly in industry and for Ba sel 2 purposes. Mean (MLE estimate of) RDD (MLDR) is $29.3 \%$ (21.3\%), a s compa red to benchmarks such as the $15 \%$ reported by Araten (2004), or the $200 \mathrm{bps}$ over the risk-free rate suggested by Machlachlan (2004). However, discount rates implied from theoretical models of credit risk, including extensions of the a symptotic structural risk factor framework (Gordy, 2003) that incorporate systematic recovery risk, are found to be signific antly lower than the RDD or MLDR. These fall into the range of $10 \%$ to $15 \%$, depending upon the specification of the factor structure, single vs. multiple or latent vs. observable proxy. Retums on defaulted debt, which can be interpreted as an appropriate discount rate for worko ut recoveries, vary signific a ntly according to contractual, obligor, equity / debt market and economic factors. At the facility struc ture level, There is some evidence that discount rate metric sare elevated forloans having better c ollateral quality rank or better protected tranches within the ca pital structure. At the obligor or fim level, discount rate measures a re elevated for obligors rated higher at origination, more fina nc ia lly levered firms at default or fims having higher Cumulative Abnormal Retums on Equity (CARs) prior to default. However, the discount rate is increasing in market implied loss severity at default. We a Iso find evidence that LGD discount rates vary pro-cyclic ally, as they vary directly with industry default rates, but there tends to be some a synchronousity in this relationship. Further, the macroeconomy is found to be a determinant, as disc ount rate measures are inversely related to short-tem interest rates. However, for other demographic s results a re inc onclusive, such as the ind ustry group of the obligor. Finally, we conduct an a nalysis of the impact of the disc ounting method upon the distribution of estimated LGD and regula tory capital. We find that a regression model based discounting, for a sub-sample of the MULGD database, results in a capital charge 73 bps greater than discounting at a constant punitive rate of $25 \%$, and 113 bps larger than discounting at the contractual coupon rate (where the capital charge ranges in 7-8\%). We conclude that this conservativeness of the risk-sensitive RDD model, as well as the evidence that the risk in recovery cash flows contain a signific ant non-d iversifia ble component, supports the a ppropria teness of this fra mework for regulatory capital calculations.

This study will proceed a sfollows. Section 2 reviews the relevant literature. Section 3 outlines the theoretic al ba sis for this study. Section 4 presents our empinical methodology. Section 5 summa rizes our disc ount rate mea sures a c cording to various segmentations of the data. Section 6 presents summary sta tistic s of our a va ila ble covariates, and presents univa ria te correlation a nalysis of these with respect to RDD. Section 7 disc usses the results of multiple regression a na lysis of RDD. Section 8 a nalyzes the influence on regula tory ca pital of differing choic es of the discount rate for LGD calculation. Section 9 investigates a ltemative, or benchmark, approaches to estimating the discount rate for worko ut recoveries (struc tural and market models). Section 10 concludes and provides possible directions for future research. 


\section{Review of the Literature}

In the generally accepted taxonomy for LG D measurement methodologies, corresponding to the three approaches eitherproposed by researchers or regulators, a re clear implic ations for the disc ounting procedure required. First, in the method for infeming LGD from observation of the pric es of defaulted instruments in the market at (or so on after defa ult), the disc ounting is implic it. Examples of this include Carty and Liebeman (1996) or Gupton and Stein (2005), who analyze the prices of defaulted marketable loansand bonds one month a fter default to their parvalues. Furthemore, in the va rious papers which have calibrated Merton structural c redit risk models to default rate and recovery da ta on defaulted instruments ${ }^{6}$, they have typic ally relied upon LGD estima tes derived from this near-to-default market price measure. Examples of this burgeoning literature are bracketed by the seminal works of Frye (2000 a ,b ,c, 2003) and more recently Barco (2007).

A related method, which some have taken to be an analogue to the workout approach practiced by banks, looks at the secondary market prices of restructured assets at emergence from bankruptcy (or from the default event defined more broadly), which various studies have shown to a verage roughly 18 months a fter default (Araten et al, 2003). This can be seen in the work of Keisman et al (2000), and subsequently this mea sure has been dubbed the "ultimate recovery" (Emery et al, 2007)7. The commona lity with the workout approach lies in that such values need to be discounted from the point of resolution back to the default date. In the studies cited herein, based upon commercially a vailable databases of large corporate defaulted loansand bonds, this rate has been taken to be the coupon rate on the debt just prior to default (called the "pre-petition rate).

The third method, considered most appropriate for banks by both bankers and supenisors, involves relating realized post-default cash flows to defaulted balances of loans: "workout LGD". These cash flows are supposed to incorporate material credit related losses as well as direct and ind irect costs of the workout process. In this context, discounting becomes a critical consideration, and the specific ation of a cash-flow model for defaulted debt becomes necessary. While many institutions have implemented this approach intemally for some time, and this has become increa singly common with the a dvent of Basel 2, there a re limited published studies; notable exceptions include Asamow and Edwards (1995), Ea lesand Bosworth (1998) and Araten et al (2003). While the implementation of workout LGD is fraught with diffic ulties, ma inly centered around data integrity and measurements issues, if executed to a reasonable degree of reliability has many advantages. Aside from compliance with supervisory requirements, the benefits to intemal risk management include

\footnotetext{
${ }^{6}$ These are extensions of the asymptotic single factor model (ASRF) framework of Vasicek (1987) and Gordy (2003), models in the Merton (1973) structural model framework, which have become the basis for the Basel II Advanced IRB capital framework. The extensions cited herein allow for recovery, in addition to default rates, to vary systematically; in the ASRF framework, LGD is exogenous and fixed.

${ }^{7}$ Also see Friedman and Sandow (2002), which forms the basis of the S\&P LossStats ${ }^{\mathrm{TM}}$ model, which produces predictive conditional distributions of LGD by the "maximum expected utility" method. The vendor model allows users to model the LGD at default or at resolution, in contrast to the counterpart Moody's LossCalc ${ }^{\mathrm{TM}}$, which is a regression based model built expressly to forecast LGD at the time of default.
} 
applic a bility to non-ma rketable debt (the bulk of most banks' loan portfolios), the ability to estimate loss rate distributions under actua rial measure, and the ability to perform verific ation of historical cash-flow data obta ined during the workout process.

An altemative perspective on defaulted debt as a $n$ asset class, as given in G uha (2003), gives rise to yet a nother proposal for the correct disc ount rate for LGD. The author documents a convergence in market value as a proportion of par with respect to bonds of equal prionity in bankruptcy approaching default. This holds rega rdless of contractual features, such a s contra ctual rate or remaining time-to-maturity. The implic ation is that while prior to default bonds a re valued under uncerta in timing of and recovery in the event of default, that va ries across issues according to both borrower and instrument characteristic s, upon defa ult such expectations become one and the same for issues of the same ranking. There is cross-sectional variation in yield s due to varied perceived default risk as well as instrument structures, but as default approac hes the cla im on the debt collapses to a common claim on the expected share of emergence value of the firm's assets due to the creditor class. Therefore, the contract rate on the debt pre-default is no longer the relevant valuation metric with respect to restructured a ssets. This was predicted by Merton (1974), who predicted in his theoretical framework that credit spreads on a fim's debt approaches the expected rate of retum on the firm's assets, as leverage increases to the point when the creditors become the owners of the firm. Schuermann (2003) echoed the implic ations of this argument by claiming that cash flows post-default represent a new asset,

Machlachlan (2003), build ing upon the latter evidence and theoretic al insights, outlines a framework that is motivated by a classic single factor CAPM model. First, a reasonable model for LGD (taken to mean the defic it of ac tualized cashflows relative to those contractually agreed upon) should involve a diminution of expected cash-flows under physical measure. Second, to the extent that cashflows occurring post-default a re systematic ally correlated, the factor loading of the retum on the fim's unlevered assets with respect to the market (e.g., the "Beta") gives rise to a risk-premium. However, to the extent that recoveries a re dependent upon collateral, which may vary differentia lly with the systematic risk factor, the market "Beta" of the defaulted asset may not coincide with the firm's asset "Beta". As a special case, such premium may be zero in the case that the defaulted loan is fully cash-secured; or something lesser than a "distressed" premium, but still positive, in the case that sec urity is so me other kind of liquid and default-free asset (e.g., a long-tem trea sury bond). Finally, an implic ation of this is that the proper disc ount rate for workout recoveries may not be singular, as we may expect it to vary according to sources of repayment in cases were a defaulted asset is secured by multiple collateral types.

In light of this framework, we may evaluate several proposals for the discount rate to compute LGD that have been put forth. The suggested practice probably on the weakest footing among those to be considered here in, is to use the contractual rate on the loan. This could be either some kind of average rate in the portfolio, or perhaps the distressed rate on the loan near default, the rationale being that this represents the opportunity cost of replacing the defaulted loan. The problem with this is that it fa ils to consider the transfomative nature of the default event, as the bank is an investor in a new financial claim, which is no longer a financial claim having promised payments subject to 
default risk, but rather an asset dependent upon the recoverability of a defaulted fim's assets or of collateral values. The appropriate discount rate depends upon the degree of undiversifiable risk inherent in this new asset, and it may be less or more (and by no means necessarily equal to) than that on the pre-existing claim.

A related approach uses some measure of the lenders cost of funds in the capital market. This could either be an avera ge cost of debt, cost of equity, or weighted average cost of capital (WACC). The rationale is that the defaulted instrument would be replaces with funds from some class of the bank's c laimants, either debt-holders, sha reholders or both. As with the contractual rate of retum on the defaulted loan, either on the partic ula instrument or some average over a portfolio, this confounds the systematic risk associa ted with two different investments: in this case, that of the bank with that of a defaulted asset. The use of the lender's cost of funds violates the principle that the valuation of a financial a sset should not depend upon what a seller wishes to receive in order to repair the balance sheet, but rather the market clearing price that a rational buyer would pay for the expected stream of retums expected on the asset. Approachesalong these have been proposed recently by several banks intemally for the purposes of satisfying supervisory requirements under Advanced Basel IRB in the U.S. ${ }^{8}$

A proposal which has given rise to some confusion is to use the risk-free rate. This is clearly at odds with the pile of evidence - see Frye (2000), Altman et al (2001) or Gupton and Stein (2002) - that LGD varies systematic a lly with the state of the economy. However, when we are in the context of pric ing expected recoveries under risk neutral (or pricing) mea sure - when such cash flows a re a lrea dy a djusted for the investor's risk aversion - then the defa ult-free tem structure is proper for disc ounting. But this is not the context under which we a re construc ting loss distributions under physic al (or a c tua ria l) mea sure - in that case a risk-a djustment to the discount rate is appropriate. The latter is of relevance for purposes of risk management or Ba sel II.

An approach that we will consider in this paper, and compare to various a ltematives, involves examining the expost retum on defaulted debt. Araten $(2003,2004)$ advocates this punitive rate approach, citing the use of $15 \%$ by JP Morgan in its computation of economic LGD, which is supported by referenced to retums demanded by "vulture" investors of distressed debt. Support for this choice is offered by reference to the historical performance of the Moody's Corporate Bond index (Hamilton and Berthault, 2000), which retumed an a nnualized $17.4 \%$ in the period $1982-2000$. However, this retum has been extremely volatile, as most of this ga in (147\%) occurred in the period 1992-1996. This has lead to the suggestion that, assuming that banks can diversify away the idiosyncratic component of this, the propermetric relates these retums to a market index. Following this argument, Hamilton and Berthaultl (2000) and Altman and J ha (2003) both a rive at estimates of a correlation to the ma rket on this defaulted loan index of about $20 \%$, implying a ma rket risk premium of 216 bps. Davydenko and Strebuleav (2002) report similar results for non-defa ulted high-yield corporate bonds (BB rated) in the period 1994-1999. Machlachlan (2003) obta ins similar results in two empiric al exerc ises. First, reg ressing Altman-

\footnotetext{
${ }^{8}$ This is based upon review of confidential bank documents by the author, hence there are no citations.
} 
NYU Salomon Center Index of Defaulted Public Bonds in the period 1987-2202 on the S\&P 500 equity ind ex, a $20 \%$ correlation also obta ins, implying a market risk premium of $216 \mathrm{bps}$. Second, he looks at monthly secondary market bid quotes for the period April 2002-August 2003, obtaining a beta estima te of 0.37, which according to the Frye (2000) extension of Basel single factor framework implies a recovery value correlation of 0.21 and an MRP of $224 \mathrm{bps}$.

Finally, we make note of an approach that is a nalogous to the option adjusted spread (OAS) methodology of option pric ing by Kupiec (2007). The author argues that as not only recoveries a re uncertain in value, but also their timing of recoveries is subject to long and variable lags, in order to estimate LGD it is necessary to estimate the market value of an uncerta in recovery strea $m$ at the time a credit defaults. Such calculation requires a forecast for the expected recovery stream as well as an estimate of the risk-adjusted discount rate for discounting expected recovery values. The methodological note discusses the qua ntita tive issues and methods that a re associated with estimating recovery distributions and their associated market risk premia. The author a rgues that the a pproach of Brady et al (2006), which suggests that an empirically derived rate of retum measures on defaulted debt, may be severely bia sed.

\section{Theoretical Framework}

In this section we lay out the theoretical basis for the problem of determining an appropriate discount rate for LGD, as well as propose va rious empirical strategies for achieving this goal. While the measurement of LGD is a standard problem in finance, the valuation of a future stream of risky cash flows, this is complicated by the fact that upon default such proceedsare no longer the contractual promised payments. Instead, we are dea ling with cash flows from either the liquidation of collateral or extracted from a defaulted entity in a workout process, so that the risk profile of the amounts and their timing is fundamenta lly different from that of the original instrument: not only is the risk in magnitude probably greater, but timing is random as well.

Let us denote the stochastic post-default cash-flow at time sby $\tilde{c}_{s}$, the random time of resolution by $\tilde{\tau}$, and the joint distributions of these by $F^{c, \tau}$. Then we can write the expectation (under physical mea sure P) of loss-given-default (LGD), the expected LGD orELGD, as the complement of the present value of recovery cash flows at time of default $t$ norma lized by the exposure-at-default (EAD):

$$
E_{t}^{P}\left[L G D_{\tau}\right] \equiv E L G D_{t}=1-\frac{\int_{c=\underline{c}}^{\bar{c}} \int_{s=t}^{\tau} c_{s} e^{-s r_{s}^{D}} d F^{\tilde{c}, \tau}(c, s)}{E A D_{t}}
$$

Where $[\underline{C}, \bar{C}]$ is the support of the cash flow relation and $r_{s}^{D}$ is the instantaneous discount rate for post-default cash- flows, which is a mapping $[0, \infty] \rightarrow[0,1]$. In general $r_{s}^{D}$ is not only time-varying, but dependent on covariates a nd could be stochastic. It is clear that equation (3.1) is fartoo general to be of any practical 
use, and it follows that under the workout method typic ally LGD is estima ted from reference data as averages a cross homogenous segments:

$$
L G D_{t}=1-\frac{1}{E A D_{t}} \sum_{s=t}^{T} \frac{C_{s}}{\left(1+r_{s}^{D}\right)^{s}}
$$

Where $c_{s}$ are either rea lized ex-post recovery cast flows when qua ntifying LGD in a reference data-set and $t=1, . .$, Tare the known times of receipt. If one if taking the approach of applying an estimated LGD or recovery rate to a an exposure c urrently in a portfolio, then if forming the estimate based upon observed ex-post cash-flows, the discount rate used in that calculation should be risk-adjusted. This is in contrast to an altemative approach, which is a lso valid, of forming expectations of magnitudes and timings of dollarcash-flows on a defaulted exposure undera pricing measure (i.e., risk-adjusted), in which ca se discounting will be performed according to the risk-free tem structure. We consider the former approach in what follows.

We now tum ourattention to the detemination of the discount rate in (3.2), $r_{s}^{D}$. First, we may take a theoretic al perspective, and follow the capital formulae (BIS, 2003), as developed by Gordy (2000) and Vasicek (2000), based upon the Merton (1974) structural modelling fra mework. In an intertemporal version of this framework, we may write the stochastic process describing the instantaneous evolution of the ith fim's (or segment's) a sset retum at time t as:

$$
\frac{d V_{i, t}}{V_{i, t}}=\mu_{i} d t+\sigma_{i} d W_{i, t}
$$

Where $V_{i, t}$ is the asset value, $\sigma_{i}$ is the retum volatility, $\mu_{i}$ is the drift (which can be taken to be the risk-free rate r under risk-neutral mea sure), and $W_{i, t}$ is a standard Weiner process that decomposes as (this is a lso known as a standardized asset retum):

$$
d W_{i, t}=\rho_{i, X} d X_{t}+\sqrt{1-\rho_{i, X}^{2}} d Z_{i, t}
$$

Where the processes (also standard Weiners) $X_{t}$ and $Z_{i, t}$ are the systematic risk factor (or standardized asset retum) and the idiosyncratic (or fim-specific) risk factor, respectively; and the factor loading $\rho_{i, x}$ is constant across all fims in segment $\mathrm{i}$ (or across time for the representative fim) ${ }^{10}$. It follows that the

\footnotetext{
${ }^{9}$ Note that this highly simplified methodology, while still widely used, is only one choice among many and far from the most elaborate or statistically rigorous of the frameworks in existence. Alternatives include predictive regressions (Gupton and Stein, 2005) or conditional distribution of LGD estimations (Friedman and Sandow, 2002). See Jacobs et al (2007) for a comparison of different methods.

${ }^{10}$ Vasicek (2002) demonstrates that under the assumption of a single systematic factor, an infinitely granular credit portfolio and LGD that does not vary systematically, a closed-form solution for capital exists that is invariant to portfolio composition
} 
instanta neous asset-value correlation amongst fims (or segments) $i$ and $\mathrm{j}$ is given by:

$$
\frac{1}{d t} \operatorname{Cor}_{i, j}^{V}\left[\frac{d V_{i, t}}{V_{i, t}}, \frac{d V_{j, t}}{V_{j, t}}\right]=\rho_{i, x} \rho_{j, x}
$$

As in Basel regula tory capital framework, it is common to assume that the factor loa ding in (3.4)-(3.5) is constant a mongst fims within specified segments, so that the asset-value correlation for segment $\mathrm{i}$ is given by $\rho_{i x}^{2} \equiv R_{i}{ }^{11}$, where $\mathrm{R}_{\mathrm{i}}$ represents the Basel notation. If we take the further step of identifying this correlation with the correlation to a market portfolio - arguably a reasonable interpretation in a single-factor, ASFM world - then we get $\rho_{i, x}^{2}=\rho_{i, M}^{2}$ It then follows from the standard CAPM that the relationship between the firm and market rates of retum is given by the beta coeffic ient:

$$
\frac{\operatorname{Cov}_{i, M}\left[\frac{d V_{i, t}}{V_{i, t}}, \frac{d V_{M, t}}{V_{M, t}}\right]}{\operatorname{Var}_{M}\left[\frac{d V_{M, t}}{V_{M, t}}\right]}=\beta_{i, M}=\frac{\sigma_{i} \sqrt{R_{i}}}{\sigma_{M}}
$$

Where $\sigma_{M}$ is volatility of the market retum. We may now conclude that in this setting the proper (time invariant) discount rate for LGD on the $i^{\text {th }}$ exposure (or segment), $r_{i}^{D}$, is equal to the expected retum on the defaulted firm's assets, which is given by the risk-free rate $r_{r f}$ and the fim-specific risk-premium $\delta_{i}$ :

$$
r_{i}^{D}=r_{r f}+\frac{\sigma_{i} \sqrt{R_{i}}}{\sigma_{M}}\left(r_{M}-r_{r f}\right)=r_{r f}+\beta_{i, M} M R P=r_{r f}+\delta_{i}
$$

Where the market risk premium is given by $R M P \equiv r_{M}-r_{r f}$ (also assumed to be constant through time) and the firm-specific risk premium is given by $\delta_{i}=\beta_{i, M} M R P$. In the context of Basel II, this a pproach identifies the systematic factor $X$ with the standardized retum on a market portfolio $R_{M}$, from it follows that the asset correlation to the former can be interpreted as a nomalized "beta" in a single factor CAPM (or just a correlation between the firm's and the market's retum), which is given by $\rho_{M, x} \equiv \sqrt{R_{i}}$. In order to a chieve intemal consistency in an Advanced IRB modeling framework, the asset retum correlation used in the regula tory capital formula should be the same as that used to discount workout recoveries for the purpose of quantifying economic LGD.

\footnotetext{
${ }^{11}$ Indeed, for many asset classes the Basel II framework mandates constant correlation parameters equally across all banks, regardless of particular portfolio exposure to industry or geography. However, for certain exposures, such as wholesale non-high volatility commercial real estate, this is allowed to depend upon the PD for the segment or rating (BIS, 2003).
} 
In a more general and more realistic framework, retums on a defaulted loan may be govemed by a stochastic process distinct from that of the firm, as in the case when the collateral securing the asset is sec ured by cash, third party gua rantees or assets not used in production. In these situations it is possible that there are two notions of a sset value correlation, one driving the correlation amongst defaults, and a nother driving the correlation between collateral values and the $d$ isc ount rate for LGD in equilibrium. This reasoning implies that it is entirely conc eivable that, especially in complex banking facilities, cash flows associated with different sources of repayment may be discounted differentially according to their level of systematic risk. In not distinguishing how betasmay differ between defaulted instruments secured differently, it is highly likely that bank capita I will be overstated, as the impact of PD-LGD correlation is given undo weight. This leads natura lly to a n extension of the Vasicek (2002) and Gordy (2000) framework in which LG D varies systema tic ally. In this fra mework, a common systematic factor drives both default and expected recovery rates in the economy, and the correlation between the two; however, the factor loa dings may differ between the asset value and LGD processes.

If we define the recovery rate on the defaulted asset as $R_{i, t} \equiv 1-\frac{L G D_{i, t}}{E A D_{i, t}}$, then in an intertemporal version of this framework, we may write the stochastic process describing the instantaneous evolution of the recovery on $i^{\text {th }}$ defaulted asset (or LGD segment, or senionity class, i) at time t as:

$$
\frac{d R_{i, t}}{R_{i, t}}=\mu_{i}^{R} d t+\sigma_{i}^{R} d W_{i, t}^{R}
$$

Where $\mu_{i}^{R}$ is the drift (which can be taken to be the expected instantaneous retum on collateral under physic al mea sure, or the risk-free nisk-neutral mea sure), $\sigma_{i}^{R}$ is the volatility of the collateral retum and $W_{i, t}^{R}$ is a standard Weiner process that decomposesas:

$$
d W_{i, t}^{R}=q_{i, x} d X_{t}+\sqrt{1-q_{i, X}^{2}} d Z_{i, t}^{R}
$$

Where the processes (also standard Weiners) $X_{t}$ is the systematic risk factor (or standardized asset return, same as in the firm value process), $Z_{i, t}^{R}$ is the idiosyncratic defaulted asset (or collateral-specific) risk factor, and the factor loa ding $q_{i, x}$ is constant across all loans in segment $\mathrm{i}$ (or across time for the seniority class). Vario us further extensions this fra mework have appeared in the literature subsequent to Frye (2000), which have in common that they allow the recovery process to depend upon a $2^{\text {nd }}$ systematic factor, which may be correlated with the macro (or market) factor $X_{t} .{ }^{12}$ We choose to focus on recent model in this stream of literature, Barco (2008), who introduces the following process for the standardized retum on the defaulted asset:

${ }^{12}$ See Pyktin (2003), Dullman and Trapp (2004), Giese (2005), Rosch and Scheule (2005) and Hillebrand (2006). 


$$
d W_{i, t}^{R}=q_{i, x} d X_{t}+\sqrt{1-q_{i, X}^{2}} d Y_{t}^{R}
$$

Where $Y_{t}^{R}$ is a second systematic factor that influences the retum on the loan collateral. Note that in this framework, the idiosyncratic component of the defaulted asset retum disappears, and is replaced by this additional source of undiversifiable risk, which can be interpreted as something related to the market for the collateral. Additionally, Barco (2003) distinguishes the standardized retum on the defaulted asset from the loss ratio per unit exposure, which is the positive part of the retum to the creditor on these assets:

$$
L_{i, t}^{R}=\left[1-\exp \left(\mu_{i}^{R}+\sigma_{i}^{R} W_{i, t}\right)\right]^{+}
$$

It follows that the LGD is unconditiona lly distributed a s a trunc ated log-nomal random variable, and it can be analyzed in a framework that gives rise to "option-theoretic-like" a nalytic formulae. In this paper, we consider a further extension to this, where the default and recovery side each have a systematic risk factor, which are correlated, and each have their own id iosync ratic factor. We therefore re-write (3.10) as:

$$
d W_{i, t}^{R}=\rho_{i, X^{R}} d X_{t}^{R}+\sqrt{1-\rho_{i, X^{R}}^{2}} d Z_{i, t}^{R}
$$

Where the two-systematic factors are bivariate standard nomal, each standard normal, but with correlation q between each other:

$$
\left(d X_{t}, d X_{t}^{R}\right)^{T} \sim N\left(\left(\begin{array}{l}
0 \\
0
\end{array}\right),\left(\begin{array}{ll}
1 & r \\
r & 1
\end{array}\right)\right)
$$

We can estimate the vector of parameters $\left(\mu_{i}, \mu_{i}^{R}, \rho_{i, X}, \rho_{i, X^{R}}, r\right)^{T}$ by a straightforward full-info mation maximum likelihood FIML), given a time series of default rates and realized LGD rates. The algorithm for FIML in the context of this model is outlined in Section 15 (Appendix 2). The resulting estimate $\hat{\rho}_{i, X^{R}}$ can be used in equation (3.7) - in conjunction with estimates of the ma rket volatility $\sigma_{M}$, firm-specific volatility $\sigma_{i}$, the MRP $\left(r_{M}-r_{r f}\right)$ and the risk-free rate $r_{r f}$ - in order to derive the theoretical disc ount rate for LGD within this model. Altematively, we may pursue altemative estima tes of $\hat{\rho}_{i, X^{R}}$, through reg ressing actual defaulted debt retums on some kind of market factor or other mea sure of systema tic risk (e.g., aggregate default rates). We consider these in Section 9.

\section{Empirical Methodology}

We now sketch the alternative empiric al stra tegies that will be employed. First, we consider model-free mea sures of the disc ount rate for workout recoveries, which involve only the observation of post-defa ult prices of debt. A simple measure, motivated in part by the availability of (and the form of what is 
available in) of a rich data-set of defaulted bonds and loans available to us, involves a nalyzing the observable market price of debt two points in time: the default event (e.g., bankruptcy or other financial distress qualifying as a default) and the resolution of the default event (e.g., emergence from bankruptcy under C hapter 11 or liquidation under Chapter 11 ). This can be interpreted as an estimate of the discount rate for each segment modeling as the expected rate of retum on the investments in defaulted instruments belonging to that segment. This a ssumes that a ll instruments within a partic ular segment a re identic al in terms of their LGD risk, and thus share the same expected rate of retum and the fact that the realized recovery deviates cross-sectionally from the expected recovery is solely because of LGD uncertainty during the recovery process. We can calculate the annualized rate of retum as on the ith loan in segment sthe as:

$$
r_{i, s}^{D}=\left(\frac{P_{i, s, t_{i}^{E}}^{E}}{P_{i, s, t_{i}^{D}}^{D}}\right)^{\frac{1}{t_{i, s}^{E}-t_{i, s}^{D}}}-1
$$

where $P_{i, s, t_{i}^{D}}^{D}\left(P_{i, s, t_{i}^{E}}^{E}\right)$ are the prices of debt at time of default $t_{i, s}^{D}$ (emergence $t_{i, s}^{E}$ ). An estimate for the discount rate appropriate for the $s^{\text {th }}$ "LGD segment" (seniority class of collateral type) can then be formed as arithmetic averagesacrossloans:

$$
\bar{r}_{s}^{D}=\frac{1}{N_{s}^{D}} \sum_{i=1}^{N_{s}^{D}}\left[\left(\frac{P_{i, s, t_{i}^{E}}^{E}}{P_{i, s, t_{i}^{D}}^{D}}\right)^{\frac{1}{t_{i, s}^{E}-t_{i, s}^{D}}}-1\right]
$$

where $N_{s}^{D}$ is the number of defaulted loans in the recovery group s. A measure of the recovery uncerta inty in recovery class sis given by sample standard deviation:

$$
\bar{\sigma}_{\bar{r}_{s}^{D}}=\sqrt{\frac{1}{N_{s}^{D}-1} \sum_{i=1}^{N_{s}^{D}}\left[\left\{\left(\frac{P_{i, s, t_{i}^{E}}^{E}}{P_{i, s, t_{i}^{D}}^{D}}\right)^{\frac{1}{t_{i, s}^{E}-t_{i, s}^{D}}}-1\right\}-\bar{r}_{s}^{D}\right]^{2}}
$$

We a lso pursue an altemative to this simple a nnua lized rate of retum on default debt ("RDD"), the most likely discount rate ("MLDR"), a sintroduced by Brady et al (2006). This involves a consideration of the price of defaulted debt $P_{i, s, t_{i}^{D}}^{D}$ as the expected, discounted recovery $P_{i, s, t_{i}^{E}}^{E}$ at rate $r_{i, s}^{D}$ over the resolution period $t_{i, s}^{E}-t_{i, s}^{D}$ :

$$
P_{i, s, t_{i}^{D}}^{D}=\frac{E_{t}^{P}\left[P_{i, s, t_{i}^{E}}^{E}\right]}{\left(1+r_{i, s}^{D}\right)^{t_{i, s}^{E}-t_{i, s}^{D}}}
$$

where expectation is taken with respect to physical mea sure $\mathrm{P}$, and it is assumed that the time-to-resolution $t_{i, s}^{E}-t_{i, s}^{D}$ is known. In order to account for the fact that we cannot observe expected recovery prices ex ante, as only by coincidence 
would they coincide, we invoke market rationality to postulate that for a segment homogenous with respect to recovery risk the difference between expected and average realized recoveries should be small. Following Brady et al (2006), we formulate this by defining the nomalized pricing emoras:

$$
\tilde{\varepsilon}_{i, s} \equiv \frac{P_{i, s, t_{i}^{E}}^{E}-P_{i, s, t_{i}^{D}}^{D} \times\left(1+r_{i, s}^{D}\right)^{t_{i, s}^{E}-t_{i, s}^{D}}}{P_{i, s, t_{i}^{D}}^{D} \times \sqrt{t_{i, s}^{E}-t_{i, s}^{D}}}
$$

This is the pricing emoras a proportion of the debt price at default (a "unit-free" mea sure of recovery uncerta inty) and the square root of the time-to-resolution. This is a mechanism to control for the likely inc rea se in uncerta inty with time-toresolution, which effec tively puts more weight on longer resolutions, inc reasing the estimate of the discount rate. The idea behind this is that more information is revealed as the emergence point is approached, hence a decrease in risk.

Altematively, we can analyze the error $\varepsilon_{i, s} \equiv \frac{P_{i, s, t_{i}^{E}}^{E}}{P_{i, s, t_{i}^{D}}^{D}}-\left(1+r_{i, s}^{D}\right)^{t_{i, s}^{E}-t_{i, s}^{D}}$ that is non-time

a djusted, and argue that its standard error is proportional to $\sqrt{t_{i, s}^{E}-t_{i, s}^{D}}$, which is consistent with an economy in which information is revealed uniformly and independently through time (Miu and Ozdemir, 2005). Assuming that the errors $\tilde{\varepsilon}_{i, s}$ in (4.5) a re standard nomal13, we may use maximum likelihood, by maximizing the log-likelihood (Ш) function:

$$
\hat{r}_{i, s}^{D}=\underset{r_{i, s}^{D}}{\arg \max } L L=\underset{r_{i, s}^{D}}{\arg \max } \sum_{i=1}^{N_{s}^{D}} \log \left[\phi\left(\tilde{\varepsilon}_{i, s}\right)\right]=\underset{r_{i, s}^{D}}{\arg \max } \sum_{i=1}^{N_{s}^{D}} \log \left[\phi\left(\frac{P_{i, s, t_{i}^{E}}^{E}-P_{i, s, t_{i}^{D}}^{D} \times\left(1+r_{i, s}^{D}\right)^{t_{i, s}^{E}-t_{i, s}^{D}}}{P_{i, s, t_{i}^{D}}^{D} \times \sqrt{t_{i, s}^{E}-t_{i, s}^{D}}}\right)\right]
$$

This tums out to be equivalent to minimizing the squared errors:

$$
\hat{r}_{i, s}^{D}=\underset{r_{i, s}^{D}}{\arg \min }\left\{\sum_{i=1}^{N_{s}} \frac{1}{t_{i, s}^{E}-t_{i, s}^{D}}\left(\frac{P_{i, s, t_{i}^{E}}^{E}-P_{i, s, t_{i}^{D}}^{D} \times\left(1+r_{i, s}^{D}\right)^{t_{i, s}^{E}-t_{i, s}^{D}}}{P_{i, s, t_{i}^{D}}^{D}}\right)^{2}\right\}=\underset{r_{i, s}^{D}}{\arg \min }\left\{\sum_{i=1}^{N_{s}} \tilde{\varepsilon}_{i, s}{ }^{2}\right\}
$$

We may derive a mea sure of uncerta inty of our estimate by the ML standard errors, which are derived from the Hessian term: deviation:

$$
\hat{\sigma}_{\hat{r}_{i, s}^{D}}=\left[-\frac{\partial^{2} L L}{\left(\partial \hat{r}_{i, s}^{D}\right)^{2}}\right]^{-\frac{1}{2}}
$$

\footnotetext{
${ }^{13}$ If the errors are i.i.d. and from symmetric distributions, then we can still obtain consistent estimates through ML, which has the interpretations as the quasi-ML estimator.
} 


\section{Empinical Results: Summary Statistic s of Disc ount Rate Measures by Segments}

In this section, and the following two, we document our empinical results. These a re based upon our analysis of defaulted bonds and loans in the J une, 2008 Moody's Ultimate Loss-Given-Default (MULGD) database. This contains the ma rket values of defa ulted instruments at near the time of defa ult ${ }^{14}$, as well as the values of such pre-petition instruments (or of instruments rec eived in settlement) at the time of default resolution. This databa se is largely representative of the U.S. large-comorate loss experience, from the mid 1980's to present, including most of the major corporate bankruptcies occuring in this period.

In this section, we disc uss va rious summa ry sta tistic s, mea sures of central tendency and dispersion, tabulating observations of our two altema tive mea sures of the disc ount for workout recoveries. These measures are the simple a nnualized return on defaulted (RDD) as defined in (4.2)-(4.3), and the optimized segment-wise most likely disc ount rate (MLDR), as defined in equations (4.5)-(4.7). We investigate segmentations such as default event type (banknuptcy vs. out-ofc ourt restruc turing), instrument type (loa ns vs. bonds), senionity rank, collateral qua lity rank, proportion debt above $\&$ below in the capital structure, duration of distress or of the resolution, annual c ohort and ind ustry. Subsequent sections investigate univariate correlation and multiple regression a nalyses of RDD,

\subsection{Summary Statistics by Debtand Default Type}

In Tables 1, condensed Table 1.1, and in Figures 1.1 through 4.2, we summarize basic characteristics (mea sures of central tendency and dispersion) of LGD disc ount rate measures, RDD and MLR, by default event type (bankruptcy under Cha pter 11 vs. out-of-court restructuring), and instrument type (loans broken down by tem and revolving - vs. bonds).

In the more expansive Table 1, the bottom panel represents the entire Moody's database, whereas the top panel summarizes the subset for which we calculated defaulted instrument retum measures. Here we also show the means and standard deviations of four key quantities: LGD mea sured at default ("DLGD") and disc ounted from resolution ("ULGD"), time-to-resolution ("TRR"), and outstanding-at-defa ult ("OAD"), for both the RDD / MLDR sample as well as for the entire MULGD database (i.e., including instruments not having tra ding prices at default). We conclude from this that our sample is for the most part representative of the broader database. For the bankrupt firms, average ULGD is $52.0 \%(45.7 \%)$, TाR is $1.7(1.6)$ years and average OAD is $\$ 202.0 \mathrm{M}(\$ 141.8 \mathrm{M})$ for the analysis (broader) samples.

The version of MULGD that we use ( $\mathrm{J}$ une 2008 release) contains 3,886 defaulted instruments, 3,391 (or $87.3 \%$ ) of which banknuptcies, and the remaining 495 distressed restruc turings. On the other hand, in the RDD / MLDR sub-set, the vast majority $(94.3 \%$ or 1,262$)$ of the total $(1,338)$ a re Chapter 11 . The reason for this is

\footnotetext{
${ }^{14}$ This an average of trading prices from 30 to 45 days following the default event. A set of dealers is polled every day and the minimum /maximum quote is thrown out. This is done by experts at Moody's.
} 
two-fold: first, the times-to-resolution of the out-of-court settlements a re so short (about 2 months on average, and many are much shorter) that post-default trading prices at 30-45 days are not a vailable; second, many of these were extreme values of RDD, and were heavily represented in the outliers that we choose to exclude from the a nalysis (35 out of 37$)^{15}$.

Overall a verage of 1,277 annua lized RDDs is $29.7 \%$, with a high standard deviation relative to the mean of $117.5 \%$, ranging from $-100 \%$ to $894 \%$. This says that there were some very high retums - as the $95^{\text {th }}$ percentile of the RDD distributions is $191 \%$, this sa ys that in well over a 100 cases investors would have more than doubled their money holding defaulted debt. On the other hand, overa II MLR is $22.4 \%$ s, with a n MLE standard error of $107.8 \%$, a sma ller estimate than the RDD but showing the same high degree of variation about the MLE.

We observe that the distribution of RDD and MLDR is signific antly different in the case of out-of-court settlements as compared to bankruptcies, with respective means and MLEs of $37.3 \%$ and $52.4 \%$ for the former, and $29.2 \%$ and $21.3 \%$ in the latter. The standard deviations and MLE SD's are also much higher, $133.3 \%$ and $104.0 \%$ for out-of-c ourt, versus $116.5 \%$ and $114.2 \%$ for ba nknuptc ies, respec tively. This la rge difference in distributional properties can be observed in the empinical distributions of RDD in Figures 1 . Since there are only 76 of these, they appearto behave so differently, and we have concemsabout the degree of recovery unc erta inty embed ded in the very short resolution time of out-of-court settlements, we make the decision to eliminate that segment from subsequent a na lysis.

Now foc using upon bankruptcies, we examine facility types. Approxima tely $30 \%$ of the sample consists of bank loans, 379 out of 1338 instruments. Loans a ppear to behave differently, yet the RDD differs from the MLDR measure in the direction of difference: they have a higher (lower) RDD (MLR) ascompared to the broa der sample, $43.3 \%$ (14.5\%) vs. overa ll figures for ba nkruptc ies of $29.2 \%$ (43.3\%). On the other hand, bonds a ppear slightly riskier and higher retuming a ccording to $M D R$, with an estimate of $23.9 \%$, yet to have less recovery risk according to average RDD of $23.3 \%$ as compared to the broader sample. Finally, in comparing revolving credits to loans, they a ppear a pproximately as risky a ccording to MLDR ( $15.2 \%$ and $14.5 \%$, respectively), yet according to RDD loans a re riskier than revolvers (43.3\% vs. $40.0 \%$ ).

\subsection{Summary Statistics by Senionity Rank and Collateral Code}

Table 2 (full), Table 2.1 (condensed), and Figures 5-6, summarize distributional properties of RDD and MLDR by seniority rankings (ba nk loans; senior secured, unsecured and subord inated bonds; and junior subord inated bonds) and collateral types. We have 2 sets of collateral types: the 19 lowest level labels appearing in MULG D (Guarantees, Oil and Gas Properties, Inventory and Accounts Receivable, Accounts Receivable, Cash, Inventory, Most Assets, Equipment, All Assets, Real Estate, All Non-c urrent Assets, Ca pital Stock, PP\&E, Sec ond Lien, Other, Unsecured, Third Lien, Intellectual Property a nd

\footnotetext{
${ }^{15}$ Based upon extensive data analysis in the Robust Statistics package of the S-Plus statistical computing application, we determined these 37 observations to be statistical outliers. The optimal cutoff was determined to be $894 \%$, above which we removed the observation from subsequent calculations.
} 
Interc ompany Debt), and a 6 level high level grouping of that we constructed from the (Cash, Acc ounts Rec eiva bles \& Guarantees; Inventory, Most Assets \& Equipment; All Assets \& Real Estate; Non-Current Assets \& Capital Stock; PP\&E \& Second Lien; and Unsecured \& Other Illiquid Collateral).

Generally, since this does not hold monotonic ally a cross collateral classes or is consistent across recovery risk mea sures, better secured or higher ranked instruments exhibit higher RDDs or MLDRs. Average RDDs (MLF estimates of MLDRs) a re $46.4 \%$ for secured vs. $17.9 \%$ for unsecured (31.7\% for sec ured vs. $18.3 \%$ for unsecured) facilities. The difference is much accentuated for the RDD as opposed to the MLDR measure. Focusing upon bank loans, we see $44.3 \%$ vs. $28.9 \%$ (17.9\% vs. 9.9\%) sp lit for secured and unsecured. However, by broad mea sures of instrument ranking, RDD and MLDR do not agree to the same extent with regard to this ordering: a verage RDD (MLDR) is $43.5 \%$ and $51.7 \%$ ( $14.5 \%$ and $38.4 \%$ ) for loans and senior secured bonds, as compared to $22.5 \%$ and $23.9 \%$ (20.9\% and $21.9 \%$ ) for senior secured and senior subord inated bonds, so the pattem is less monotonic for MLDR (lower for loans).

However, in the case of RDD, while unsecured loans have lower mea sures of recovery risk than secured loans, within the secured loan class we have that these measures increase with the collateral quality rank. Across all seniorities, there is an almost monotonic inc rease in RDD from $27.8 \%$ for Ca sh, to $43.4 \%$ for All Assets \& Real Esta te, to $54.8 \%$ for PP\&E \& Sec ond Lien. This result does not ca my over to the MLD mea sure: $33.3 \%$ for Cash, down to $30.4 \%$ for All Assets \& Real Estate, and back up to about the same level of 33.7\% for PP\&E \& Sec ond Len.

\subsection{Summary Statistics by Year of Default}

Table 3 and Figures 7.1-7.2 summa nize distributional properties of RDD and MLDR by the calendaryear in which the instrument went into default. Here we are trying to get an idea of the cyclic al properties of a measure of the discount rate for LGD. We observe that there is weak evidence of LGD discount rate measures being pro-cyclical, or elevated during the downtum periods; however, there appears to some asynchronic ity, as (especially in the most recent downtum) these tend to peak in the years a fter the episode is over. With regard to whether and how this quantity varies with the state of the economy, there are some slight differences a cross the two metrics, RDD vs. MLDR, as well as a cross the two recessionary episodes, which we identify as the years 1990-91 and 2000-02 (when the Moody's speculative grade default rate is highest). One caution here is the censoring issue: low counts in the beginning and end of the sample, rendering inference problematic.

In the $1^{\text {st }}$ episode, the averages of RDD do appear to be elevated in comparison to the periods immediately preceding and following, $46.4 \%$ and $43.8 \%$ in 1990 and 1991; while the peaks of the 1980's and 1990's a re 29.1 and $27.5 \%$, respectively (and furthermore, in many 2 years during the 1990's the average is in fact negative). But in the $2^{\text {nd }}$ episo de, the RDD does not appear elevated until 2002 , when it increases to $50.8 \%$ in that yearfrom $-4.0 \%$ and $16.2 \%$ in the years 2000 and 2001, respectively; and the peak of the current decade occurs in 2003, with a verage RDD of $64.2 \%$, and it rema ins a bove $40 \%$ until 2006 . 
In the case of MLDR, it is a lso hard to clearly discem cyclic ality. While the estimate does appear elevated in 1991 (39.4\%) relative to the 1990's (although it is $35.5 \%$ in 1989), and its peak in the $1990 \mathrm{~s}$ is $20.4 \%$ in 1996 . While MLR is elevated in 2001 and 2002 relative to the 1990 s ( $24.5 \%$ and $32.8 \%$, respectively), as with the RDD it peaks in the current decade, and even later still in 2005 (50.8\%)

Mea sure of $d$ ispersion in disc ount rates estimates a lso exhib it this weak pattem of elevation a round the downtum periods. The standard deviation of RDD is higher in 1990-91 (143.3\% and $117.7 \%$ ) than in the late 1980s (where it is highest at $108.3 \%$ in 1989), yet the local peak occ urs at $172.3 \%$ in 1992 . A similar pattem for this statistic occurs in the second downtum period, genera lly higher but peaking in the year after, rising monotonically from $53.3 \%$ in 1999 to $161.2 \%$ in 2003 , thereafterfalling monotonically. In the case of MLD, we see a peak in the MLE estimate of the standard emor peaking $91.4 \%$ in 1991, and the second peak occurning in 2000 at $60.3 \%$; but there is a nother local maximum in the current decade, $53.2 \%$ in 2005.

There a re some pattems with respect to othervariables in this da ta-set that are worthy of note. While the credit cycle is clear whether one looks at the count or volume of defaults in this data-set, which correspond to the 5 highest average Moody's specula tive grade default rate, it is not clear if loss sevenity is higher in these periods for this sub-set of MULGD. In the $1^{\text {st }}$ episo de, while LGD does have a local peak of an average $75.6 \%$ in 1990, it is again elevated in 1992 (58.9\%), and has a 1990's peak of 70.6\% in 1994. In the $2^{\text {nd }}$ episode, LGD peaks in 1999 and 2000 , respective a verages of $65.0 \%$ and $62.6 \%$, whic $h$ slightly leads the downtum; however, LGD does rema in low on a verage after 2002. Second, we note that it is diffic ult to see how avera ge time-to-resolution varies with the cycle. We observe that it is lower on average during the 2 years of the $1^{\text {st }}$ downtum than in the 1980s (1.69 and 1.61 years in 1990 and 1991, respectively), and then having peaks in the mid-90's (2.08 years in 1995), a lthough it bounces a round non-monotonic ally in this period. However, in the $2^{\text {nd }}$ recessionary episode timeto-resolution is higher than the surrounding years, rising from 1.35 years in 1999, to 1.74 and 1.73 years in 2000 and 2001, respectively; a nd then never rising above 1.12 in 2005.

\subsection{Summary Statistics by Time-to-Resolution and Time-in- Distress}

Ta ble 4 and Figures 8.1-8.2 summa nize distributional properties of RDD and MLDR by two duration measures: the "time-in-distress" (TID), defined as the time (in years) from the last cash pay date to the default sate, and the "time-toresolution" (TIR), the duration from the date of default to the resolution or settlement date. These help us under the tem-structure of the discount rate for workout recoveries, and answer the question, does the length of time in workout, or under pre-default "watch", influence the uncerta inty in recovery cash flows that is implic it in the disc ount rate measure, RDD or MLDR. We examine features of RDD and MLDR by quartiles of the TIR and TID distributions, where the $1^{\text {st }}$ refers to the bottom fifth of durations in length, and the $5^{\text {th }}$ qua rtile the top longest.

We can observe some pattems, although they are non-monotonic, and the two disc ount rate measures do not agree on the shape. First, focusing on the TR, in 
the case of RDD both the mean and standard deviations decline in longer duration buckets. Average RDD declines, a lbeit bumpily, from $70.8 \%$ at the $1^{\text {st }}$ quartile, to $17.8 \%$ in the middle, and $7.5 \%$ at the top quartile. The standard deviation declines monotonic ally, from $178.5 \%$ at the bottom, to $45.0 \%$ at the top quartile. This has the interpretation that greater uncerta inty in recovery cashflows is reflected in higher a verage and volatility of retums on defaulted debt, and as this recovery uncerta inty is resolved over time, there is a concomitant decline in retum and in volatility of retum. However, MLR is not telling the same story. The MLE estimate peaks at $42.9 \%$ in the $4^{\text {th }}$ quartile, while staying in the range of $17-24 \%$ in the bottom 2 quartiles, and falls back to this range in the top quartile (18.5\%); this is somewhat suggestive of a humped shape, a lbeit nonmonotonic. However, the MLE standard error of MLDR exhibits a dramatic ally different pattem, dropping off from $96.6 \%$ in the $1^{\text {st }}$ qua rtile to a rather low range for the remaining quartiles, and then bo8uncing a round: $5.7 \%$ and $7.6 \%$ in the $2^{\text {nd }}$ and $3^{\text {rd }}$ quartiles, then peaking again at $18.5 \%$ in the $4^{\text {th }}$, and falling back to $6.7 \%$ in the top.

Like with TIR, the RDD and MLDR measures of recovery uncerta inty behave a little differently with respect to TID bucket. Mean RDD exhibits a general decline, a lbeit non-monotonic in middle range, from $41.3 \%$ in the $1^{\text {st }}$ qua rile, to $31.0 \%$ in the middle, and $21.3 \%$ at the top. The standard emor of the mean RDD has a Ushaped pattem, going from $145.6 \%$ at the bottom quartile, bottoming out at $93.1 \%$ in the middle, and increasing back to $133.0 \%$ at the top. On the other hand, the MLE standard emor of MLDR exhibits a general, a lbeit non-monotonic , hump shape: from $24.7 \%$ in the $1^{\text {st }}$ quartile, to $53.3 \%$ in the middle, and $26.9 \%$ at the top (with inexplic able plunges to $6.6 \%$ and $5.5 \%$ at the $2^{\text {nd }}$ and $4^{\text {th }}$ quartiles, respectively).

Taken together, this has the interpretation that we see some evidence that the longer in distress prior to default, or in the restructuring process following default, the more uncerta inty is resolved and the lower is the a ppropriate discount rate for workout recoveries that properly a djusts for the risk.

\subsection{Summary Statistics by Credit Rating at Origination}

Table 5 and Figures 9.1-9.2 summa nize distrib utional properties of RDD and MLDR by the earliest ava ilable Moody's senior unsec ured credit rating for the obligor. This provides some evidence that LGD discount rate estimates a re augmented for defaulted obligors that had, at origination (or time of first public rating), better cred it ratings or higher credit qua lity. This implies that in this sense we have higher rec overy unc erta inty embed ded in the recovery cash-flows of better rated credits, and that the appropriate discount rate for such credits should be higher, controlling for other risk factors. But, as with many of the other results herein, the relationships a re not monotonic in these tabularanalyses, and the high degree of dispersion in the estimates calls sta tistic al signific ance of the sepa ration a mongst categories into question.

Mean RDD generally dec lines a s credit ratings worsen, a lbeit unevenly. While the average is $26.4 \%$ for the AA-A c ategory, it goes from $48.6 \%$ for BBB, down to $32.1 \%$ and $19.6 \%$ for B and CC-C CC; but note the a nomalous dip to $18.1 \%$ for BB. The MLE estima te of MLDR exhibits a similar overall downward yet kinky drift: from 
$111.6 \%$ at $\mathrm{BBB}, 22.1 \%$ and $13.2 \%$ at $\mathrm{BB}$ and $\mathrm{B}$; but there is a strange low value of $20.7 \%$ at AA-A (a s with RDD), and it peaks up a bit to $18.3 \%$ at CC-CCC. However, if we look at the investment grade (IG) vs. non-investment grade (NIG) split, the picture is clearer, as we see mean RDD (MLE of MLDR) as $33.3 \%$ and $26.1 \%$ (23.7\% and $18.5 \%$ ) for IG and NIG, respectively.

There is much less in the way of recogniza ble or intuitive pattems with respect to the dispersion mea sures. In the case of RDD, the standard deviations generally increase in worsening rating, and in a double humped pattem. The latter is a bit surprising, and we would a ssocia te grea ter recovery risk with a grea ter mea sure in the variation of the estimate. However, for MLDR, there is a general decline in the MLE estimate of the standard error, peak at BBB and declining thereafter, which is more what we would expect. In the IG vs. NIG comparison, we see that the standard deviation of RDD inc reases from $81.8 \%$ to $212.8 \%$, while on the other hand the MLE standard error of MLDR declines from $25.9 \%$ to $8.1 \%$.

\subsection{Summary Statistics by Loan Position in the Capital Structure ("Tranc he Safety Index")}

Table 6 and Figures 10.1-10.2 summarize distributional properties of RDD and MLDR by measures of the relative debt cushion of the defaulted instrument. MULGD provides the proportion of debt either above ("degree of subord ination") or below ("debt cushion") any defaulted instrument, according to the seniority rank of the class to which the instrument belongs. It has been shown that the more debt below, or the less debt above, the better is the ultimate recovery (or the lower is the ultimate LGD) of a defaulted bond or loan (Keisman, 2000). We can also think of this position in the capital struc ture in terms of "tranche safety" - the less debt above, more debt below, or the thinner the tranche, then the more likely it is that there will be some recovery. However, this is not the entire story, but this measure has been demonstrated to be an importa nt determinant of ultimate LGD; therefore, we suspect that it will have bearing on the performance of defaulted debt.

Here, we offer evidence that retums on defaulted debt measured by RDD (or the appropriate discount rate as measured by MLDR) are increasing in the degree of tranc he thickness or relative debt cushion, in the sense of the difference between debt below and debt above. To the end of showing this in tabular form, we define the Tranche Safety Index (TSI) as:

$$
T S I \equiv \frac{1}{2}[\% \text { Debt Below }-\% \text { Debt Above }+1]
$$

This ranges between zero and 1 , where it is near unity the greater the difference between debt below and above (i.e., the thinnest tranche or the most subord inated), and closest to zero when debt below is nil and most of the debt is above (i.e., the thickest tranche or the grea test debt cushion). In Table 6, we examine the quantiles of the $T S I$, where the bottom $20^{\text {th }}$ percentile of the $T \pi$ distribution represents the least protected instruments, and the top $20^{\text {th }}$ percentile the most protected. Additionally, we define several dummy variables in order to capture this phenomenon, as in Brady et al (2006). "No Debt Above 
and Some Debt Below" (NDA/SDB) represents a group that should be the best protected, while "Some Debt Above and Some Debt Below" (SDA/SDB) and "No Debt Above and No Debt Below" (NDA/NDB) represent intermediate groups, and "No Debt Below and Some Debt Above" (NDA/SDA) should be the best protected group.

There is some mixed in Table 6 evidence, as for quintiles of $T \pi$ the results a re nonmonotonic forboth RDD and MLDR. There is a U-shape in a verage RDD with respect to quintiles of TSI, sta rting at $33.0 \%$ at the bottom quintile, having a minimum in the $2^{\text {nd }}$ of $9.6 \%$, and increa sing thereafter to $26.8 \%, 43.6 \%$ and $53.2 \%$ at the top. The pattem is a lso U-shaped for MLDR, but the minimum occurs at the mid quintile (14.4\%), having peaks at the lowest (33.8\%) and the highest (29.6\%) quintiles. The dispersion measures for these are a lso U-shaped, as with the central tendency mea sures bottoming in the $2^{\text {nd }}$ and $3^{\text {rd }}$ quintiles of RDD and MLDR, respectively.

In regard to the dummy variables, there is a general decline in discount rate measures from the most to least favourable positions. In the case of RDD, it is highest for NDA/SDB (44.2\%), lower and similar for SDA/SDB and NDA/NDB (25.1\% and $26.3 \%$, and lowest for the most subord inated (18.1\%). But in the case of $M L D$, the relationship amongst these dummies is bumpier but for the most part in the same direction, highest for NDA/SDB and SDA/SDB (25.3\% a nd 35.4\%), and lowest for NDA/NDB and NDB/SDA (12.0\% and 19.7\%). The dispersion measures a re similar in the ir pattems for theses dummies, across the two recovery uncerta inty measures exhib iting an a pproximate inverse U-sha pes for both.

\subsection{Summary Statistics by Industry Groups}

Table 7 and Figures 11.1-11.2 summarize distributional properties of RDD and MLR by industry group. These 8 high level categories were derived from the Moody's 12 industry group ings judgmenta lly, in consulta tion with subject-matter experts, with an eye toward finding mea ningful groupings with some separation in recovery risk measures. Among all the segmentation considered thus far, we see the greatest disa greement between the RDD and MLDR mea sures of the discount rate. In the case of mean RDD, we observe that the industry groups Leisure Time / Media, High Technology / Telecommunic ations and Aerospace / Auto / Capital Goods / Equipment exhib it elevated estimates of 36.6\%, 41.0\% and $41.3 \%$, respectively. However, in the case of MDR, the Forest / Building products / Homebuilders ca tegory has the highest MLE estimate of $34.9 \%$, while the lowest is Transportation, at $5.8 \%$, which is also substantially below the overall a verage of RDD at $6.0 \%$.

\section{Empirical Results: Distributional Properties of Covariates and Univariate Comelation Analysis}

In this section we analyze the independent variables ava ila ble to us and calculated from MULGD, as well as data attached to this from Compustat and CRSP. Ta bles 8, 8.1-7 and Figures 12.1-\# summarizes the distributional properties of key covariates in our databa se and their univa ria te correlations to RDD. We 
have grouped these in to the following categories: Financial Statement and Market Valuation, Equity-Price Performance and Capital Structure, Credit Quality / C redit Market, Instrument / Contra ctual, Durations / Vinta ge and Ma cro / Cyc lic al, Capital Struc ture, C redit Quality / C red it Market, Instrument / Contractual, Macro / Cyclic al and Duration / Vintage.

\subsection{Summary Statistics and Comelation Analysis: Financial Statement and Market Valuation}

In this section we consider the financial variables, alone and in conjunction with and equity market metric s, extracted from Compustat or CRSP. The Compustat variables are taken from the date nearest to the $1^{\text {st }}$ instrument default date of the obligor, but no nearer than on month, and no further than one year, to default. These are shown in the top panel of Table 8, in condensed form in Table 8.1, and in Figures 12.1-12.3. First, We see some evidence that leverage is positively related to RDD, suggesting that fims that were nearer to their "default points" prior to the event had defaulted debt that performed better over the resolution period, all else equal. This is according to an accounting measure, Book Value of Total Liabilities / Book Value of Total Assets (BVTL/BVTA), which has a substantial positive correlation of $17.2 \%$. However, this result does not camy over to a market measure, Book Value of Total Liabilities / Market Value of Total Assets (BVTL/BVTA), which has a rather small (a lbeit sta tistic a lly signific ant) c orrelation of $-1.2 \%$. Note that these results are robust to altematives, such as Book Value of Total Assets / Book Value of Equity or Book Value of Total Assets / Market Value of Equity, or variations on those. Note the extreme degree of leverage present in this defaulted population, with a median BVTL/BVTA of 1.13, and a maximum of 3.92. Also note the high degree of coverage for these mea sures, 111 out of 1267 . In the multiva riate a nalysis, the variable BVTL/BVTA enters in the favored model for RDD.

Regarding variables measuring size of the firm, by either accounting or market values, we see mixed evidence point to a negative relationship to RDD. This holds most true for Market Value of Total Assets (MVTA), which has a rea sona bly robust correlation of $-8.2 \%$. On the other hand, the two accounting measures, Net Sales and Book value of Assets (BVA), show a weaker but still inverse relationship, correlations of $-2.7 \%$ and $-1.8 \%$, respectively. We a re not sure what a good story is here - a candidate includes coordination issues in larger bankruptcies that cause the debt of these companies to underperform during the resolution process; but one can be equally credible in positing that larger companies have better wherewithal to emerge successfully from such a process. In none of our regressions did variables in this dimension appear to make a signific a nt contribution.

Next, we consider a set of variables measuring the degree of market valuation rela tive to stated value, or altema tively the degree of intangibility in assets: Tobin's Q, Market Value of Total Assets / Book Value of Total Assets (MVTA/BVTA or "Market-to-Book"), Book Value of Intangibles / Book Value of Total Assets (BVI/BVTA), and the Price / Eamings Ratio (PE). In this group, there is evid ence of a positive relationship to the disc ount rate for LGD, which is strongest by farfor MVTA/BVTA, having a correlation of $18.5 \%$. BVI/BVTA and PE Ratio a re 
signific a ntly weaker, having correlations to RDD of $2.0 \%$ a nd $4.0 \%$, respectively. Tobin's Q makes the least contribution, with a nil coeffic ient of $-0.1 \%$. MVTA/BVTA enters into some of our candidate regression models signific antly, but not the final model chosen. We speculate that the intuition here is a kin to a "growth stock effect" - such types of fims may have available a greater range of investment options, that when come to fruition results in better performance of the defaulted debt on average.

Next we consider a range of variables that mea sure the liquidity position of the firm: Current ratio (CR), Interest Coverage ratio (ICR), Working Capital / Book Value of Total Assets (WC/BVTA) and Cash Flow / Current Lia bilities (CF/CL). These measures are evenly split in their relation to RDD, which in all cases is weak: positive for CR and WC/BVTA (2.3\% and $2.8 \%$ ), and negative for ICR and CF/CL $(-6.6 \%$ and $3.0 \%)$. The reasonably robust magnitude on the inverse correlation in the case of ICR may not be as puzzling as at first blush, as one can make the argument that a fim with a dequate a bility to service debt that is nonetheless in default may be more likely to have a fundamental problem, all else equal. However, this variable does not make it to a ny of our candidate multiple regression models.

We displa y 3 covariates in Table 8 and Table 8.1 that measure the cash-flow generating ability of the entity: Free Asset Ratio (FAR), Free Cash Flow / Book Value of Total Assets (FCF/BVTA) and the Cash Flow from Operations / Book Value of Total Assets (CFO/BVTA). Results a re mixed, a strong (weak) negative relationship for FAR (FCF/BVTA), and a weak positive relationship for CFO/BVTA. The intuition here may be considered stra ined, as it is natural to think that the a bility to throw off cash may signal a firm with an underlying business model that is viable, which is conduc ive to a successful emergence from default and well performing debt; however, this may also be take to mean an "excess" of cash with not good investments to apply it to and a basically poor economic position. At any rate, note that FAR does make it into one of our three candidate multiple regression models, but not the final one.

Finally for the financia ls, we have a set of variables that mea sure some notion of a c counting profita bility: Net Inc ome / Book Value of Total Assets (NI/BVTA), Net Income / Market Value of Total Assets (NI/MVTA), Reta ined Ea mings / Book Value of Total Assets (RE/ BVTA), Retum on Assets (ROA) a nd Retum on Equity (ROE). With the exception of the small positive correlation for NI/MVTA $(-0.2 \%)$, these a re genera lly modest but inversely related to RDD: correlations of $-2.9 \%,-6.7 \%,-8.1 \%$ and $-2.8 \%$ for NI/BVTA, RE/BVTA, RO A a nd ROE, respec tively. As with other dimension of risk considered here, we resort to a "backward story", relative to the expectation that least-bad profitability mitigates credit or default risk: that is, if already in default, than better accounting profita bility may a harbinger of deeper woes for the firm, as reflected in the perfomance of its debt to emergence. 


\subsection{Summary Statistics and Comelation Analysis: Equity Price Performance Variables}

In this section we consider the equity price perfomance metrics, extracted from CRSP at the date nearest to the $1^{\text {st }}$ default date of the obligor, but no nearer than on month to default. These are shown in the $2^{\text {nd }}$ from top panel of Table 8 , in condensed form in Table 8.2, and in Figure 12.4.

The 1-Month Equity Retum Volatility ("1M-ERV"), the standard deviation of daily equity retums in the month prior to default, exhibits small positive correlation of $2.3 \%$ to RDD. This sign is expla inable by an option theoretic view of recoveries, since the value of a call-option on the residual cash flows of the fims to creditors firm are expected to increase in asset value volatility, which is reflected to some degree in equity volatility. On the other hand, the 1-Year Expected Equity Retum ("IY-EER"), defined as the average retum on the obligor's stock in excess of the risk- free rate the year prior to default, exhibits a modest degree of nega tive correlation (-6.4\%). We find this a little puzzling. On the other hand, the Cumula tive Abnomal Retums ("CAR") on equity, the retums in excess of a market model in the 90 days prior to default, have a the strongest positive relationship to RDD of the group, $10.9 \%$. This is understandable, as the equity markets may have a reasonable forecast of the firm's ability to become rehabilitated in the emergence from default, as reflected in "less poor" stock price perfomance relative to the market. Note this is one of two variables in this group that enters the candidate regression models. Market capitalization of the firm relative to the market as a whole ("MCRM"), defined as the logarithm of the sc aled market capita liza tion ${ }^{16}$, a lso has a signific ant nega tive univa ria te correlation to the market of $-8.6 \%$, and enters all of the regressions, as with CAR. We have no cleara priori expectation for this variable, perhaps we would expect larger companies to have the "resiliency" to betternavigate financial distress, counter to what we are measuring. The Stock Price Relative to the Market ("SPRM"), which is the percentile ranking or the absolute level of the stock price in the market, has a moderate negative correlation to RDD of $-5.4 \%$. The purpose of this variable is to capture the delisting effect when a stock price goes very low, and we might expect the opposite sign on this correlation. Finally, the Stock Price Trading Range ("SPTR"), defined as the stock price minus its 3year low divided by the difference between its 3-yearhigh and 3-yearlow, is showing only a small negative correlation to RDD of $2.8 \%$. This is a nother counterintuitive result, as one might expect that a stock doing better as compared to its recent range to signal a better quality fim whose debt might do better in default, but the data is not showing that, or much less of any kind of relationship here.

\footnotetext{
${ }^{16}$ The scale factor is defined as the market capitalization of the stock exchange where the obligor trades time 10,000 .
} 


\subsection{Summary Statistics and Comelation Analysis: Capital Structure Variables}

In this section we consider capital struc ture metrics, extracted from the MULGD data at the default date of the obligor. These a re shown in the $3^{\text {rd }}$ from top panel of Table 8, in condensed form in Table 8.3, and in Figure 12.5.

The two measures of capital struc ture complexity, Number of Instruments ("NI") and Number of Creditor Classes ("NCC"), show an inverse relationship to defaulted debt performance. NI (NCC) has a modest negative correlation to RDD of $-4.0 \%(-3.2 \%)$. We might expect that a simpler capital structure to be conducive to favorable defaulted debt performance according to a coord ination story. Note that neither of these variables enters the final regression models. While most companies in our database have relatively simple capital structures, with $\mathrm{NI}$ and NCC having medians of 4 and 2, respectively, there are some rather complex structures (the respective maxima are 80 and 7).

We have three variables that measure the nature of debt composition: Percent Secured Debt ("PSCD"), Percent Bank Debt ("PSD") and Percent Subord inated Debt ("PSBD"). The typic al firm in our da ta base has a p proxima tely $40 \%$ of its debt either secured, subord inated or bank funded. All of these exhibit moderate positive correlation to RDD: $9.2 \%, 7.3 \%$ and $5.6 \%$ for PSCD, PBD and PSBD, respectively. The result on PBD may be attributed to either a monitoring, or "optimal forec losure boundary choice" (Ca rey and Gordy, 2007), story. As with the complexity variable, none of these appear in the regression model.

\subsection{Summary Statistics and Comelation Analysis: Credit Quality / Credit Market Variables}

In this section we consider credit quality / credit market metrics, extracted from the MULGD database and Compustat at the default date of the obligor. These a re shown in the $4^{\text {thfrom }}$ top panel of Table 8, in condensed form in Table 8.4, and in Figure 12.6.

Two of the variables in this group have, what may seem to be at first glance, counter-intuitive relationships to RDD. First, the Altman Z-Score ("AZS"), which is a vailable in Compustat, has a rela tively large negative correlation of $-11.2 \%$ (note that higher values of the AZS ind ic a te lowerbankruptcy risk). Second, the LGD implied by the trading price at default - which forms the basis for the RDD calculation - exhibits a moderate positive correlation to RDD of $6.88 \%$. As this variable has been shown to have predic tive power for ultima te LGD (Emery et al, 2007), at first glance this relationship may seem diffic ult to und erstand ${ }^{17}$. But note that the same research demonstrates that LGD at default is a lso an upwardly biased estimate of ultima te LGD in some sense. Therefore, we might just as well expect the opposite relationship to hold, as Intuitively it may be that otherwise high qua lity debt may perform better on average if it is (perhaps unjustifiably) "beaten down". Indeed, LGD enters all of our regression models with this sign, 
and as a more influential variable than suggested by this correlation; but AZS does not make it to a ny of our regression models.

The rema ining variables in this group a re reflective of the Moody's ratings at the first point that the debt is rated. These are the Moody's Original C redit Rating Investment Grade Dummy (MOCR-IG ), Moody's Orig inal C redit Rating - Major Code(MOCR-MJ C; i.e., numeric al codes for whole rating classes), Moody's Original Credit Rating - Minor Code(MOCR-MNC; i.e., numeric al codes for notched rating classes) and Moody's Long Run Default Rate - Minor Code(MLRDR-MNC; i.e., empiric al default rates associated with notc hed rating classes). The only meaning univaria te result here is the small positive correlation of $2.4 \%$ in the case of MOCR-IG, consistent with Brady et al (2006). This variable enters signific antly into our candidate regression models.

Two other va ria bles in this group have "intuitive" correlations to RDD, but do not enter the regressions signific antly: Credit Spread (CS) and Contractual Coupon Rate (CCR). These are negatively and moderately a ssociated with RDD, having coeffic ients of $-5.7 \%$ and $-5.8 \%$ for C S and CCR, respectively.

\subsection{Summary Statistics and Comelation Analysis: Instrument/ Contractual Variables}

In this section we consider instrument / contractual metrics, extracted from the MULGD database at the default date of the obligor. These are shown in the

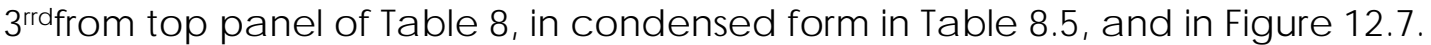

Consistent with the analysis of the previous section, the correlations with RDD in this group reflect that more instruments more senior, better secured or in a safer tranche experience better performance of defaulted debt. The Senior Rank (SR and Collateral Rank (CR) codes both have negative and rea sonably sized c orrelation coeffic ients with RDD, $-9.6 \%$ and $-10.0 \%$ for $S R$ a nd $C R$, respec tively. Percent Debt Below (PDB) and Percent Debt Above (PDA) are positively (negatively) correlated to RDD, c oeffic ients of $10.5 \%(-6.5 \%)$. And the Tranche Safety Index (TSI), constructed from the latter two variables as detailed in the previous section, has a signific ant positive correlation with RDD of $9.7 \%$. This is consistent with our understanding that there is in fact more recovery risk associated with low expected LGD segments.

\subsection{Summary Statistics and Comelation Analysis: Macroeconomic / Cyclical Variables}

In this section we consider macroeconomic / cyclic al metrics, extracted from the MULGD database at the default date of the obligor. These are shown in the $2^{\text {nd }}$ from bottom panel of Table 8, in condensed form in Table 8.6, and in Figure 12.812.9. Confirming the more casual a nalysis of Section 5.3 , where we a nalyzed LGD disc ount rate measures RDD and MLDR b a verages over annual cohort, through a nalyzing correlations we find that these mea sures vary procyclic ally. That is, debt defaulting in downtum periods tends to perform better, implying 
that a higher discount rate for recovery cash-flows is wa ranted to adjust for elevated recovery risk.

We have measures of the aggregate default rate, extracted from Moody's Default rate Service (DRS) database. These are lagging 12-month default rates, with cohorts formed on an overlapping quarterly basis (e.g., the default rate for the $4^{\text {th }}$ quarter of 2008 would represent the fraction of Moody's rated issuers in the beginning of $4 \mathrm{Q} 07$ that defaulted over the subsequent yea $\left.{ }^{18}\right)$. The four versions of this are the Moody's All-Corporate Quarterly Default Rate ("MACQDR"), the Moody's Speculative Grade Quarterly Default Rate ("MSG QDR"), the Moody's All-Corporate Quarterly Defa ult Rate by Ind ustry 19 ("MACQDRI"), Moody's Specula tive Grade Quarterly Defa ult Rate by Industry ("MSG QDRI"). All of these have a mild, a lbeit significant, positive linear correlation with RDD: $5.7 \%, 5.4 \%, 7.4 \%$ and $6.7 \%$ for MACQDR, MSG Q DR, MACQDRI and MSGQDRI, respectively. In our regression results of the next section, we will see that MACQDRI is the systematic risk va riable to enter the c andidate regression models, in spite of not having the highest univariate correlation.

The next set of variables represent measures of aggregate equity market performance, the Fama and French (FF) portfolio retums, which a re commonly used in the finance litera ture20. These a re Excess Retum on the Market ("FFERM"), Rela tive Retum on Small Stocks' ("FF-RRSS") and the Relative Retum on Value Stocks²2 ("FF-ERVS"). We measure these on a monthly basis, in the month prior to instrument default. We see that RDD is not related to aggregate retum on the market factor FF-ERM, as the correlation $-0.1 \% 23$. On the other hand, RDD seems to have a small positive (negative) relation to FF-RRSS (FF-RRVS), with correlations of $2.4 \%(-3.6 \%)$. We have one more aggregate equity market retum variable, 2-Year Stock Market Volatility (2Y-SMV), defined as the standard deviation of the S\&P 500 retum in the 2-years prior to default. This va riable shows a negligible negative linear correlation to RDD of $-0.4 \%$. Note that none of these aggregate equity market variables a re signific ant in any of the multiple regression models and do not appear in any further a nalysis of RDD.

Fina lly, we consider a ggregate interest rates, the 1-Month Trea sury Bill Yield ("1MTBY") and the 10-Yearf Treasury Bond Yield ("10Y-TBY"). Both of these exhibit moderate negative correlation to RDD, of $-10.4 \%$ and $-6.7 \%$ for $1 \mathrm{M}-\mathrm{TBY}$ and $10 \mathrm{Y}-$ TBY, respectively. However, only the $1 \mathrm{M}$-TBY a ppears in the final regressions. The intuition here may be that defaulted debt performs better in low interest rate environments, which is associated with lower aggregate economic activity, as well as a higher marginal utility of consumption on the part of investors.

\footnotetext{
${ }^{18}$ We follow the practice of adjusting for withdrawn ratings by subtracting one-half the number of withdrawn obligors from the number of available-to-default (or the numerator of the default rate).

${ }^{19}$ We use our high level 8 categories discussed in Section 5.7.

20 These can be downloaded from Kenneth French's website:

${ }^{21}$ This is more commonly termed the Small Minus Large (SML) portfolio (see Fama and French, 1992).

${ }^{22}$ This is more commonly termed the High Minus Low (HML) portfolio, meaning high vs. low market-tobook ratio (see Fama and French, 1992).

${ }^{23}$ Results for the S\&P 500 return, not shown, are very similar.
} 


\subsection{Summary Statistics and Comelation Analysis: Duration / Vintage Variables}

In this section we consider duration / vintage metrics, based on calc ulations from extracted dates in the MULGD database. These are shown in the bottom panel of Table 8, in condensed form in Table 8.7, and in Figure 12.10.

We can conclude from this section that the duration / vintage measures that would be in one's information set at the time of instrument default are largely uninformative regarding the performance of defaulted debt. The variables that we have chosen to display include Time from Origination to Default ("TOD"), Time from First Rating to Default ("TFRD"), Time from Last Cash-pay Date to Default ("TDD" or "Time in Distress"), Time from Default to Origination("TRR" or "Time-to-Resolution") and Time from Origination to Maturity ("TOM"). We see that the two vintage measures, TOD and TFRD, have negative but negligible c orrelations to RDD, $-0.7 \%$ and $-0.5 \%$. Counter to the a nalysis of TID quintiles in Section 5.4, where we found some evidence of a negative relationship with RDD, here we see only a very small positive correlation of $0.2 \%$. However, we do see results consistent with that a nalysis for TIR, as the correlation to RDD is nega tive and a sizable 10.6\%; but note that this variable does not signific a ntly enter any of the candidate multiple regression models disc ussed in the subsequent section. Finally, the TOM variable is inversely related to RDD, but this is rather weak, a correlation of $-1.3 \%$.

\section{Empinical Results: Multiple Regression Analysis of the Retums on Defaulted Debt}

In this section we disc uss the construction and results of multiple regression models for RDD. In order to cope with the highly non-nomal nature of the nature of the RDD distribution, we tum to the various tec hniques have been employed in the finance and economic literature to classify data in models with constrained dependent variables, either qualitative or bounded in some region. However, much of the credit risk related literature has foc used upon qualitative dependent variables, which the case of PD estimation naturally falls into. Maddala $(1981,1983)$ introduces, disc usses and fo mally compare the different Generalized Linear Models ("GLMs"). Here we consider the case most relevant for RDD estimation, and that least pursued in the GLM literature. In this context, since we are dealing with a random variable in a bounded region, this is most conveniently modelled through employing a beta distribution. Therefore, we follow Mallick and Gelfand (1994), in which the GLM link function ${ }^{24}$ is taken as a mixture of cumulative beta distributions, which we tem the beta-link GLM (BLGLM). We can solve for the parameters of the model through maximum likelihood, which is deta iled in Section 14 (Appendix 1).

The coeffic ient estimates and diagnostic statistic sfor our "lea ding" three models a re shown in Table 9. These are determined through a combination of

\footnotetext{
${ }^{24}$ In the terminology of GLMs, the link function connects the expectation of some function of the data (usually the random variable weighed by density, in the case of the expected value) to a linear function of explanatory variables.
} 
a utomated statistic al procedures ${ }^{25}$ and expert judgment, where we try to balance to sometimes competing considerations of in-sample fit with the sensibility of the models. Essentially, the three models shown in Table 9 had the best fit to the sample data, while spanning what we thought was the best set of risk factors, based upon prior expectations a s well as the univaria te a nalysis. Note that there is much overlap between the models, as Model 2 differs from Model 1 by two variables (it has MV / BV instead of $\mathrm{TL} / \mathrm{TA}$, has RSIZ), and Model 3 from Model 2 by two variables as well (FAR in lieu of TSI and LGD).

Across the 3 candidate models, we observe that all c oeffic ients estimates atta in a high degree of sta tistical signific ance, in a lmost all ca ses at better than the $5 \%$ level26, and in many cases at much better than the $1 \%$ level. The number of observations for which we had all of these explanatory variables is close for Models 1 and 2, 959 and 958, respectively; but there is a siza ble drop-off for Model 3, only 791 observations. In all cases, the likelihood functions converged to stable global maxima. ${ }^{27}$ Model 3 a chieves the best in-sample fit by McFadden pseudo r-squared of $41.7 \%$, followed by Model 2 (38.8\%) and Model 1 (32.5\%). In terms of maximized log-likelihood, Model 3 is far better than the others (-504.0), and Model 1 is only slightly better than Model 2 (-592.3 vs. -594.7) in spit of having one less explanatory variable, but as these models a re not nested this may not be so meaningful a comparison. Overall, we deem these to signify good fit, given to non-linea rity of the problem, the rela tively high dimension as well as the high level of noise in the RDD variable.

We now tum to the signs and individual economic signific ance of the variables, note that we report partial effects ("PE"), which a re akin to straight coeffic ient estimates in an ord inary least squa res regression. Roughly spea king, this represents a change in the dependent variable for a unit change in a covariate, holding other variables fixed at their average sample values ${ }^{28}$.

First, we consider the systematic risk variables. In the case of the Moody's speculative default rate by ind ustry, that appears in all models. we see from the PE's ranging in 2.05-2.25. This implies that a percentage point elevation in a ggregate default rates adds about $2.15 \%$ in retum on defaulted debt on average, all else equal, which can be considering highly signific ant in an economic sense. For example, the near quadrupling in default rates between 1996 and 2001 would imply an increase in expected RDD about 12\%. On the other hand, the PE's on the 1-Month Trea sury yield are in the range of -0.49 to 0.37 , so that debt defa ulting when short-tem ra tes a re a bout $2 \%$ higher will experience about $0.8 \%$ deterioration in performance, ceteris paribus.

Next, we consider the contractual variables. The dummy variable for secured collateral has PE's ranging in $0.24-0.25$ a cross all models, suggesting the presence of any kind of sec unity can be expected to a ugment RDD by a bout $25 \%$. The TIS, appearing only in Models 1 and 2, has a PE ranging in $0.43-0.45$, suggesting that going up a single decile in this mea sure can increa se RDD by about $4.5 \%$.

\footnotetext{
${ }^{25}$ To this end, we employ an alternating direction stepwise model selection algorithm.

${ }^{26}$ Moody's investment grade rating in model 3 is on the borderline, having a p-value of 0.06 , just shy of significance at the $5 \%$ level.

${ }^{27}$ The estimation was preformed in S+ 7.0 using built-in optimization routines.

${ }^{28}$ See Greene () for a discussion of this concept in the context of probit and logit regressions.
} 
Tuming to the credit quality / ma rket variables, for LGD at default, only in Models 1 and 2, PE's a re about 0.28-0.33, implying that a $10 \%$ lower expected recovery rate by the market at default can lead to about a 3\% lower ultimate LGD. The dummy variable for a Moody's investment grade rating at origination, a ppearing in all models, has PE's ranging from 0.15 in Model 3 to 0.21 in Model 1 . This tells us that "fallen angels" a re expected to have about $15-20 \%$ better retum on their defaulted debt.

On the other hand, the single relative stock price performance variable, $C A R$, is in all 3 models with PE's ranging in 0.37-0.40. This says that, for exa mple, a firm with $10 \%$ better price performance relative to the market in the 90 days prior to default will experience about $4 \%$ better retum on its defaulted debt.

In the case of the financial ratios, TL/ TA appears only in Model 1, having a PE of 0.27 . This means that a the debt of a defaulted fim having $20 \%$ higher leverage will have about $3 \%$ greater retum on its debt. MV / BV appears in Models 2 and 3 , with PE's of $0.14-0.19$, so that a $10 \%$ higher market valuation translates into 1.5 $2 \%$ better retum on defaulted debt. Finally in this group, the cash-flow measure FAR only a ppears in Model 3, with a PE of -0.24 . If a defaulted fim has $10 \%$ greater cash generating a bility by this mea sure, then hold ing other factors constant its RDD should retum about $2-2.5 \%$ less.

Fina lly, the size of the firm relative to the market a ppears in only Models 2 and 3. The PE's of about -0.06 to $-0.04 \%$. As this is in loga nithmic tems, we interpret this a s if a defaulted fim doubles in rela tive market c apita lization, then we should expect its RDD to be depressed by around $5 \%$, all other factors being held constant.

In order to settle upon a "favored model", we performed an out-of-sample and out-of-time a nalysis. Fixing the expla na tory variables in each model, we reestimated the models for different sub-samples of the available data, starting from the middle of the data-set in year 1996. We then evaluate how the model predicts the realized RDD a year ahead. We employed a resampling procedure, sampling randomly with replacement from the development data-set (e.g., the period 1987-1996), and in each iteration re-estimating the model. Then from the year a head, we resample with replacement (e.g., the 1997 cohort), and evaluate the goodness-of-fit for the model. This is performed 1000 time, then a year is added, and this is repeated until the sample is exhausted. At the end of the procedure, we collect the r-squared's, and study their distribution, for each of the 3 models. The results of this show that the mean out-of-ample r-squared in Model 1 is highest, at 21.2\%, followed by Model 3 (17.8\%) and Model 2 (12.1\%). On the basis of the numeric al standard emors (on the order 1-2\%), we deem these to be signific antly different. Given the best performance on this basis, in conjunction with other considerations, we decide that Model 1 is the best. The other reasons fro choosing Model 1 are is parsimony relative to Model 2, and that it conta ins a credit market variable (LGD), the latter we believe makes for a more compelling story. 


\section{Analysis of the Regulatory Capital Impact of the Disc ount Rate for LGD}

In this section we disc uss the results of an exerc ise in which we asses the effect upon regulatory capital of the discount rate choice with respect to workout recoveries. The results of this a na lysis a ppear in Table 10 and Figures 13.1 through 13.6. We compare three methods of disc ounting LGD: the contractual coupon rate (CCR), the RDD regression Model 1, and a punitive discount rate (PDR). The $C C R$ is available to us in the MULGD database. In the case of the PDR, we somewhat arbitra rily pick a flat $25 \%$, which is about the average of our fullsample mean RDD (29.2\%) and the full-sa mple MLE estimate of the MLDR (22.4\%). We believe this to be a conservative approach to implementing the PDR method.

We perform the exerc ise of treating our sub-set of the MULGD databa se as a hypothetical non-defaulted portfolio, for which we happen to know the postdefault cash-flows, and need only discount those to form an estimate of LGD. The formula for regulatory capital (denoted by $K^{R}$ ) that we compute is a version of the published formula (Basel II U.S. Final Rule, page 69335):

$$
K^{R}=\left(N\left(\frac{N^{-1}(P D)+\sqrt{R} N^{-1}(0.999)}{\sqrt{1-R}}\right)-P D\right) \times L G D^{D}
$$

Where PD is the estimated probability of default, $R$ is the asset value correlation, and $\mathrm{N}\left(\mathrm{N}^{-1}\right)$ is the Nomal cumula tive (inverse) distribution ${ }^{29}$. We estimate PD by the Moody's long-run default rates associated with each observation, according to it's rating at approximately one-year prior to default (see Table 10.1). We derive $\mathrm{R}$ from the regulatory fomula ${ }^{30}$ :

$$
R=0.12+0.18 \times e^{-50 \times P D}
$$

The "downtum" LGD, LGDD, is derived from the supervisory mapping function:

$$
L G D^{D}=0.08+0.92 \times L G D
$$

Where LGD is calculated as the actual loss rate in the database, according to the different methods of discounting. We assume a unit EAD, so that capital is normalized to represent a fraction of par, and portfolio capital is simply the a rithmetic average of loan-level capital.

The results in Table 10 show that discounting according to the RDD regression model results in higher estimates of disc ounted LGD, a nd higher regulatory capital requirements, as compared to either disc ounting at the contractual rate or a constant punitive rate. Among all three methods, discounting by the contractual coupon rate is least conservative.

\footnotetext{
${ }^{29}$ The main difference with the formula in the Final Rule is that we ignore the maturity adjustment for wholesale capital.

${ }^{30}$ Results are not materially different when using a flat asset correlation $\mathrm{R}=6.12 \%$, the MLE estimate from calibrating the 2-factor ASRF model to annual Moody's all-corporate default rates for the period 19872007.
} 
First considering the distribution of LGD, we note from Figures 13.1 and 13.2 that while all three mea sures provide highly correlated estimates of LGD (r-squareds of 0.79 and 0.78 for RDD vs. contract and punitive, respectively), the RDD model provides estima tes shifted considerably upward (respec tive intercept terms of 0.22 and 0.08 ). Furthermore, note that in the companison of the RDD model to the contract rate all the cases where the latter would yield a zero LGD, yet by a risk sensitive discount we get a non-zero LGD (sometimesa very large LGD). From the summary statistic s in Table 10 we see that under the RDD model is has a higher mean (median) LGD of $64.1 \%$ (72.1\%), as compared to $59.0 \%(62.1 \%)$ under a punitive rate, and $52.1 \%(55.0 \%)$ under the contract rate. Examining the distributions of LGD in this portfolio in Figures 13.3 and 13.4, it is clear that under RDD model discounting there is a shift in probability mass to the right, compared with either the contract rate (Figure 13.3) or a punitive rate (Figure 13.4).

Sec ond, considering the regulatory capital impact of disc ounting, we observe that under the RDD regression model ca pital is signific a ntly higher tha $n$ under either the contra ctual coupon rate or a punitive rate. Portfolio capital under our model is $8.04 \%$ (the mean of the distribution), 73 bps higher than under a punitive disc ount rate, where portfolio capital is $7.31 \%$. Under the contractual discount rate it is even lower, $6.91 \%$, a difference of $40 \mathrm{bps}$ ( $113 \mathrm{bps}$ ) to a punitive rate (the RDD model). This is evident by examining the distributions of portfolio regulatory capital in Figures 12.5 and 13.6, where we see that the density mass is shifted right-ward under the RDD model relative to either the contract rate or the $25 \%$ punitive disc ount rate. However, we see that there is less peakedness and skewness in the distribution of capital und er the RDD model as compa red to contract or punitive rate discounting, so that most of the difference iscoming in the body and not the tails of the distribution (although the standard deviation is higher).

We can interpret these results as follows. The model for RDD is discounting at a much higher rate types of loans that have larger recovery cash flows, in order to a djust for the increased recovery risk associa ted with those. This mechanism operates through the discounted LGD. Furthemore, one can argue that the ma rket is impounding other material direct and ind irect costs into this empiric al measure, such as workout costs.

\section{Benchmarking Analysis of Altemative Modeling Frameworks for the LGD Disc ount Rate}

In this section we disc uss the results of an exerc ise in which we investigate altemative means for deriving the appropriate discount rate for workout recoveries. This exerc ise is summarized in Table 11, where we divide the methodologies into 4 types: market or model based, purely empinical (ex-post retums based), model-free or and regulatory prescriptions. In the model based approaches, we specify in the second column if it is a regression model, or if it is the calibration of a structural model to default and loss data, both of which producing a n estimate of the correlation of LGD to a systematic risk factor. In the case of the latter, there are 2 varieties that we consider: the single-factor model of Frye (2000), and the 2-factor model developed herein, both of which having systematic recovery risk. In the case of any of the model based 
approaches in the top panel, we employ a simplified version of the intertemporal Capital Asset Pricing Model (CAPM) in equation (3.7), in which case we need to make further assumptions. We take the risk-free rate to be $5 \%$, which is a commonly made assumption in practic al modelling situa tions, when we wish to abstract from term-struc ture effects. In the case of the market risk premium $(M R P)$ and the volatility of the market $\left(\sigma_{M}\right)$, we take the average and standard deviation of the Fama-French retum on the market factor. Finally, for firmspecific asset volatility $\left(\sigma_{i}\right)$, out of convenience and for lack of data, we use the $32 \%$ estimate derived by Frye (2000).

The general conclusion that a rises from this compa rison is that the model based a pproaches that invoke a CAPM struc ture as in equation (3.7), whether structural calibration or regression, generate disc ount rate estimates signific a ntly lower than purely empinical a pproaches (in the range of $7-11 \%$, as compared to 14 $43 \%$ formodel-free approaches). We also see that in the model-based approaches, discount rate estimates for loans tend to be lower than forbonds, and this is reversed for empiric al based a pproaches. Secondly, model-based approaches tend to produce lower estimates forloans than bonds, which is generally reversed for empinic al approaches. Finally, in model-ba sed a pproac hes as implemented, there is not a great degree of sensitivity to the correlation estimate, a sthe other assumptions rema in fixed and camy a lot of weight.

While the comparison to the model-free approaches is inconclusive, as it relies upon factors outside the scope of this a nalysis, we may assume that they lie closer to the implications of the model-based than the empirical-based approaches. Among the lower estimates we find $7.2 \%$ from Machlachlan's regression of 90 defaulted bond bid quotes on the S\&P 500 retum for the period $4 / 02-8 / 03$. Clearly, the sample size and limited time period makes us uneasy a bout relying on that estimate, even as a lower bond. This is lower than other approaches correlating defaulted bond retums to broad stock indices. The highest estimate is Altman and J ha (2003), where regressing the Altma n / Solomon Center defaulted bond index on the S\&P 500 retums for the period 1986-2002, they come up with an $11.1 \%$ disc ount rate (based upon a $20.3 \%$ correlation estimate), the highest in this group. Regressing monthly RDD on the Fama-French market factorgives a disc ount rate of $6.8 \%(6.6 \%)$ for the period 1987-2007 (1995-2007), based upon a correlation estimate of 13.2\% (11.8\%), not far from Maclachlan's 7.2\% distressed bond bi-ask quote estimate. Using a ltemative defaulted debt ind ic es yield simila restima tes, a sillustrated by the Solomon Center Defaulted Debt and Defaulted Loan indices, compiled by Ed Altman. In the case of bonds (loans), a regression of the respective monthly index retums on the S\&P 500 ind ex retums for the period 1/99-9/08 comes up with implied disc ount rates of $10.6 \%$ (6.5\%). If instea d we use the Moody's trailing 12 month specula tive grade default rate in lieu of an equity index as the systematic variable (which is arguably more appropriate) and our RDD measure for the same periods and frequencies, this yields a slightly higher disc ount rate of $8.7 \%$ (7.9\%) for bonds (loans) in 1987-2007 (1995-2007), based upon a 13.2\% (11.8\%) correlation estimate.

Tuming to the structural type models, we start to see some higher values, depending upon the factor structure. In the well known single-factor model of Frye (2000), where LGD is driven by the same systema tic variable as PD, his 
calibration on Moody's loss data 1982-1999 yields a discount rate estimate of $7.3 \%$, as per the $17 \%$ LGD-PD correlation estimate that he derives.

However, we employ a 2-factorversion of the structural model using Moody's data from 1987-2007 (encompassing 2 downtums), and find higher estimates: $8.0 \%(9.9 \%)$ for bank loans (senior secured bonds), with the difference being very slight for loans.

A well cited empinical model is the $15 \%$ results cited by J.P. Morgan (Araten, 2004), which is supposed ly based upon ex-post realized retums on the Moody's Bankrupt Bond Index for the period 1988-1998 (Hamilton and Berthault, 2000), as well as a commonly cited rate of retum demanded by vulture investors. This sumprisingly close to the MLDR estimate that we get in this study for loans of $14.5 \%$; however, the RDD estima te that we get for loans is $43.3 \%$, fa r a bove that, as well a selevated far above the overa II RDD (MLDR) estimates of $29.2 \%(21.3 \%)$. The overa ll MLDR estima te of Brady et al (2006), based upon the S\&P LossStats databa se, is closer to this well-known figure, at $14 \%$.

It is interesting to note that a rounded $10 \%$ figure, whic h many of these studies come close to (e.g., Frye (2000), Altman \& J ha (2003)), is currently being cited by several banks as their choic of a discount rate for LGD based upon their "weighted average cost of capital", "cost of equity" or "average contract rate" in their portfolio.

Comparing the empinical estimates in the litera ture, whether model-based or purely empinical, to the model-free approaches, is largely inconclusive. Probably the closest to any of these methodologies disc ussed above would be using the ma rket price of debt at default (G upton and Stein, 2002), as that would embed a market consensus on an appropriate discount rate. However, the applicability of this would be conditional upon a bank having a policy of selling defaulted debt almost immediately, or otherwise hedging its recovery risk. The cost of equity (Eales and Bosworth, 1998) would only be comparable if the bank's business were entirely defa ulted debt investing, c lea lly a n unlikely scenario. Any of the approachesadvocating some measure of the promised retum on the debt - either the contra ct (Asamow and Edward, 1995 or Carty et al, 1998) or coupon (Friedman and Sandow, 2003) rate - would have to be such that the rate is adjusted to a truly distressed level prior to default for any kind of comparability to obtain. Finally, the risk-free rate suggestion (Ca rey and Gordy, 2006) is the clear outlier, as it is at odds with our thesis a dvanced herein.

Fina lly, rega rding the supenisory requirements of either Basel II in the U.S. (OCC et al, 2007) or the U.K (FSA, 2003), we conclude that something between a model-based and purely empinical approach, would best be in the spirit of this. We can think that the $10-15 \%$ implied by the fomer may be a lower bound, and the $20-40 \%$ implied from directly mea suring defaulted debt performance in some manner forms an upperbound, on the discount rate in the spint of the supervisory language. The extent to which a Bank is closer to the formervs. the latter depends on two institution-spec ific factors. First, the degree of systematic risk inherent in the loan portfolio in question, and second, the a mount of non0sytenmatic yet non-diversifiable risk conta ined in the said portfolio. It is the latter qua ntity that moves us towa rd the elevated discount rates as estimated herein, the empiric al RDD and MLDR that we observe. 


\section{Conclusions and Directions for Future Research}

In this paper, we have address questions surround ing the discount rate that should be applied to workout recoveries, for purposes of Basel II compliance as well as intemal credit risk mea surement purposes. To this end, we perform a comprehensive a nalysis of empinic ally derived disc ount rates for LGD, derived from market price at default and emergence prices of defaulted debt. We utilize the Moody's Ultimate Loss-Given-Default database in order to accomplish this. Altemative methodologies for estimating such empiric a lly derived disc ount rates a re examined, the retum on defaulted debt (RDD) and the most likely disc ount rate (MLDR) measures. First, we examine the distributional properties of the disc ount rate measures a cross different segmentations in the data set (e.g., default type, facility type, time period, seniority, industry). Second, we develop a multiple regression model for RDD in the generalized linear model (GLM) class. Having a model for assigning a proper, risk-a djusted discount rate to defaulted instruments, we quantify the effect of discounting on the distribution of economic LGD, and on estimated regulatory capital, for a hypothetic al portfolio. Finally, we perform a benchmarking a nalysis, companing the empirical RDD and MLDR methods developed herein to altemative techniques I the litera ture, including model or market based approa ches that develop a risk premium over the risk-free rate.

We find that empiric ally derived disc ount rate measures vary signific antly according to certa in different factors. There is some evidence that discount rate metric s a re elevated for loans having better collateral quality ra nk or better protected tranches within the capital structure; and for obligors rated higher at origination, more financially levered or having higher Cumulative Abnomal Retums on Equity (CARs) at default. However, disc ount rate measures a re increasing in market implied loss seventy at default. We also find evidence that LGD disc ount rates vary pro-cyc lic ally, as they vary directly with industry default rates, but there tends to a lag in the relationship; further, they are inversely related to short-tem interest rates. However, for other demogra phic s results a re inconclusive, such as the industry group of the obligor. Finally, we conduct an a nalysis of the impact of the disc ounting method upon the distribution of estimated LGD and regulatory capital. We find that a regression model based discounting, for a sub-sa mple of the MULGD database, results in a signific antly higher capital charge than either discounting at a constant punitive rate or at the contractual coupon rate. Our empiric ally derived estima tes of the appropriate discount rate for workout recoveries are to be significantly higher than what has been found in the previous literature, as well as what is used commonly in ind ustry and for Ba sel 2 purposes. Further, disc ount rates implied from a theoretical model of credit risk incorporating systematic recovery risk in an a symptotic structural risk factorframework (Gordy, 2003) are found to be significantly lower than the RDD or MLR. We conclude that this conservativeness of the risk-sensitive RDD model, as well as the evidence that the risk in recovery cash flows conta in a signific ant non-diversifiable component, supports the appropriateness of this framework for regulatory ca pital calculations.

This research, as enlightening as we believe it to be, opens up further questions regarding which disc ount rate for worko ut recoveries is optimal in some sense, from either a supenvisory or risk mea surement perspective. A great challenge in 
this regard we see as somehow rec onciling the results of this empiric al exerc ise, the implic a tions of struc tural c redit models as well as common industry practice. We suspect that genera lizations of the ASRF framework may hold promise in this regard, a s well have seen that incorporating systematic LGD as well as a second factor spec ific to recovery risk has resulted in higher estima tes tha n previously obta ined. Fruitful a venues of extension could be incorporating stochastic duration of bankruptcy resolution, simulta neous calibration by rating and seniority class, or incorporating strategic banknuptcy. On the empinical side, it would be useful to quantify the undiversifiable and non-systematic component of recovery risk, as that would help us sharpen our upper bound on the appropriate discount rate for LGD, as we argue has been derived herein. Finally, with a view towards the evolution 0of supenvisory requirements, an exa mination of the impact of this choice upon economic credit, or even integrated, risk capital. 


\section{Tables}

\begin{tabular}{|c|c|c|c|c|c|c|c|c|c|c|c|c|c|c|c|c|c|}
\hline \multicolumn{18}{|c|}{$\begin{array}{l}\text { Table } 1 \text { - Characteristics of RDD }{ }^{1} \text { and MLDR }{ }^{2} \text { Observations by Default and Instrument Type } \\
\text { (Moody's Ultimate LGD Database 1987-2007) }\end{array}$} \\
\hline & & & \multicolumn{5}{|c|}{ Bankruptcy } & \multicolumn{5}{|c|}{ Out-of-Court } & \multicolumn{5}{|c|}{$\begin{array}{rr}\text { Total } \\
\end{array}$} \\
\hline & & & Count & MLDR & MSE & Average & \begin{tabular}{|l|} 
Standard \\
Deviation
\end{tabular} & Count & MLDR & MSE & Average & \begin{tabular}{|l|} 
Standard \\
Deviation \\
\end{tabular} & Count & MLDR & MSE & Average & $\begin{array}{l}\text { Standard } \\
\text { Deviation }\end{array}$ \\
\hline \multirow{10}{*}{ 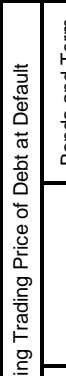 } & \multirow{5}{*}{ 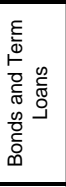 } & $\operatorname{RDD}^{1}$ & \multirow{5}{*}{1121} & \multirow[t]{5}{*}{$21.74 \%$} & \multirow[t]{5}{*}{$128.51 \%$} & $28.86 \%$ & $121.85 \%$ & \multirow{5}{*}{73} & \multirow[t]{5}{*}{$66.98 \%$} & \multirow{5}{*}{$108.26 \%$} & $38.86 \%$ & $135.78 \%$ & \multirow{5}{*}{1194} & \multirow{5}{*}{\multicolumn{2}{|c|}{$21.86 \% \mid 120.83 \%$}} & $29.48 \%$ & $122.71 \%$ \\
\hline & & LGD at Default ${ }^{3}$ & & & & $59.62 \%$ & $30.54 \%$ & & & & $40.73 \%$ & $27.07 \%$ & & & & $58.43 \%$ & $30.67 \%$ \\
\hline & & Discounted LGD ${ }^{4}$ & & & & $55.12 \%$ & $37.01 \%$ & & & & $35.15 \%$ & $24.76 \%$ & & & & $53.90 \%$ & $36.68 \%$ \\
\hline & & Time-to-Resolution ${ }^{5}$ & & & & 1.7439 & 1.4336 & & & & $17.90 \%$ & $40.73 \%$ & & & & 1.6482 & 1.4422 \\
\hline & & Principal at Default $^{6}$ & & & & 194,478 & 267,800 & & & & 390,990 & 479,024 & & & & 206,492 & 288,783 \\
\hline & \multirow{5}{*}{ 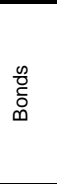 } & $\mathrm{RDD}^{1}$ & \multirow{5}{*}{888} & $23.88 \%$ & $162.22 \%$ & $23.27 \%$ & $119.93 \%$ & \multirow{5}{*}{71} & $66.93 \%$ & $111.31 \%$ & $39.96 \%$ & $137.54 \%$ & \multirow{5}{*}{959} & $24.02 \%$ & $150.44 \%$ & $24.50 \%$ & $121.32 \%$ \\
\hline & & LGD at Default ${ }^{2}$ & & & & $65.53 \%$ & $28.31 \%$ & & & & $41.77 \%$ & $26.64 \%$ & & & & $63.73 \%$ & $28.86 \%$ \\
\hline & & Discounted LGD ${ }^{3}$ & & & & $27.00 \%$ & $31.10 \%$ & & & & $36.14 \%$ & $24.37 \%$ & & & & $26.44 \%$ & $31.01 \%$ \\
\hline & & Time-to-Resolution ${ }^{4}$ & & & & 1.3205 & 1.1599 & & & & $24.01 \%$ & $58.26 \%$ & & & & 1.2931 & 1.1631 \\
\hline & & Principal at Default $^{5}$ & & & & \begin{tabular}{|l|}
261,431 \\
\end{tabular} & 417,060 & & & & 397,859 & 483,936 & & & & 257,588 & 413,525 \\
\hline 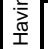 & & $\mathrm{RDD}^{1}$ & & $14.14 \%$ & $3.50 \%$ & $31.95 \%$ & $58.58 \%$ & & N/A & N/A & $0.01 \%$ & $0.01 \%$ & & $15.24 \%$ & $3.57 \%$ & $31.28 \%$ & $58.14 \%$ \\
\hline 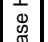 & & LGD at Default ${ }^{2}$ & & & & $34.57 \%$ & $27.42 \%$ & & & & $3.33 \%$ & $4.04 \%$ & & & & $33.94 \%$ & $27.50 \%$ \\
\hline 趂 & $\frac{3}{0}$ & Discounted LGD ${ }^{3}$ & 141 & & & $27.00 \%$ & $31.10 \%$ & 3 & & & $0.00 \%$ & $0.00 \%$ & 144 & & & $26.44 \%$ & $31.01 \%$ \\
\hline वृ & & \begin{tabular}{|l|} 
Time-to-Resolution \\
\end{tabular} & & & & 1.3205 & 1.1599 & & & & $0.27 \%$ & $0.00 \%$ & & & & 1.2931 & 1.1631 \\
\hline 造 & & \begin{tabular}{|l|} 
Principal at Default \\
\end{tabular} & & & & 261,431 & 417,060 & & & & 76,933 & 30,490 & & & & \begin{tabular}{|l|}
257,588 \\
\end{tabular} & 413,525 \\
\hline 客 & & $\mathrm{RDD}^{1}$ & & $14.45 \%$ & $32.82 \%$ & $43.31 \%$ & $106.72 \%$ & & N/A & N/A & $0.010 \%$ & $0.009 \%$ & & $14.45 \%$ & $32.83 \%$ & $42.74 \%$ & $106.13 \%$ \\
\hline $\begin{array}{c}\substack{\alpha \\
0 \\
0} \\
0\end{array}$ & & LGD at Default ${ }^{2}$ & & & & $43.31 \%$ & $106.72 \%$ & & & & $2.55 \%$ & $3.15 \%$ & & & & $35.33 \%$ & $35.33 \%$ \\
\hline 흥 & డ్డ & Discounted LGD ${ }^{3}$ & 374 & & & $28.88 \%$ & $31.70 \%$ & 5 & & & $0.00 \%$ & $0.00 \%$ & 379 & & & $28.50 \%$ & $31.66 \%$ \\
\hline$\sum_{i}^{0}$ & & Time-to-Resolution $^{4}$ & & & & 1.4130 & 1.2132 & & & & $18.84 \%$ & $54.73 \%$ & & & & 1.2513 & 1.2202 \\
\hline 苂 & & Principal at Default $^{5}$ & & & & 204,251 & 284,142 & & & & 105,020 & 57,797 & & & & 202,942 & 282,547 \\
\hline 䍜 & & $\mathrm{RDD}^{1}$ & & $21.31 \%$ & $114.15 \%$ & $29.21 \%$ & $116.49 \%$ & & $52.54 \%$ & $104.03 \%$ & $37.33 \%$ & $133.25 \%$ & & $22.38 \%$ & $107.83 \%$ & $29.67 \%$ & $117.46 \%$ \\
\hline 현 & & LGD at Default ${ }^{2}$ & & & & $56.79 \%$ & $31.22 \%$ & & & & $39.32 \%$ & $27.50 \%$ & & & & $55.78 \%$ & $31.28 \%$ \\
\hline 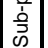 & 西 & \begin{tabular}{|l|} 
Discounted LGD \\
\end{tabular} & 1262 & & & $51.98 \%$ & $37.45 \%$ & 76 & & & $33.76 \%$ & $25.21 \%$ & 1338 & & & $50.94 \%$ & $37.09 \%$ \\
\hline & & \begin{tabular}{|l|} 
Time-to-Resolution \\
\end{tabular} & & & & 1.6966 & 1.4116 & & & & 0.1720 & 0.4006 & & & & 1.6100 & 1.4187 \\
\hline & & \begin{tabular}{|l|} 
Principal at Default \\
\end{tabular} & & & & 201,958 & 288,884 & & & & 378,593 & 473,392 & & & & 211,992 & 304,884 \\
\hline & & Discounted LGD ${ }^{3}$ & & & & $52.70 \%$ & $38.28 \%$ & & & & $20.48 \%$ & $29.65 \%$ & & & & $48.68 \%$ & $38.80 \%$ \\
\hline & & \begin{tabular}{|l|} 
Time-to-Resolution \\
\end{tabular} & 2712 & & & 1.7029 & 1.3458 & 386 & & & 0.2371 & 0.5783 & 3098 & & & 1.5203 & 1.3644 \\
\hline & & Principal at Default $^{5}$ & & & & 144,150 & 218,187 & & & & 199,686 & 343,228 & & & & 151,069 & 238,020 \\
\hline 発 & & Discounted LGD ${ }^{3}$ & & & & $52.70 \%$ & $38.28 \%$ & & & & $20.48 \%$ & $29.65 \%$ & & & & $48.68 \%$ & $38.80 \%$ \\
\hline 苋 & 它 & \begin{tabular}{|l|} 
Time-to-Resolution \\
\end{tabular} & 2712 & & & 1.7029 & 1.3458 & 386 & & & 0.2371 & 0.5783 & 3098 & & & 1.5203 & 1.3644 \\
\hline 总 & & Principal at Default $^{5}$ & & & & 144,150 & 218,187 & & & & 199,686 & 343,228 & & & & 151,069 & 238,020 \\
\hline 总 & $\stackrel{\frac{n}{\omega}}{\stackrel{\nu}{\nu}}$ & Discounted LGD ${ }^{3}$ & & & & $17.94 \%$ & $28.73 \%$ & & & & $1.89 \%$ & $7.32 \%$ & & & & $15.72 \%$ & $27.37 \%$ \\
\hline$\underset{\square}{\mathscr{Q}}$ & गั & Time-to-Resolution ${ }^{4}$ & 679 & & & 1.3906 & 1.1507 & 109 & & & 0.1578 & 0.5322 & 788 & & & 1.2200 & 1.1666 \\
\hline 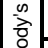 & $\widetilde{\widetilde{a}}$ & Principal at Default $^{5}$ & & & & 132,497 & 286,104 & & & & 87,536 & 177,706 & & & & \begin{tabular}{|l|}
126,278 \\
\end{tabular} & 274,032 \\
\hline$\sum_{\Sigma}^{\circ}$ & & \begin{tabular}{|l|} 
Discounted LGD \\
\end{tabular} & & & & $21.74 \%$ & $31.47 \%$ & & & & $3.35 \%$ & $11.52 \%$ & & & & $19.32 \%$ & $30.26 \%$ \\
\hline 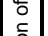 & (َ) & Time-to-Resolution ${ }^{4}$ & 1288 & & & 1.4130 & 1.2132 & 196 & & & 0.1884 & 0.5473 & 1484 & & & 1.2513 & 1.2202 \\
\hline 产 & & Principal at Default $^{5}$ & & & & 123,620 & 229,593 & & & & 109,288 & 291,125 & & & & 121,727 & 238,566 \\
\hline 흥 & & Discounted LGD ${ }^{3}$ & & & & $45.74 \%$ & $39.12 \%$ & & & & $16.39 \%$ & $27.50 \%$ & & & & $42.00 \%$ & $39.08 \%$ \\
\hline 足 & 榙 & Time-to-Resolution $^{4}$ & 3391 & & & 1.6404 & 1.3149 & 495 & & & 0.2196 & 0.5689 & 3886 & & & 1.4594 & 1.3320 \\
\hline 岀 & & Principal at Default ${ }^{5}$ & & & & 141,816 & 233,374 & & & & 126,278 & 274,032 & & & & 146,042 & 245,914 \\
\hline & $\begin{array}{l}\text { he } \\
\text { he }\end{array}$ & $\begin{array}{l}\text { nus the price of detaulte } \\
\text { late dollar loss-given-de } \\
\text { this can be expressed } \\
\text { instrument outstanding } \\
\text { in years from the instru }\end{array}$ & efa & din & $\begin{array}{l}\text { ulted deb } \\
\text { at default }\end{array}$ & ultima & $\begin{array}{l}\text { - (total } \\
\text { loss)/(out } \\
\text { ecovery. }\end{array}$ & cove & t & en & bankrup & $y$ or tim & & til the tim & e of ultin & & \\
\hline
\end{tabular}




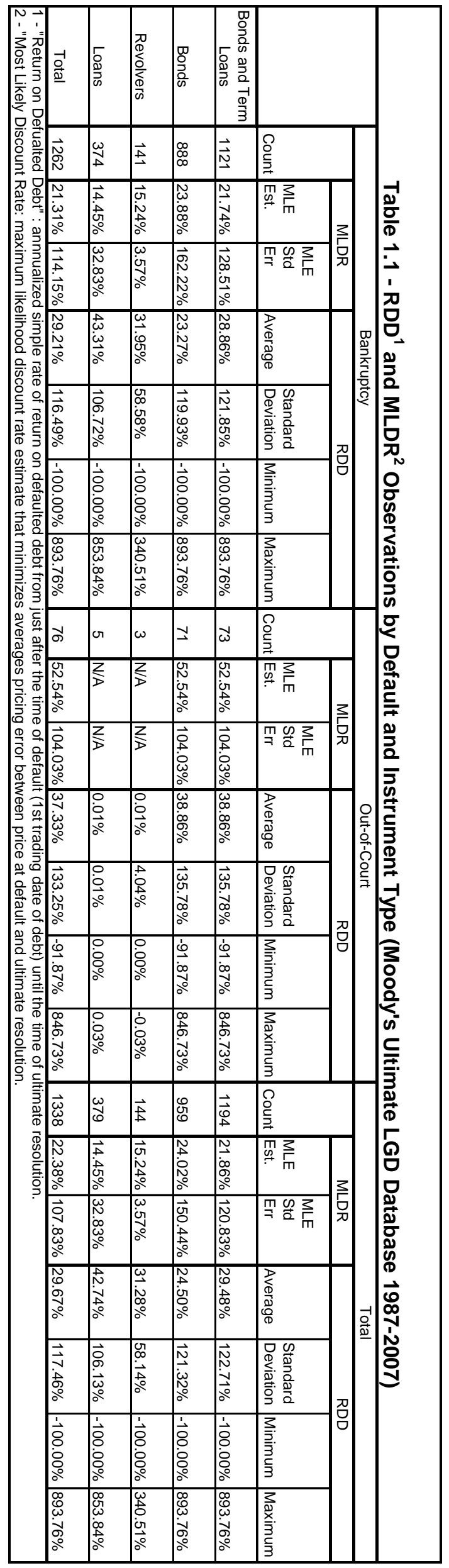




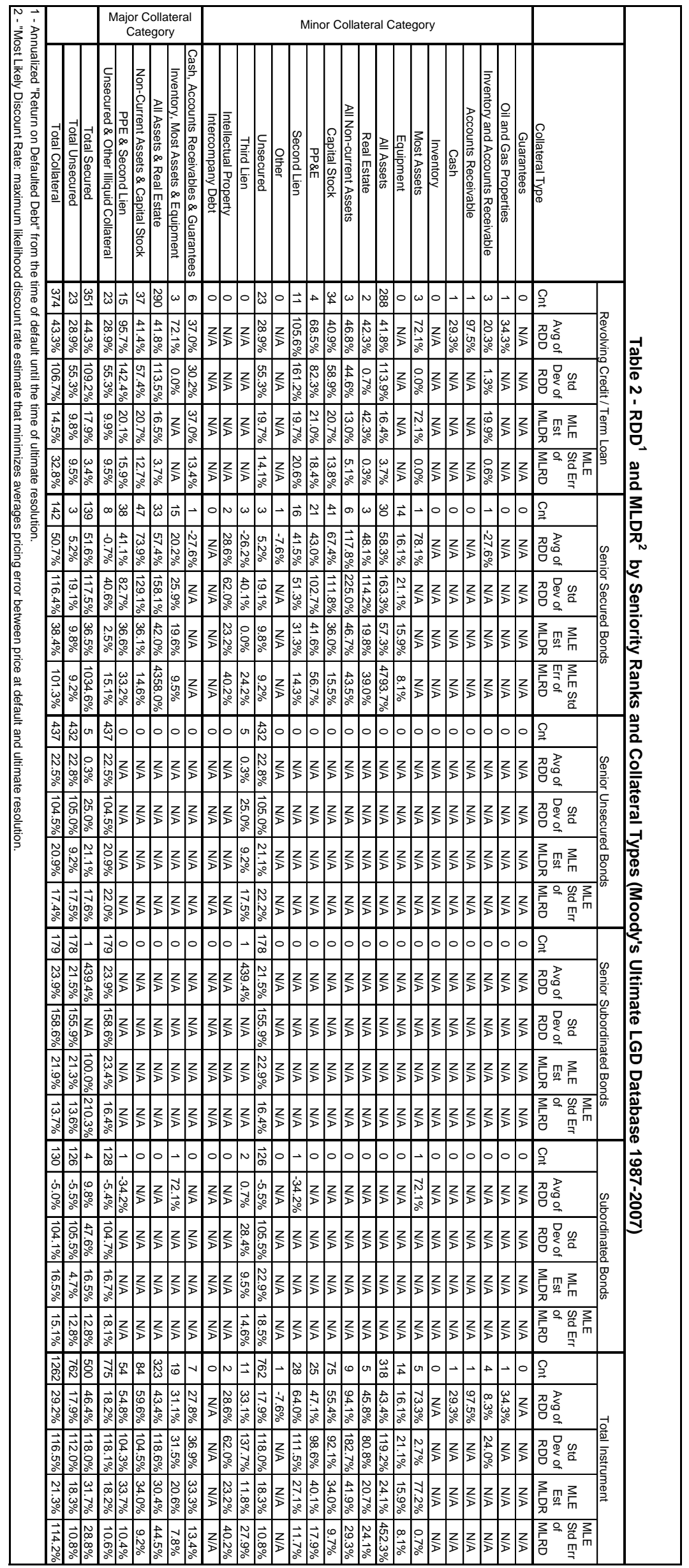




\begin{tabular}{|c|c|c|c|c|c|c|c|c|c|c|}
\hline \multicolumn{11}{|c|}{$\begin{array}{c}\text { Table } 2.1-\text { RDD }^{1} \text { and MLDR }{ }^{2} \text { by Seniority Ranks and Major Collateral Types } \\
\text { (Moody's Ultimate LGD Database 1987-2007) }\end{array}$} \\
\hline \multicolumn{2}{|r|}{ Collateral Type } & $\begin{array}{c}\text { Cash, } \\
\text { Accounts } \\
\text { Receivables \& } \\
\text { Guarantees }\end{array}$ & $\begin{array}{c}\text { Inventory, } \\
\text { Most Assets \& } \\
\text { Equipment }\end{array}$ & $\begin{array}{l}\text { All Assets \& } \\
\text { Real Estate }\end{array}$ & $\begin{array}{l}\text { Non-Current } \\
\text { Assets \& } \\
\text { Capital Stock }\end{array}$ & $\begin{array}{l}\text { PPE \& Second } \\
\text { Lien }\end{array}$ & $\begin{array}{c}\text { Unsecured \& } \\
\text { Other Illiquid } \\
\text { Collateral }\end{array}$ & Total Secured & $\begin{array}{c}\text { Total } \\
\text { Unsecured }\end{array}$ & $\begin{array}{c}\text { Total } \\
\text { Collateral } \\
\end{array}$ \\
\hline \multirow{5}{*}{ 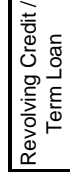 } & Cnt of RDD & \begin{tabular}{|c|}
6 \\
\end{tabular} & 3 & 290 & 37 & 15 & 23 & 351 & 23 & 374 \\
\hline & Avg of RDD & $37.0 \%$ & $72.1 \%$ & $41.8 \%$ & $41.4 \%$ & $95.7 \%$ & $28.9 \%$ & $44.3 \%$ & $28.9 \%$ & $43.3 \%$ \\
\hline & Std Dev of RDD & $30.2 \%$ & $0.0 \%$ & $113.5 \%$ & $57.4 \%$ & $142.4 \%$ & $55.3 \%$ & $109.2 \%$ & $55.3 \%$ & $106.7 \%$ \\
\hline & MLE Est of MLDR & $37.0 \%$ & $\mathrm{~N} / \mathrm{A}$ & $16.5 \%$ & $20.7 \%$ & $20.1 \%$ & $9.9 \%$ & $17.9 \%$ & $9.9 \%$ & $14.5 \%$ \\
\hline & MLE Std Err of MLDR & $13.4 \%$ & $\mathrm{~N} / \mathrm{A}$ & $3.7 \%$ & $12.7 \%$ & $15.9 \%$ & $9.5 \%$ & $3.4 \%$ & $9.5 \%$ & $32.8 \%$ \\
\hline \multirow{5}{*}{ 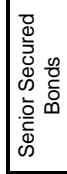 } & Cnt of RDD & 1 & 15 & 33 & 47 & 38 & 8 & 139 & 3 & 142 \\
\hline & Avg of RDD & $-27.6 \%$ & $20.2 \%$ & $57.4 \%$ & $73.9 \%$ & $41.1 \%$ & $-0.7 \%$ & $51.6 \%$ & $5.2 \%$ & $50.7 \%$ \\
\hline & Std Dev of RDD & $\mathrm{N} / \mathrm{A}$ & $25.9 \%$ & $158.1 \%$ & $129.1 \%$ & $82.7 \%$ & $40.6 \%$ & $117.5 \%$ & $19.1 \%$ & $116.4 \%$ \\
\hline & MLE Est of MLDR & $\mathrm{N} / \mathrm{A}$ & $19.6 \%$ & $42.0 \%$ & $36.1 \%$ & $36.6 \%$ & $2.5 \%$ & $36.5 \%$ & $9.8 \%$ & $38.4 \%$ \\
\hline & MLE Std Err of MLDR & $\mathrm{N} / \mathrm{A}$ & $9.5 \%$ & $4358.0 \%$ & $14.6 \%$ & $33.2 \%$ & $15.1 \%$ & $1034.6 \%$ & $9.2 \%$ & $101.3 \%$ \\
\hline \multirow{5}{*}{ 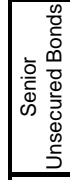 } & Cnt of RDD & 0 & 0 & 0 & 0 & 0 & 437 & 5 & 432 & 437 \\
\hline & Avg of RDD & $\mathrm{N} / \mathrm{A}$ & $\mathrm{N} / \mathrm{A}$ & $\mathrm{N} / \mathrm{A}$ & $\mathrm{N} / \mathrm{A}$ & $\mathrm{N} / \mathrm{A}$ & $22.5 \%$ & $0.3 \%$ & $22.8 \%$ & $22.5 \%$ \\
\hline & Std Dev of RDD & $\mathrm{N} / \mathrm{A}$ & $\mathrm{N} / \mathrm{A}$ & $\mathrm{N} / \mathrm{A}$ & $\mathrm{N} / \mathrm{A}$ & $\mathrm{N} / \mathrm{A}$ & $104.5 \%$ & $25.0 \%$ & $105.0 \%$ & $104.5 \%$ \\
\hline & MLE Est of MLDR & $\mathrm{N} / \mathrm{A}$ & $\mathrm{N} / \mathrm{A}$ & $\mathrm{N} / \mathrm{A}$ & $\mathrm{N} / \mathrm{A}$ & $\mathrm{N} / \mathrm{A}$ & $20.9 \%$ & $21.1 \%$ & $9.2 \%$ & $20.9 \%$ \\
\hline & MLE Std Err of MLDR & $\mathrm{N} / \mathrm{A}$ & $\mathrm{N} / \mathrm{A}$ & $\mathrm{N} / \mathrm{A}$ & $\mathrm{N} / \mathrm{A}$ & $\mathrm{N} / \mathrm{A}$ & $22.0 \%$ & $17.6 \%$ & $17.5 \%$ & $17.4 \%$ \\
\hline \multirow{5}{*}{ 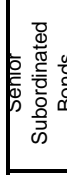 } & Cnt of RDD & 0 & 0 & 0 & 0 & 0 & 179 & 1 & 178 & 179 \\
\hline & Avg of RDD & $\mathrm{N} / \mathrm{A}$ & $\mathrm{N} / \mathrm{A}$ & $\mathrm{N} / \mathrm{A}$ & $\mathrm{N} / \mathrm{A}$ & $\mathrm{N} / \mathrm{A}$ & $23.9 \%$ & $439.4 \%$ & $21.5 \%$ & $23.9 \%$ \\
\hline & Std Dev of RDD & $\mathrm{N} / \mathrm{A}$ & $\mathrm{N} / \mathrm{A}$ & $\mathrm{N} / \mathrm{A}$ & $\mathrm{N} / \mathrm{A}$ & $\mathrm{N} / \mathrm{A}$ & $158.6 \%$ & $\mathrm{~N} / \mathrm{A}$ & $155.9 \%$ & $158.6 \%$ \\
\hline & MLE Est of MLDR & $\mathrm{N} / \mathrm{A}$ & $\mathrm{N} / \mathrm{A}$ & $\mathrm{N} / \mathrm{A}$ & $\mathrm{N} / \mathrm{A}$ & $\mathrm{N} / \mathrm{A}$ & $23.4 \%$ & $100.0 \%$ & $21.3 \%$ & $21.9 \%$ \\
\hline & MLE Std Err of MLDR & $\mathrm{N} / \mathrm{A}$ & $\mathrm{N} / \mathrm{A}$ & $\mathrm{N} / \mathrm{A}$ & $\mathrm{N} / \mathrm{A}$ & $\mathrm{N} / \mathrm{A}$ & $16.4 \%$ & $210.3 \%$ & $13.6 \%$ & $13.7 \%$ \\
\hline \multirow{5}{*}{ 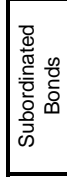 } & Cnt of RDD & 0 & 1 & 0 & 0 & 1 & 128 & 4 & 126 & 130 \\
\hline & Avg of RDD & $\mathrm{N} / \mathrm{A}$ & $72.1 \%$ & $\mathrm{~N} / \mathrm{A}$ & $\mathrm{N} / \mathrm{A}$ & $-34.2 \%$ & $-5.4 \%$ & $9.8 \%$ & $-5.5 \%$ & $-5.0 \%$ \\
\hline & Std Dev of RDD & $\mathrm{N} / \mathrm{A}$ & $\mathrm{N} / \mathrm{A}$ & $\mathrm{N} / \mathrm{A}$ & $\mathrm{N} / \mathrm{A}$ & $\mathrm{N} / \mathrm{A}$ & $104.7 \%$ & $47.6 \%$ & $105.5 \%$ & $104.1 \%$ \\
\hline & MLE Est of MLDR & $\mathrm{N} / \mathrm{A}$ & $\mathrm{N} / \mathrm{A}$ & $\mathrm{N} / \mathrm{A}$ & $\mathrm{N} / \mathrm{A}$ & $\mathrm{N} / \mathrm{A}$ & $16.7 \%$ & $16.5 \%$ & $4.7 \%$ & $16.5 \%$ \\
\hline & MLE Std Err of MLDR & $\mathrm{N} / \mathrm{A}$ & $\mathrm{N} / \mathrm{A}$ & $\mathrm{N} / \mathrm{A}$ & $\mathrm{N} / \mathrm{A}$ & $\mathrm{N} / \mathrm{A}$ & $18.1 \%$ & $12.8 \%$ & $12.8 \%$ & $15.1 \%$ \\
\hline \multirow{5}{*}{ 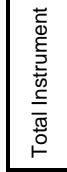 } & Cnt of RDD & 7 & 19 & 323 & 84 & 54 & 775 & 500 & 762 & 1262 \\
\hline & Avg of RDD & $27.8 \%$ & $31.1 \%$ & $43.4 \%$ & $59.6 \%$ & $54.8 \%$ & $18.2 \%$ & $46.4 \%$ & $17.9 \%$ & $29.2 \%$ \\
\hline & Std Dev of RDD & $36.9 \%$ & $31.5 \%$ & $118.6 \%$ & $104.5 \%$ & $104.3 \%$ & $118.1 \%$ & $118.0 \%$ & $112.0 \%$ & $116.5 \%$ \\
\hline & MLE Est of MLDR & $33.3 \%$ & $20.6 \%$ & $30.4 \%$ & $34.0 \%$ & $33.7 \%$ & $18.2 \%$ & $31.7 \%$ & $18.3 \%$ & $21.3 \%$ \\
\hline & MLE Std Err of MLDR & $13.4 \%$ & $7.8 \%$ & $44.5 \%$ & $9.2 \%$ & $10.4 \%$ & $10.6 \%$ & $28.8 \%$ & $10.8 \%$ & $114.2 \%$ \\
\hline
\end{tabular}




\begin{tabular}{|c|c|c|c|c|c|c|c|c|c|}
\hline \multicolumn{10}{|c|}{$\begin{array}{c}\text { Table } 3 \text { - RDD }{ }^{1} \text {, MLDR }{ }^{2} \text {, LGD }{ }^{3} \text {, Default Rate }{ }^{4} \text {, Dollar Loss }{ }^{5} \text { and } \\
\text { Duration }{ }^{6} \text { of Defaulted Instruments by Cohort Year } \\
\text { (Moody's Ultimate LGD Database 1987-2007) }\end{array}$} \\
\hline Year & $\begin{array}{l}\text { Count } \\
\text { of RDD }\end{array}$ & $\begin{array}{l}\text { Average } \\
\text { of RDD }\end{array}$ & $\begin{array}{l}\text { Std Dev } \\
\text { of RDD }\end{array}$ & $\begin{array}{l}\text { MLE } \\
\text { Est of } \\
\text { MLDR }\end{array}$ & $\begin{array}{l}\text { MLE Std } \\
\text { Err of } \\
\text { MLDR }\end{array}$ & $\begin{array}{l}\text { Average } \\
\text { LGD at } \\
\text { Default }{ }^{2}\end{array}$ & \begin{tabular}{|l|} 
Average \\
of \\
Moody's \\
Speculati \\
ve Grade \\
Default \\
Rate
\end{tabular} & $\begin{array}{l}\text { Average } \\
\text { of Total } \\
\text { Defaulted } \\
\text { Amount } \\
(\$ M M)^{4}\end{array}$ & 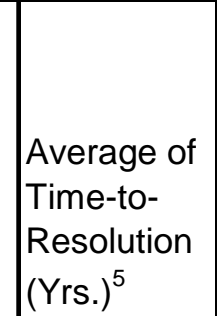 \\
\hline 1987 & 5 & $-5.03 \%$ & $10.81 \%$ & $-2.90 \%$ & $202.18 \%$ & $70.08 \%$ & \begin{tabular}{|l|}
$4.71 \%$ \\
\end{tabular} & 3,803 & \begin{tabular}{|l|l}
3 & 2.0379 \\
\end{tabular} \\
\hline 1988 & 11 & & & & & & & & \\
\hline 1989 & 14 & $29.07 \%$ & $108.33 \%$ & $35.47 \%$ & $29.34 \%$ & & & & \\
\hline 1990 & 64 & $46.40 \%$ & $143.41 \%$ & $17.58 \%$ & & & & & 6991 \\
\hline 1991 & 92 & $43.75 \%$ & 117. & 39.44 & & & & & 5074 \\
\hline 1992 & 27 & $32.54 \%$ & $172.26 \%$ & $5.33 \%$ & $15.73 \%$ & & & & 7309 \\
\hline 1993 & & $.32 \%$ & & $13.38 \%$ & & & & & \\
\hline 1994 & & $7.64 \%$ & & 12.1 & & & & & \\
\hline 1995 & & & 107 & 11. & & & & & \\
\hline 1996 & & $7.43 \%$ & $0 \%$ & $20.42 \%$ & & & & & \\
\hline 1997 & 7 & $9.14 \%$ & & $-1.27 \%$ & & & & & \\
\hline 1998 & & $-37.79 \%$ & $49.62 \%$ & $-25.43 \%$ & & & & & \\
\hline 1999 & 92 & $6.83 \%$ & $53.26 \%$ & $10.74 \%$ & $6.53 \%$ & $01 \%$ & $6.12 \%$ & 28,296 & 1.3468 \\
\hline 2000 & 105 & $-3.95 \%$ & $67.96 \%$ & $7.59 \%$ & & & & & .7394 \\
\hline 2001 & 257 & $16.15 \%$ & $101.98 \%$ & $24.59 \%$ & & $.25 \%$ & & 96, & 7314 \\
\hline 2002 & 207 & $50.77 \%$ & $147.80 \%$ & $32.83 \%$ & 17.4 & & & 183 & 3021 \\
\hline 2003 & & $64.24 \%$ & $161.24 \%$ & $46.20 \%$ & 15. & & & & 9826 \\
\hline 2004 & & $60 \%$ & $88.50 \%$ & $15.73 \%$ & & & & & \\
\hline 2005 & & $.59 \%$ & 118 & 50.8 & 53. & & & & \\
\hline & 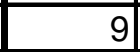 & & & & & & & & \\
\hline 2007 & & $9.98 \%$ & & -31.1 & & & & & \\
\hline Total & 1,262 & $29.21 \%$ & $116.49 \%$ & $22.38 \%$ & $107.83 \%$ & $55.78 \%$ & $7.14 \%$ & 567,520 & 1.4594 \\
\hline \multicolumn{10}{|c|}{$\begin{array}{l}1 \text { - Annualized "Return on Defaulted Debt" from just after the time of default (1st trading date of debt) } \\
\text { until the time of ultimate resolution. }\end{array}$} \\
\hline \multicolumn{10}{|c|}{$\begin{array}{l}2 \text { - "Most Likely Discount Rate": maximum likelihood discount rate estimate that minimizes averages } \\
\text { pricing error between price at default and ultimate resolution. }\end{array}$} \\
\hline \multicolumn{10}{|c|}{3 - One minus the price of defaulted debt at the time of default. } \\
\hline \multicolumn{10}{|c|}{$\begin{array}{l}4 \text { - Proportion of Moody's speculative rated companies defaulted during the year relative to those } \\
\text { rated at the begining of the year. }\end{array}$} \\
\hline \multicolumn{10}{|c|}{5 - The total instrument or obligor outstanding at default. } \\
\hline \multicolumn{10}{|c|}{ - The time in years from the instrument or firm default date to the time of ultimate recovery. } \\
\hline
\end{tabular}




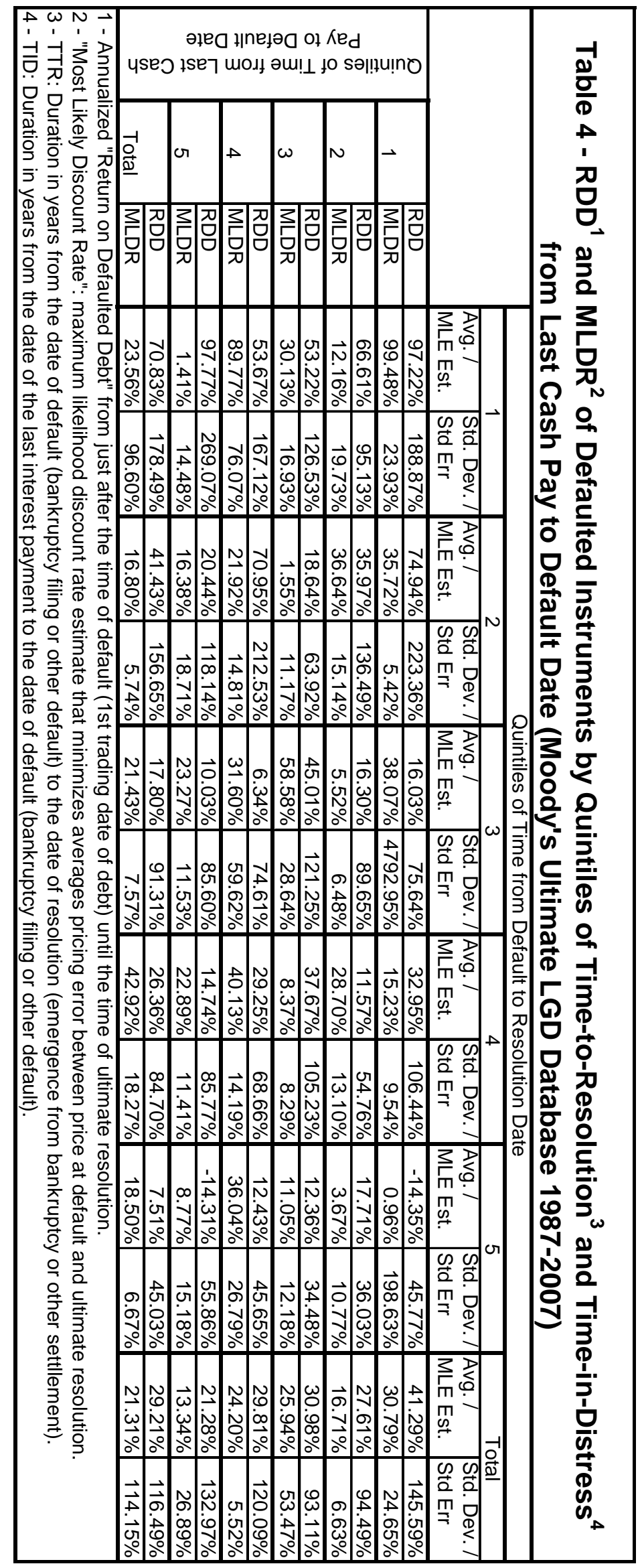




\section{Table $5-$ RDD $^{1}$ and MLDR ${ }^{2}$ of Defaulted Instruments by Credit Rating at Origination \\ (Moody's Ultimate LGD Database 1987-2007)}

\begin{tabular}{|c|c|c|c|c|c|c|}
\hline & & Count & $\begin{array}{l}\text { Average } \\
\text { of RDD }\end{array}$ & $\begin{array}{l}\text { Standard } \\
\text { Deviation } \\
\text { RDD }\end{array}$ & $\mid \begin{array}{l}\text { MLE } \\
\text { Estimate } \\
\text { of MLDR }\end{array}$ & $\begin{array}{l}\text { MLE } \\
\text { Standard } \\
\text { Error of } \\
\text { MLDR }\end{array}$ \\
\hline \multirow{8}{*}{ 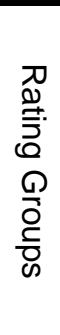 } & AA-A & 130 & $26.43 \%$ & $63.36 \%$ & $20.67 \%$ & $28.16 \%$ \\
\hline & BBB & 58 & $48.62 \%$ & $110.94 \%$ & $111.61 \%$ & $51.45 \%$ \\
\hline & BB & 299 & $18.10 \%$ & $91.67 \%$ & $22.13 \%$ & $7.18 \%$ \\
\hline & $\mathrm{B}$ & 497 & $32.06 \%$ & $140.92 \%$ & $13.24 \%$ & $13.68 \%$ \\
\hline & CC-CCC & 89 & $19.58 \%$ & $78.55 \%$ & $18.30 \%$ & $7.93 \%$ \\
\hline & Investment Grade (BBB-A) & 188 & $33.28 \%$ & $80.75 \%$ & $23.70 \%$ & $25.89 \%$ \\
\hline & Junk Grade (CC-BB) & 885 & $26.09 \%$ & $212.83 \%$ & $18.48 \%$ & $8.10 \%$ \\
\hline & Total & 1262 & $29.21 \%$ & $116.49 \%$ & $21.31 \%$ & $114.15 \%$ \\
\hline
\end{tabular}

1 - Annnualized "Return on Defaulted Debt" from just after the time of default (1st trading date of debt) until the time of ultimate resolution.

2 - "Most Likely Discount Rate": maximum likelihood discount rate estimate that minimizes averages pricing error between price at default and ultimate resolution.

\begin{tabular}{|c|c|c|c|c|c|c|}
\hline \multicolumn{7}{|c|}{$\begin{array}{c}\text { Table } 6 \text { - RDD }{ }^{1} \text { and MLDR }{ }^{2} \text { of Defaulted Instruments by } \\
\text { Tranche Safety Index }{ }^{3} \text { (TSI) Quintiles and Categories } \\
\text { (Moody's Ultimate LGD Database 1987-2007) }\end{array}$} \\
\hline & & Count & $\begin{array}{l}\text { Average } \\
\text { RDD }\end{array}$ & \begin{tabular}{|l|} 
Standard \\
Deviation \\
RDD
\end{tabular} & MLDR & $\begin{array}{l}\text { ILE Std } \\
\text { rr MLDR }\end{array}$ \\
\hline \multirow{10}{*}{ 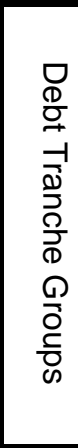 } & & 154 & $33.03 \%$ & & & \\
\hline & & 324 & & & & \\
\hline & & & & & & \\
\hline & & 326 & & & & \\
\hline & $\mathrm{TSI}$ & 86 & $53.23 \%$ & & & $32.06 \%$ \\
\hline & & 427 & & & & $6.87 \%$ \\
\hline & $\mathrm{SDB}^{5}$ & 232 & $08 \%$ & & & $8.46 \%$ \\
\hline & $\mathrm{A} / \mathrm{NDB}^{6}$ & 154 & $\%$ & & & $93.37 \%$ \\
\hline & $\mathrm{B} / \mathrm{SDA}^{\prime}$ & 449 & & & & $17.73 \%$ \\
\hline & Total & 1262 & $29.21 \%$ & $116.49 \%$ & $21.31 \%$ & $114.15 \%$ \\
\hline \multicolumn{7}{|c|}{$\begin{array}{l}1 \text { - Annnualized "Return on Defaulted Debt" from just after the time of default (1st trading } \\
\text { date of debt) until the time of ultimate resolution. }\end{array}$} \\
\hline \multicolumn{7}{|c|}{$\begin{array}{l}2 \text { - "Most Likely Discount Rate": maximum likelihood discount rate estimate that minimizes } \\
\text { averages pricing error between price at default and ultimate resolution. }\end{array}$} \\
\hline \multicolumn{7}{|c|}{$\begin{array}{l}3 \text { - An index of the tranche safety calculated as TTS }=(\% \text { Debt Below - \% Debt Above }+1) \\
4 \text { - No Debt Above \& Some Debt Below } \\
5 \text { - Some Debt Above \& Some Debt Below } \\
6 \text { - o Debt Above \& No Debt Below } \\
7 \text { - No Debt Below \& Some Debt Above }\end{array}$} \\
\hline
\end{tabular}


Table $7-$ RDD $^{1}$ and MLDR ${ }^{2}$ of Defaulted Instruments by Industry (Moody's Ultimate LGD Database 1987-2007)

\begin{tabular}{|c|c|c|c|c|c|}
\hline \multirow[b]{2}{*}{ Industry Group } & \multirow[b]{2}{*}{ Count } & \multicolumn{2}{|c|}{ RDD } & \multicolumn{2}{|c|}{ MLDR } \\
\hline & & Average & $\begin{array}{l}\text { Standard } \\
\text { Deviation }\end{array}$ & $\begin{array}{l}\text { MLE } \\
\text { Estimate }\end{array}$ & $\begin{array}{l}\text { MLE } \\
\text { Standard } \\
\text { Error }\end{array}$ \\
\hline Aerospace / Auto / Capital Goods / Equipment & 156 & $41.30 \%$ & $122.21 \%$ & $22.29 \%$ & $22.80 \%$ \\
\hline Consumer / Service Sector & 235 & $34.27 \%$ & $121.28 \%$ & $28.84 \%$ & $61.19 \%$ \\
\hline Energy / Natural Resources & 183 & $26.56 \%$ & $55.42 \%$ & $20.35 \%$ & $34.96 \%$ \\
\hline Healthcare / Chemicals & 93 & $24.03 \%$ & $90.98 \%$ & $17.99 \%$ & $10.77 \%$ \\
\hline High Technology / Telecommunications & 225 & $40.98 \%$ & $159.31 \%$ & $17.92 \%$ & $6.94 \%$ \\
\hline Leisure Time / Media & 114 & $36.58 \%$ & $114.81 \%$ & $26.42 \%$ & $13.25 \%$ \\
\hline Transportation & 236 & $6.02 \%$ & $99.95 \%$ & $5.76 \%$ & $16.04 \%$ \\
\hline Forest / Building Products / Homebuilders & 20 & $23.01 \%$ & $128.62 \%$ & $34.94 \%$ & $21.06 \%$ \\
\hline Grand Total & 1,262 & $29.21 \%$ & $116.49 \%$ & $22.38 \%$ & $107.83 \%$ \\
\hline
\end{tabular}

1 - Annnualized "Return on Defaulted Debt" from just after the time of default (1st trading date of debt) until the time of ultimate resolution.

2 - "Most Likely Discount Rate": maximum likelihood discount rate estimate that minimizes averages pricing error between price at default and ultimate resolution. 


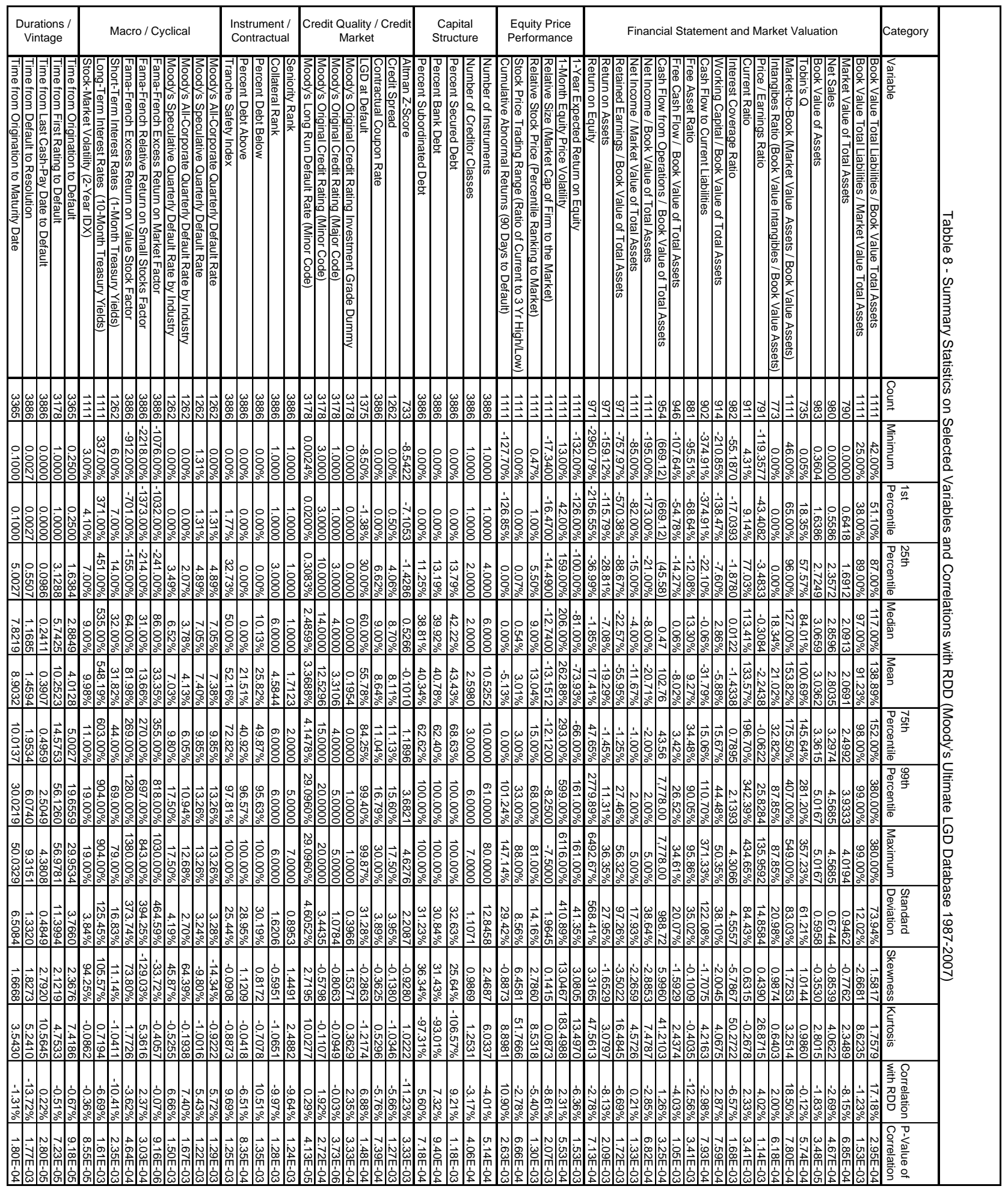


Table 8.1 - Summary Statistics on Financial Statement and Market Valuation Variables and Correlations with RDD (Moody's Ultimate LGD Database 1987-2007)

\begin{tabular}{|c|c|c|c|c|c|c|c|c|c|c|c|c|}
\hline Variable & Cnt & Minimum & \begin{tabular}{|l} 
25th \\
Prcntle
\end{tabular} & Median & Mean & $\begin{array}{l}\text { 75th } \\
\text { Prcntle }\end{array}$ & Maximum & Std Dev & Skew & Kurt & $\begin{array}{l}\text { Corr } \\
\text { with } \\
\text { RDD }\end{array}$ & $\begin{array}{l}\text { P-Val of } \\
\text { Corr }\end{array}$ \\
\hline BVTL / BVTA & 1111 & $42.00 \%$ & $87.00 \%$ & $117.00 \%$ & $138.89 \%$ & $152.00 \%$ & $380.00 \%$ & $73.94 \%$ & 1.5817 & 1.7579 & $17.18 \%$ & $2.95 \mathrm{E}-04$ \\
\hline BVTL / MVTA & 1111 & $25.00 \%$ & $89.00 \%$ & $97.00 \%$ & $91.23 \%$ & $98.00 \%$ & $99.00 \%$ & $12.02 \%$ & -2.6681 & 8.6235 & $-1.23 \%$ & 1.53E-03 \\
\hline MVTA & 790 & 0.0000 & 1.6912 & 2.0913 & 2.0691 & 2.4992 & 4.0194 & 0.9462 & -0.7762 & 2.3489 & $-8.15 \%$ & $6.85 \mathrm{E}-04$ \\
\hline Net Sales & 980 & 0.0000 & 2.3572 & 2.8596 & 2.8035 & 3.2974 & 4.5685 & 0.6744 & -0.8539 & 4.0622 & $-2.69 \%$ & 4.67E-04 \\
\hline BVA & 983 & 0.3604 & 2.7249 & 3.0659 & 3.0362 & 3.3615 & 5.0167 & 0.5958 & -0.3530 & 2.8015 & $-1.83 \%$ & $3.48 \mathrm{E}-05$ \\
\hline Tobin's Q & 735 & $0.05 \%$ & $57.57 \%$ & $84.01 \%$ & $100.69 \%$ & $145.64 \%$ & $357.23 \%$ & $61.21 \%$ & 1.0144 & 0.9860 & $-0.12 \%$ & $5.74 \mathrm{E}-04$ \\
\hline MVTA / BVTA & 1111 & $46.00 \%$ & $96.00 \%$ & $127.00 \%$ & $153.82 \%$ & $175.50 \%$ & $549.00 \%$ & $83.03 \%$ & 1.7253 & 3.2514 & $18.50 \%$ & $7.80 \mathrm{E}-04$ \\
\hline BVI / BVTA & 773 & $0.00 \%$ & $0.00 \%$ & $18.34 \%$ & $21.02 \%$ & $32.82 \%$ & $87.85 \%$ & $20.98 \%$ & 0.9874 & 0.6403 & $2.00 \%$ & 6.18E-04 \\
\hline PE Ratio & 791 & -119.3577 & -3.4833 & -0.3084 & -2.2438 & -0.0622 & 135.9592 & 14.8584 & 0.4390 & 26.8715 & $4.02 \%$ & $1.14 \mathrm{E}-03$ \\
\hline $\mathrm{CR}$ & 911 & $4.31 \%$ & $77.03 \%$ & $113.41 \%$ & $133.57 \%$ & $196.70 \%$ & $434.65 \%$ & $84.43 \%$ & 0.6315 & -0.2678 & $2.33 \%$ & 3.41E-03 \\
\hline ICR & 982 & (55.19) & (1.88) & \begin{tabular}{|l|}
0.01 \\
\end{tabular} & (1.43) & \begin{tabular}{|l|}
0.79 \\
\end{tabular} & 4.31 & 4.56 & -5.7867 & 50.2722 & $-6.57 \%$ & $1.68 \mathrm{E}-03$ \\
\hline WC / BVTA & 914 & $-210.85 \%$ & $-7.60 \%$ & $2.86 \%$ & $-5.88 \%$ & $15.67 \%$ & $50.35 \%$ & $38.10 \%$ & -2.0045 & 4.0675 & $2.87 \%$ & 7.59E-04 \\
\hline $\mathrm{CF} / \mathrm{CL}$ & 902 & $-374.91 \%$ & $-22.10 \%$ & $-0.06 \%$ & $-31.79 \%$ & $15.06 \%$ & $371.33 \%$ & $122.08 \%$ & -1.7075 & 4.2163 & $-2.98 \%$ & 7.93E-04 \\
\hline FAR & 881 & $-95.51 \%$ & $-12.08 \%$ & $13.30 \%$ & $9.27 \%$ & $34.48 \%$ & $95.86 \%$ & $35.02 \%$ & -0.1009 & -0.4035 & $-12.56 \%$ & $3.41 \mathrm{E}-03$ \\
\hline FCF / BVTA & 946 & $-107.64 \%$ & $-14.27 \%$ & $0.06 \%$ & $-8.02 \%$ & $3.42 \%$ & $34.61 \%$ & $20.07 \%$ & -1.5929 & 2.4374 & $-4.03 \%$ & $1.05 \mathrm{E}-03$ \\
\hline CFO / BVTA & 954 & (669.12) & (45.58) & 0.47 & 102.76 & 43.56 & $7,778.00$ & 988.72 & 5.9960 & 41.2103 & $1.26 \%$ & $3.25 \mathrm{E}-04$ \\
\hline $\mathrm{NI} / \mathrm{BVTA}$ & 1111 & $-195.00 \%$ & $-21.00 \%$ & $-8.00 \%$ & $-20.71 \%$ & $-2.00 \%$ & $5.00 \%$ & $38.64 \%$ & -2.8853 & 7.4787 & $-2.85 \%$ & $6.82 \mathrm{E}-04$ \\
\hline $\mathrm{NI} / \mathrm{MVTA}$ & 1111 & $-85.00 \%$ & $-15.00 \%$ & $-4.00 \%$ & $-11.67 \%$ & $-1.00 \%$ & $5.00 \%$ & $17.93 \%$ & -2.2659 & 4.5726 & $0.21 \%$ & 1.33E-03 \\
\hline RE / BVTA & 971 & $-757.97 \%$ & $-88.67 \%$ & $-22.57 \%$ & $-55.95 \%$ & $-1.25 \%$ & $56.32 \%$ & $97.26 \%$ & -3.5022 & 16.4845 & $-6.69 \%$ & $1.72 \mathrm{E}-03$ \\
\hline ROA & 971 & $-159.12 \%$ & $-28.81 \%$ & $-7.08 \%$ & $-19.29 \%$ & $-1.45 \%$ & $36.35 \%$ & $27.95 \%$ & -1.6529 & 3.0797 & $-8.13 \%$ & $2.09 \mathrm{E}-03$ \\
\hline ROE & 971 & $-2950.79 \%$ & $-36.99 \%$ & $-1.85 \%$ & $17.41 \%$ & $47.65 \%$ & $6492.67 \%$ & $568.41 \%$ & 3.3165 & 47.5613 & $-2.78 \%$ & 7.13E-04 \\
\hline
\end{tabular}

Table 8.2 - Summary Statistics on Equity Price Performance Variables and Correlations with RDD (Moody's Ultimate LGD Database 1987-2007)

\begin{tabular}{|c|c|c|c|c|c|c|c|c|c|c|c|c|c|c|}
\hline Variable & Cnt & Minimum & \begin{tabular}{|l|} 
1st \\
Percentile
\end{tabular} & $\begin{array}{l}\text { 25th } \\
\text { Prcntle }\end{array}$ & Median & Mean & $\begin{array}{l}\text { 75th } \\
\text { Prcntle }\end{array}$ & $\begin{array}{l}\text { 99th } \\
\text { Prcntle }\end{array}$ & Maximum & Std Dev & Skew & Kurt & $\begin{array}{l}\text { Corr } \\
\text { with } \\
\text { RDD }\end{array}$ & $\begin{array}{l}\text { P-Val of } \\
\text { Corr }\end{array}$ \\
\hline 1-Yr Expected Equity Return & 1111 & $-132.00 \%$ & $-126.00 \%$ & $-100.00 \%$ & $-81.00 \%$ & $\begin{array}{ll}-73.93 \% \\
\end{array}$ & $-66.00 \%$ & $161.00 \%$ & $161.00 \%$ & $41.35 \%$ & 3.0805 & 13.4970 & $-6.36 \%$ & $1.53 \mathrm{E}-03$ \\
\hline 1-Month Equity Return Volatility & 1111 & $13.00 \%$ & $42.00 \%$ & $159.00 \%$ & $206.00 \%$ & $262.88 \%$ & $293.00 \%$ & $599.00 \%$ & $6116.00 \%$ & $410.89 \%$ & 13.0467 & \begin{tabular}{|l}
183.4988 \\
\end{tabular} & $2.31 \%$ & $5.53 \mathrm{E}-04$ \\
\hline Market Cap to Relative to Market & 1111 & -17.3400 & -16.4700 & -14.4900 & -12.7400 & -13.1512 & -12.1200 & -8.2500 & -7.5000 & 1.9645 & 0.1415 & 0.0873 & $-8.61 \%$ & $2.07 \mathrm{E}-03$ \\
\hline Stock Price to Relative to Market & 1111 & 0.0047 & 0.0100 & 0.0550 & $9.00 \%$ & \begin{tabular}{|l|l|}
0 & $13.04 \%$ \\
\end{tabular} & $15.00 \%$ & $68.00 \%$ & $81.00 \%$ & $14.16 \%$ & 2.7860 & 8.5318 & $-5.40 \%$ & $1.30 \mathrm{E}-03$ \\
\hline Stock Price Trading Range & 1111 & 0.0000 & 0.0000 & 0.0007 & $0.54 \%$ & $3.01 \%$ & $3.00 \%$ & $33.00 \%$ & $88.00 \%$ & $8.56 \%$ & 6.4581 & 51.7666 & $-2.78 \%$ & $6.66 \mathrm{E}-04$ \\
\hline Cumulative Abnormal Returns & 1111 & $-127.70 \%$ & $-126.85 \%$ & $0.00 \%$ & $0.00 \%$ & $-5.13 \%$ & $0.00 \%$ & $101.24 \%$ & $147.14 \%$ & $29.42 \%$ & -0.8873 & 8.8981 & $10.90 \%$ & $2.63 \mathrm{E}-03$ \\
\hline
\end{tabular}

Table 8.3 - Summary Statistics on Capital Structure Variables and Correlations with RDD (Moody's Ultimate LGD Database 1987-2007)

\begin{tabular}{|c|c|c|c|c|c|c|c|c|c|c|c|c|}
\hline Variable & Cnt & Min & $\begin{array}{l}\text { 25th } \\
\text { Prcntle }\end{array}$ & Median & Mean & $\begin{array}{l}\text { 75th } \\
\text { Prcntle }\end{array}$ & Max & Std Dev & Skew & Kurt & $\begin{array}{l}\text { Corr } \\
\text { with } \\
\text { RDD }\end{array}$ & $\begin{array}{l}\text { P-Val of } \\
\text { Corr }\end{array}$ \\
\hline Number of Instruments & 3886 & 1.0000 & 4.0000 & 6.0000 & 10.5252 & 10.0000 & 80.0000 & 12.8458 & 2.4687 & 6.0337 & $-4.01 \%$ & 5.14E-04 \\
\hline Number of Creditor Classes & 3886 & 1.0000 & 2.0000 & 2.0000 & 2.5980 & 3.0000 & 7.0000 & 1.1071 & 0.9869 & 1.2531 & $-3.17 \%$ & $4.06 \mathrm{E}-04$ \\
\hline Percent Secured Debt & 3886 & $0.00 \%$ & $13.79 \%$ & $42.22 \%$ & $43.43 \%$ & $68.63 \%$ & $100.00 \%$ & $32.63 \%$ & $25.64 \%$ & $-106.57 \%$ & $9.21 \%$ & $1.18 \mathrm{E}-03$ \\
\hline Percent Bank Debt & 3886 & $0.00 \%$ & $13.19 \%$ & $39.92 \%$ & $40.78 \%$ & $62.40 \%$ & $100.00 \%$ & $30.84 \%$ & $31.43 \%$ & $-93.01 \%$ & $7.32 \%$ & 9.40E-04 \\
\hline Percent Subordinated Debt & 3886 & $0.00 \%$ & $11.25 \%$ & $38.81 \%$ & $40.34 \%$ & $62.62 \%$ & $100.00 \%$ & $31.23 \%$ & $36.34 \%$ & $-97.31 \%$ & $5.60 \%$ & \begin{tabular}{|l|}
$7.18 \mathrm{E}-04$ \\
\end{tabular} \\
\hline
\end{tabular}

\begin{tabular}{|c|c|c|c|c|c|c|c|c|c|c|c|c|c|c|}
\hline Table 8.4 - Sun & mmary & y Statisti & $\begin{array}{l}\text { ics on Cre } \\
\text { (Moody's }\end{array}$ & $\begin{array}{l}\text { edit Qua } \\
\text { Ultimate }\end{array}$ & $\begin{array}{l}\text { ality / Cre } \\
\text { LGD D }\end{array}$ & $\begin{array}{l}\text { edit Mark } \\
\text { atabase }\end{array}$ & $\begin{array}{l}\text { ket Varia } \\
1987-2\end{array}$ & $\begin{array}{l}\text { ables and } \\
\text { 2007) }\end{array}$ & Correlat & ations wi & ith RDD & & & \\
\hline Variable & Cnt & Min & $\mid \begin{array}{l}1 \text { st } \\
\text { Percentile }\end{array}$ & \begin{tabular}{|l|}
25 th \\
Prcntle
\end{tabular} & Median & Mean & \begin{tabular}{|l|} 
75th \\
Prcntle
\end{tabular} & \begin{tabular}{|l|}
99 th \\
Prcntle
\end{tabular} & Max & Std Dev & Skew & Kurt & $\begin{array}{l}\text { Corr } \\
\text { with } \\
\text { RDD }\end{array}$ & \begin{tabular}{|l} 
P-Val of \\
Corr
\end{tabular} \\
\hline Altman Z-Score & 733 & -8.5422 & -7.1053 & -1.4286 & 0.5266 & -0.1010 & 1.1896 & \begin{tabular}{|l|l|}
5 & 3.6821 \\
\end{tabular} & 4.6276 & 2.2087 & -0.9280 & 1.0222 & $-11.23 \%$ & $3.33 \mathrm{E}-03$ \\
\hline Credit Spread & 1262 & 0.0000 & 0.0050 & 0.0406 & $8.70 \%$ & $8.11 \%$ & $11.13 \%$ & $15.60 \%$ & $17.50 \%$ & $3.95 \%$ & -0.1380 & -1.0346 & $-5.66 \%$ & $1.27 \mathrm{E}-03$ \\
\hline Contractual Coupon Rate & 3886 & $0.00 \%$ & $0.00 \%$ & $6.62 \%$ & $9.00 \%$ & $8.64 \%$ & $11.04 \%$ & $16.79 \%$ & $30.00 \%$ & $3.89 \%$ & $-36.25 \%$ & $52.96 \%$ & $-5.76 \%$ & $7.39 \mathrm{E}-04$ \\
\hline LGD at Default & 1375 & $-8.50 \%$ & $-1.38 \%$ & $30.00 \%$ & $60.00 \%$ & $55.78 \%$ & $84.25 \%$ & $99.40 \%$ & $99.87 \%$ & $31.28 \%$ & $-28.63 \%$ & $-121.74 \%$ & $6.88 \%$ & $1.48 \mathrm{E}-04$ \\
\hline Moody's Original Credit Rating Investment Grade & 3178 & 0.0000 & 0.0000 & 0.0000 & 0.0000 & 0.1954 & 0.0000 & 1.0000 & 1.0000 & 0.3966 & 1.5371 & 0.3629 & $2.35 \%$ & $3.33 \mathrm{E}-04$ \\
\hline \begin{tabular}{|l|} 
Moody's Original Credit Rating (Major Code) \\
\end{tabular} & 3178 & 1.0000 & 1.0000 & 3.0000 & 4.0000 & 3.3106 & 4.0000 & 5.0000 & 5.0000 & 1.0784 & -0.8063 & -0.0949 & $-0.03 \%$ & $3.73 \mathrm{E}-06$ \\
\hline Moody's Original Credit Rating (Minor Code) & 3178 & 3.0000 & 3.0000 & 10.0000 & 14.0000 & 12.5296 & 15.0000 & 20.0000 & 20.0000 & 3.4435 & -0.5798 & -0.1107 & $1.92 \%$ & $2.72 \mathrm{E}-04$ \\
\hline Moody's Long Run Default Rate (Minor Code) & 3178 & 0.0000 & 0.0002 & 0.0031 & 0.0249 & 0.0337 & 0.0415 & 0.2910 & 0.2910 & 0.0461 & 2.7195 & 10.0277 & $0.29 \%$ & $4.13 \mathrm{E}-05$ \\
\hline
\end{tabular}


Table 8.5 - Summary Statistics on Instrument / Contractual Variables and Correlations with RDD (Moody's Ultimate LGD Database 1987-2007)

\begin{tabular}{|c|c|c|c|c|c|c|c|c|c|c|c|c|}
\hline Variable & Cnt & Min & $\begin{array}{l}25 \text { th } \\
\text { Prcntle }\end{array}$ & Median & Mean & $\begin{array}{l}\text { 75th } \\
\text { Prcntle }\end{array}$ & Max & Std Dev & Skew & Kurt & $\begin{array}{l}\text { Corr } \\
\text { with } \\
\text { RDD }\end{array}$ & $\begin{array}{l}\text { P-Val of } \\
\text { Corr }\end{array}$ \\
\hline Seniority Rank & 3886 & 1.0000 & 1.0000 & 1.0000 & 1.7123 & 2.0000 & 7.0000 & 0.8953 & 1.4491 & 2.4882 & $-9.64 \%$ & $1.24 \mathrm{E}-03$ \\
\hline Collateral Rank & 3886 & 1.0000 & 3.0000 & 6.0000 & 4.5844 & 6.0000 & 6.0000 & 1.6206 & -0.5951 & -1.0651 & $-9.97 \%$ & $1.28 \mathrm{E}-03$ \\
\hline Percent Debt Below & 3886 & $0.00 \%$ & $0.00 \%$ & $10.13 \%$ & $25.82 \%$ & $49.87 \%$ & $100.00 \%$ & $30.19 \%$ & $81.72 \%$ & $-70.78 \%$ & $10.51 \%$ & $1.35 \mathrm{E}-03$ \\
\hline Percent Debt Above & 3886 & $0.00 \%$ & $0.00 \%$ & $0.00 \%$ & $21.51 \%$ & $40.92 \%$ & $100.00 \%$ & $28.95 \%$ & $112.09 \%$ & $-4.18 \%$ & $-6.51 \%$ & $8.35 \mathrm{E}-04$ \\
\hline Tranche Safety Index & 3886 & $0.00 \%$ & $32.73 \%$ & $50.00 \%$ & $52.16 \%$ & $72.82 \%$ & $100.00 \%$ & $25.44 \%$ & $-9.08 \%$ & $-88.73 \%$ & $9.69 \%$ & $1.25 \mathrm{E}-03$ \\
\hline
\end{tabular}

Table 8.6 - Summary Statistics on Macroenonomic and Cyclical Variables and Correlations with RDD (Moody's Ultimate LGD Database 1987-2007)

\begin{tabular}{|c|c|c|c|c|c|c|c|c|c|c|c|c|}
\hline Variable & Cnt & Minimum & $\begin{array}{l}\text { 25th } \\
\text { Prcntle }\end{array}$ & Median & Mean & $\begin{array}{l}\text { 75th } \\
\text { Prcntle }\end{array}$ & Maximum & Std Dev & Skew & Kurt & $\begin{array}{l}\text { Corr } \\
\text { with } \\
\text { RDD }\end{array}$ & $\begin{array}{l}\text { P-Val of } \\
\text { Corr }\end{array}$ \\
\hline Moody's All-Corporate Quarterly Default Rate & 1262 & $0.00 \%$ & $4.89 \%$ & $7.05 \%$ & $7.38 \%$ & $9.85 \%$ & $13.26 \%$ & $3.28 \%$ & -0.1434 & -0.9222 & $5.72 \%$ & $1.29 \mathrm{E}-03$ \\
\hline Moody's Speculative Quarterly Default Rate & 1262 & $1.31 \%$ & $4.89 \%$ & $7.05 \%$ & $7.40 \%$ & $9.85 \%$ & $13.26 \%$ & $3.24 \%$ & -0.0980 & -1.0016 & $5.43 \%$ & $1.22 \mathrm{E}-03$ \\
\hline Moody's All-Corporate Quarterly Default Rate by Industry & 1262 & $0.00 \%$ & $2.07 \%$ & $3.78 \%$ & $4.13 \%$ & $6.05 \%$ & $12.68 \%$ & $2.70 \%$ & 0.6439 & -0.1938 & $7.40 \%$ & $1.67 \mathrm{E}-03$ \\
\hline Moody's Speculative Quarterly Default Rate by Industry & 1262 & $0.00 \%$ & $3.49 \%$ & $6.52 \%$ & $7.03 \%$ & $9.80 \%$ & $17.50 \%$ & $4.19 \%$ & 0.4587 & -0.5255 & $6.66 \%$ & $1.50 \mathrm{E}-03$ \\
\hline Fama-French Excess Return on Market Factor & 3886 & $-1076.00 \%$ & $-241.00 \%$ & $86.00 \%$ & $33.35 \%$ & $355.00 \%$ & $1030.00 \%$ & $464.59 \%$ & -0.3372 & -0.4057 & $-0.07 \%$ & $9.16 \mathrm{E}-06$ \\
\hline Fama-French Relative Return on Small Stocks Factor & 3886 & $-2218.00 \%$ & $-214.00 \%$ & $31.00 \%$ & $13.66 \%$ & $270.00 \%$ & $843.00 \%$ & $394.25 \%$ & -1.2903 & 5.3616 & $2.37 \%$ & $3.03 \mathrm{E}-04$ \\
\hline Fama-French Excess Return on Value Stock Factor & 3886 & $-912.00 \%$ & $-155.00 \%$ & $64.00 \%$ & $81.98 \%$ & $269.00 \%$ & $1380.00 \%$ & $373.74 \%$ & 0.7380 & 1.7726 & $-3.62 \%$ & $4.64 \mathrm{E}-04$ \\
\hline Short-Term Interest Rates (1-Month Treasury Yields) & 1262 & $6.00 \%$ & $14.00 \%$ & $32.00 \%$ & $31.82 \%$ & $44.00 \%$ & $79.00 \%$ & $16.83 \%$ & 0.1114 & -1.0411 & $-10.41 \%$ & $2.35 \mathrm{E}-03$ \\
\hline Long-Term Interest Rates (10-Month Treasury Yields) & 1111 & $337.00 \%$ & $451.00 \%$ & $535.00 \%$ & $548.19 \%$ & $603.00 \%$ & $904.00 \%$ & $125.45 \%$ & 1.0557 & 0.7194 & $-6.69 \%$ & $1.61 \mathrm{E}-03$ \\
\hline Stock-Market Volatility (2-Year IDX) & 1111 & $3.00 \%$ & $7.00 \%$ & $9.00 \%$ & $9.98 \%$ & $11.00 \%$ & $19.00 \%$ & $3.84 \%$ & 0.9425 & -0.0862 & $-0.36 \%$ & $8.55 \mathrm{E}-05$ \\
\hline
\end{tabular}

Table 8.7 - Summary Statistics on Duration / Vintage Variables and Correlations with RDD (Moody's Ultimate LGD Database 1987-

\begin{tabular}{|c|c|c|c|c|c|c|c|c|c|c|c|c|}
\hline Variable & Cnt & Min & $\begin{array}{l}\text { 25th } \\
\text { Prcntle }\end{array}$ & Median & Mean & $\begin{array}{l}\text { 75th } \\
\text { Prcntle }\end{array}$ & Max & Std Dev & Skew & Kurt & $\begin{array}{l}\text { Corr with } \\
\text { RDD }\end{array}$ & $\begin{array}{l}\text { P-Val of } \\
\text { Corr }\end{array}$ \\
\hline Time from Origination to Default & 3365 & 0.2500 & 1.6384 & 2.8849 & 4.0128 & 5.0027 & 29.9534 & 3.7660 & 2.3676 & 7.4186 & $-0.67 \%$ & $9.18 \mathrm{E}-05$ \\
\hline Time from First Rating to Default & 3178 & 1.0000 & 3.1288 & 5.7425 & 10.2523 & 14.5753 & 56.9781 & 11.3994 & 2.1219 & 4.7533 & $-0.51 \%$ & $7.23 \mathrm{E}-05$ \\
\hline Time from Last Cash-Pay Date to Default & 3886 & 0.0000 & 0.0986 & 0.2411 & 0.3907 & 0.4959 & 4.3808 & 0.4849 & 2.7920 & 10.5645 & $0.22 \%$ & $2.80 \mathrm{E}-05$ \\
\hline Time from Default to Resolution & 3886 & 0.0027 & 0.5507 & 1.1685 & 1.4594 & 1.9534 & 9.3151 & 1.3320 & 1.8273 & 5.2410 & $-13.72 \%$ & $1.77 \mathrm{E}-03$ \\
\hline Time from Origination to Maturity Date & 3365 & 0.1000 & 5.0027 & 7.8219 & 8.9032 & 10.0137 & 50.0329 & 6.5084 & 1.6668 & 3.5430 & $-1.31 \%$ & $1.80 \mathrm{E}-04$ \\
\hline
\end{tabular}

Table 9 - Beta-Link Generalized Linear Model for Annualized Returns on Defaulted Debt (Moody's Ultimate LGD Database 1987-2007)

\begin{tabular}{|c|c|c|c|c|c|c|}
\hline \multirow[b]{2}{*}{ Variables } & \multicolumn{2}{|c|}{ Model 1} & \multicolumn{2}{|c|}{ Model 2} & \multicolumn{2}{|c|}{ Model 3} \\
\hline & \begin{tabular}{|l|} 
Partial \\
Effect
\end{tabular} & P-Value & \begin{tabular}{|l} 
Partial \\
Effect
\end{tabular} & P-Value & \begin{tabular}{|l|} 
Partial \\
Effect
\end{tabular} & P-Value \\
\hline Intercept & 0.3094 & $1.42 \mathrm{E}-03$ & 0.51005 & 9.35E-04 & 0.4342 & 6.87E-03 \\
\hline Moody's 12 Month Lagging Speculative Grade Default Rate by Industry & 2.0501 & 1.22E-02 & 2.2538 & $6.94 \mathrm{E}-03$ & 2.1828 & $1.36 \mathrm{E}-02$ \\
\hline Collateral Rank Secured & 0.2554 & $7.21 \mathrm{E}-03$ & 0.2330 & 1.25E-02 & 0.2704 & 9.36E-04 \\
\hline Tranche Safety Index & 0.4548 & 3.03E-02 & 0.4339 & 3.75E-02 & & \\
\hline Loss Given Default & 0.3273 & 1.44E-02 & 0.2751 & 3.88E-02 & & \\
\hline Cumulative Abnormal Returns on Equity Prior to Default & 0.3669 & $1.51 \mathrm{E}-03$ & 0.3843 & $1.00 \mathrm{E}-03$ & 0.4010 & 9.39E-04 \\
\hline Total Liabilities to Total Assets & 0.2653 & 5.22E-08 & & & & \\
\hline Moody's Original Rating Investment Grade & 0.2118 & 2.80E-02 & 0.2422 & 6.84E-03 & 0.1561 & $6.25 \mathrm{E}-02$ \\
\hline 1-Month Treasury Yield & -0.4298 & 3.04E-02 & -0.3659 & $1.01 \mathrm{E}-02$ & -0.4901 & 3.36E-02 \\
\hline Size Relative to the Market & & & -0.0366 & 4.76E-02 & -0.0648 & $3.41 \mathrm{E}-03$ \\
\hline Market Value to Book Value & & & 0.1925 & 2.64E-05 & 0.1422 & $5.63 E-03$ \\
\hline Free-Asset Ratio & & & & & -0.2429 & $2.25 \mathrm{E}-02$ \\
\hline Degrees of Freedom & \multicolumn{2}{|c|}{959} & \multicolumn{2}{|c|}{958} & \multicolumn{2}{|c|}{783} \\
\hline Log-Likelihood & \multicolumn{2}{|c|}{-592.30} & \multicolumn{2}{|c|}{-594.71} & \multicolumn{2}{|c|}{-503.99} \\
\hline McFadden Pseudo R-Squared (In-Sample) & \multicolumn{2}{|c|}{$32.48 \%$} & \multicolumn{2}{|c|}{$38.80 \%$} & \multicolumn{2}{|c|}{$41.73 \%$} \\
\hline McFadden Pseudo R-Squared (Out-Of-Sample) - Bootstrap Mean & \multicolumn{2}{|c|}{$21.23 \%$} & \multicolumn{2}{|c|}{$12.11 \%$} & \multicolumn{2}{|c|}{$17.77 \%$} \\
\hline McFadden Pseudo R-Squared (Out-Of-Sample) - Bootstrap Standard Error & \multicolumn{2}{|c|}{$2.28 \%$} & \multicolumn{2}{|c|}{$1.16 \%$} & \multicolumn{2}{|c|}{$1.70 \%$} \\
\hline
\end{tabular}


Table 10 - Summary Statistics on Discounted LGD and Regulatory Capital for Different Discounting Methodologies (Moody's Ultimate LGD Database 1987-2007)

\begin{tabular}{|c|c|c|c|c|c|c|c|c|c|c|c|c|}
\hline & Count & Minimum & \begin{tabular}{|l|} 
1st \\
Percentile
\end{tabular} & \begin{tabular}{|l|} 
25th \\
Percentile
\end{tabular} & Median & Mean & \begin{tabular}{|l|}
75 th \\
Percentile
\end{tabular} & \begin{tabular}{l|}
99 th \\
Percentile
\end{tabular} & Maximum & \begin{tabular}{|l|} 
Standard \\
Deviation
\end{tabular} & Skewness & Kurtosis \\
\hline Discounted LGD - Contractual Coupon Rate ${ }^{2}$ & 960 & $5.00 \%$ & $5.00 \%$ & $13.68 \%$ & $54.97 \%$ & $52.07 \%$ & $88.17 \%$ & $100.00 \%$ & $100.00 \%$ & $35.86 \%$ & -0.0569 & -1.5467 \\
\hline Discounted LGD - RDD Regression Model ${ }^{3}$ & 960 & $5.00 \%$ & $5.00 \%$ & $33.29 \%$ & $72.10 \%$ & $64.05 \%$ & $95.07 \%$ & $105.00 \%$ & $105.00 \%$ & $33.03 \%$ & -0.3122 & -1.2998 \\
\hline Discounted LGD - Punitive Discount Rate ${ }^{4}$ & 960 & $5.00 \%$ & $5.00 \%$ & $33.08 \%$ & $62.12 \%$ & $59.03 \%$ & $89.62 \%$ & $100.00 \%$ & $100.00 \%$ & $31.53 \%$ & -0.2133 & -1.3288 \\
\hline Regulatory Capital - Contractual Coupon Rate & 960 & $0.00 \%$ & $0.03 \%$ & $78 \%$ & $2.66 \%$ & $6.91 \%$ & $9.91 \%$ & $37.78 \%$ & $57.15 \%$ & $9.18 \%$ & 1.9366 & 4.32 \\
\hline Regulatory Capital - RDD Regression Model & 960 & $0.00 \%$ & $0.03 \%$ & $1.00 \%$ & $3.72 \%$ & $8.04 \%$ & $10.87 \%$ & $39.96 \%$ & $60.03 \%$ & $9.86 \%$ & 1.7132 & 3.3883 \\
\hline Regulatory Capital - Punitive Discount Rate & 960 & $0.00 \%$ & $0.07 \%$ & $0.94 \%$ & $3.14 \%$ & $7.31 \%$ & $10.14 \%$ & $38.19 \%$ & $57.22 \%$ & $9.26 \%$ & 1.8544 & 3.992 \\
\hline
\end{tabular}

1 - Basel II capital formula (Final Rule, 2007) based upon Asymptotic Single Risk Factor (ASRF) model (Gordy, 2003): $\mathrm{K}^{\mathrm{R}}=\mathrm{N}\left(\left[\mathrm{N}^{-1}(\mathrm{PD})+\mathrm{N}^{-1}(0.999)^{\star} \mathrm{R}^{.5}\right] /\left[(1-\mathrm{R}){ }^{.5}\right)\right]-$

$P D)^{\star}\left(0.08+.92^{*} L G D\right)$, where $K^{R}$ denotes regulatory capital, LGD is discounted LGD in the MULGD database, PD is the average default rate according to the Moody's rating, and the asset correlation is the Final Rule prescribed $R=0.12+0.18^{\star} \exp \left(-50^{\star} \mathrm{PD}\right)$ for wholesale exposures. Unit LEQ is assumed on each loan, so thatportfolio capital is the mean of the

2 - Contract rate on instrument prevailing just before defult.

3- Model 1 of Table 9: RDD $=0.31+2.05^{*}$ (Moody's Speculative Grade Default Rate $)+0.26^{\star}$ (Collateral Flag Secured) $+0.45^{\star}$ T.I.S. $+0.33^{*}$ LGD $+0.37^{\star}$ C.A.R. $+0.27^{\star}$ TL/TA +

$0.21^{*}$ (Moody's Original Rating Investment Grade) $-0.43^{*}$ (1-Month T-Bill Yield)

$4-25 \%$ per annum

Table 10.1: Moody's Long Run Default Rates

(Annual Cohorts 1982-2007)

\begin{tabular}{|l|r|}
\hline Rating & Default Rate \\
\hline Aaa & $0.020 \%$ \\
\hline Aa1 & $0.020 \%$ \\
\hline Aa & $0.020 \%$ \\
\hline Aa3 & $0.016 \%$ \\
\hline A1 & $0.002 \%$ \\
\hline A2 & $0.024 \%$ \\
\hline A3 & $0.032 \%$ \\
\hline Baa1 & $0.141 \%$ \\
\hline Baa2 & $0.141 \%$ \\
\hline Baa3 & $0.308 \%$ \\
\hline Ba1 & $0.662 \%$ \\
\hline Ba2 & $0.756 \%$ \\
\hline Ba3 & $1.733 \%$ \\
\hline B1 & $2.486 \%$ \\
\hline B2 & $4.148 \%$ \\
\hline B3 & $8.118 \%$ \\
\hline Caa1 & $9.913 \%$ \\
\hline Caa2 & $17.359 \%$ \\
\hline Caa3 & $23.715 \%$ \\
\hline Ca & $29.096 \%$ \\
\hline C & $32.164 \%$ \\
\hline
\end{tabular}




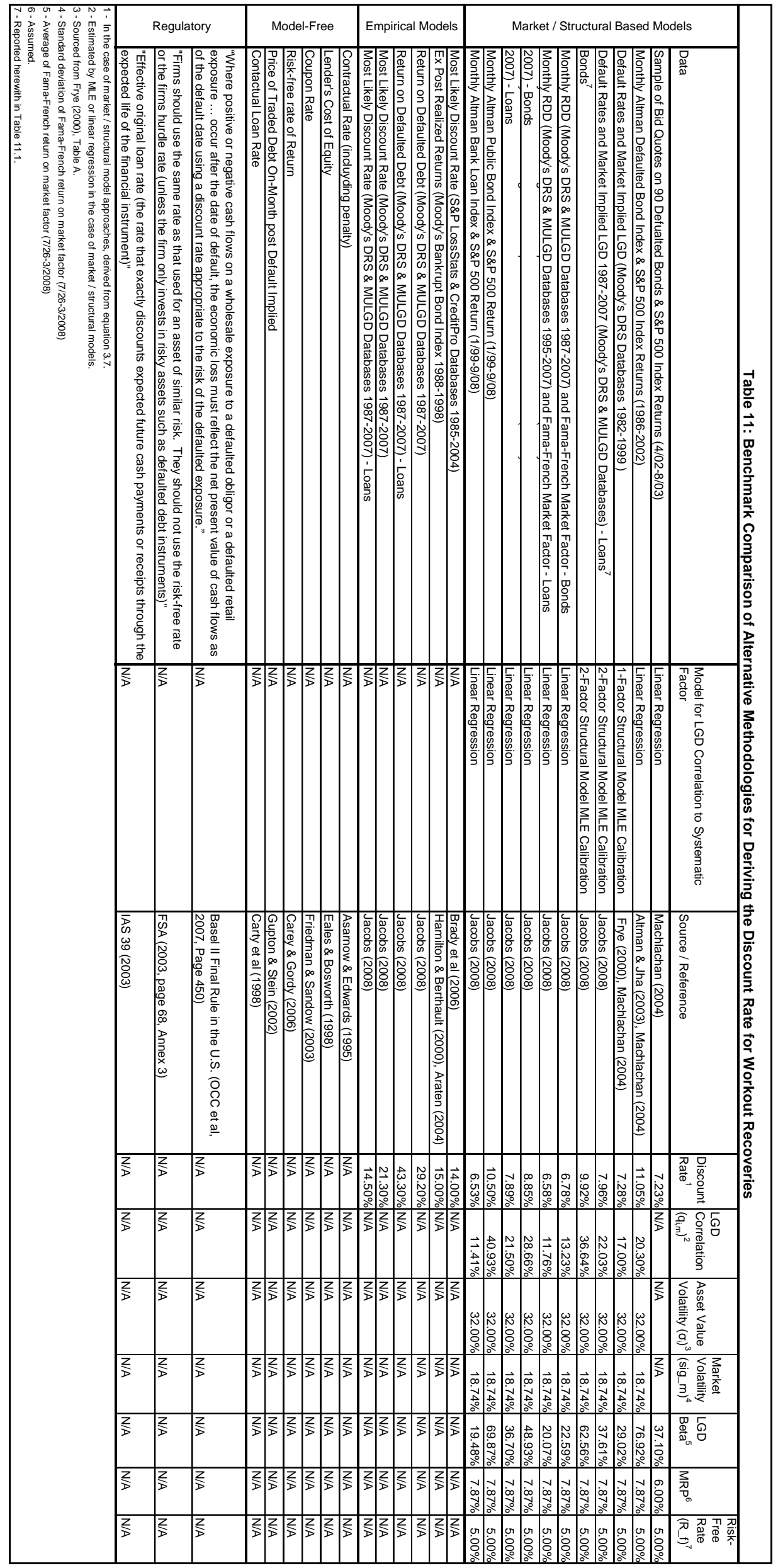




\section{Table 11.1: Simultaneous Full-Information Maximum Likelihood Estimation of 2-Factor Structural Credit Model}

\section{Moody's DRS Annual Speculative-Grade Default Rates and MULGD Market Implied Loss-Given-Default (1987-2007)}

Asset Value Process for Rating Class $r: A_{t, r}=\rho_{r} X_{t}+\left(1-\rho_{r}^{2}\right)^{5} Z_{t, r}$, Idiosyncratic PD Variable: $Z_{t, r} \sim \operatorname{NID}(0,1)$, Systematic PD Variable: $X_{t}$, Asset Value Factor Loading (Correlation): $\rho_{\mathrm{r}}\left(\rho_{\mathrm{r}}^{2}\right)$

Loss Rate Process for Seniority Class s: $L_{t, s}=\rho_{s} Y_{t}+\left(1-\rho_{s}{ }^{2}\right)^{5} Z_{t, s}$, Idiosyncratic LGD Variable: $Z_{t, s} \sim \operatorname{NID}(0,1)$, Systematic LGD Variable: $Y_{t}$, Recovery Value Factor Loading (Correlation): $\rho_{\mathrm{s}}\left(\rho_{\mathrm{s}}^{2}\right)$

Conditional Default Rate: $R\left(X_{t} \mid P D_{r}, \rho_{r}\right)=\Phi\left[\left(\Phi^{-1}\left[P D_{r}\right]-\rho_{r} X_{t}\right) /\left(1-\rho_{r}^{2}\right)^{.5}\right], P D_{r}$ : Long-Run (Expected) Probability of Default for Rating Class $r$

Conditional Loss Rate: $L\left(Y_{t} \mid L G D_{s}, \rho_{s}\right)=\Phi\left[\left(\Phi^{-1}\left[L G D_{s}\right]-\rho_{s} Y_{t}\right) /\left(1-\rho_{s}^{2}\right)^{.5}\right]$, LGDs: LongRun (Expected) Loss-Given-Default for Seniority Classs $S$

$Z_{t, r}, Z_{t, s} \sim \operatorname{NID}(0,1) ;\left(X_{t}, Y_{t}\right) \sim N 2\left([0,0]^{\top},\left[\left(1, r_{X, Y}\right)^{\top},\left(r_{X, Y}, 1\right)^{\top}\right]\right.$

\begin{tabular}{|c|c|c|c|}
\hline \multicolumn{2}{|c|}{ Parameter } & $\begin{array}{l}\text { MLE } \\
\text { Estimate }\end{array}$ & $\begin{array}{l}\text { Standard } \\
\text { Error }\end{array}$ \\
\hline \multicolumn{2}{|c|}{ Asset Value Correlation $\left(\rho_{r}\right)$} & $8.01 \%$ & $4.66 \%$ \\
\hline \multicolumn{2}{|c|}{ Long-Run Probability of Default $\left(\mathrm{PD}_{\mathrm{r}}\right)$} & $4.96 \%$ & $3.01 \%$ \\
\hline \multirow{2}{*}{ 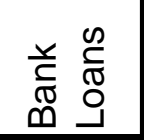 } & Recovery Value Correlation for Loans $\left(\rho_{1}^{2}\right)$ & $22.03 \%$ & $4.79 \%$ \\
\hline & Long-Run Loss-Given-Default for Loans (LGDI) & $28.90 \%$ & $13.23 \%$ \\
\hline \multirow{2}{*}{ 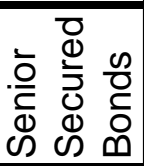 } & Recovery Value Correlation for Bonds $\left(\rho_{b}{ }^{2}\right)$ & $36.64 \%$ & $11.10 \%$ \\
\hline & Long-Run LGD for Bonds ( $\left.L G D_{b}\right)$ & $44.61 \%$ & $26.06 \%$ \\
\hline \multicolumn{2}{|c|}{$\begin{array}{l}\text { Correlation between Systematic Factors in Default and Loss } \\
\text { Rate (PD-LGD) Processes }\left(r_{x y}\right)\end{array}$} & $64.42 \%$ & $18.83 \%$ \\
\hline
\end{tabular}




\section{Figures}

Figure 1: Distribution of Return on Defaulted Debt (All Instrumer

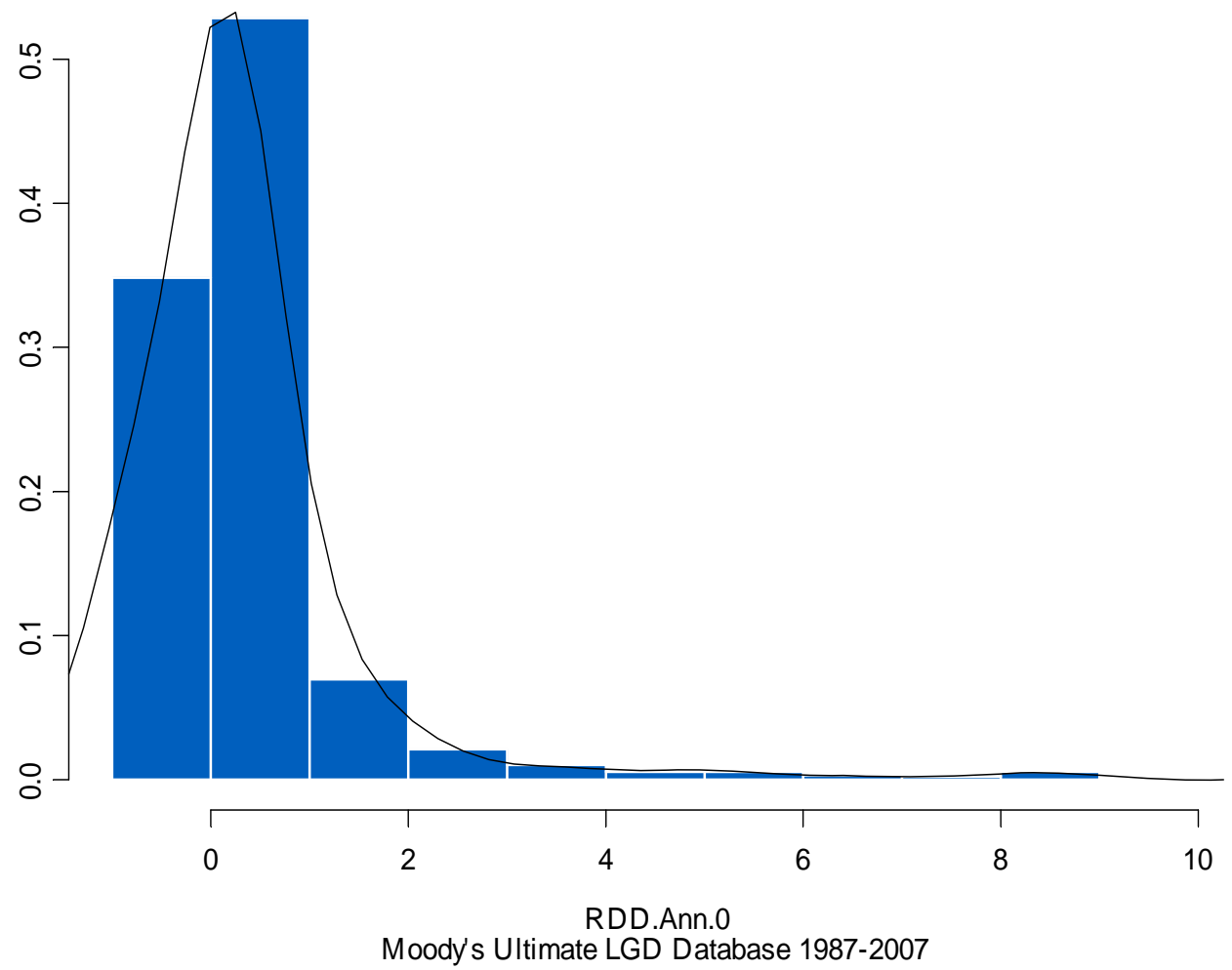

Figure 2.1: Distribution of Return on Defaulted Debt (Bankruptcies)

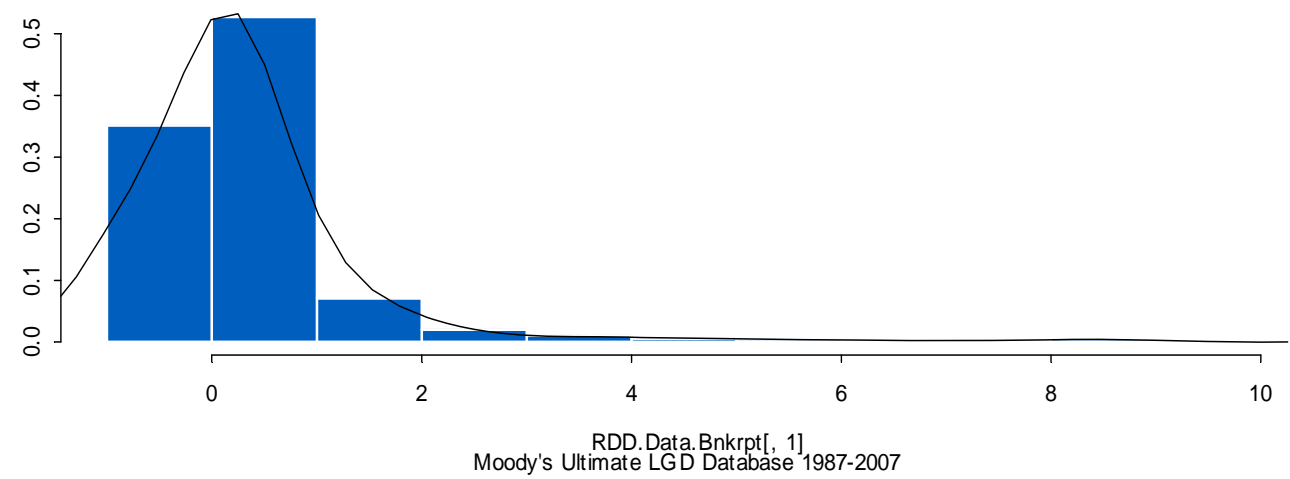

Figure 2.2: Distribution of Return on Defaulted Debt (Out-of-Court Settlements

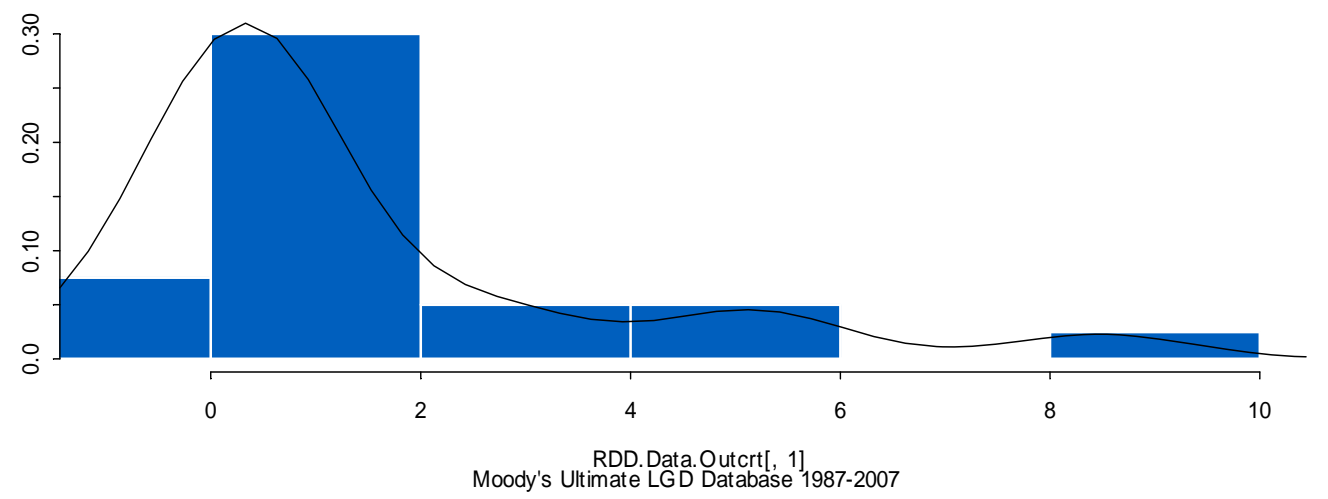


Figure 3.1: Distribution of Return on Defaulted Debt (Bonds)

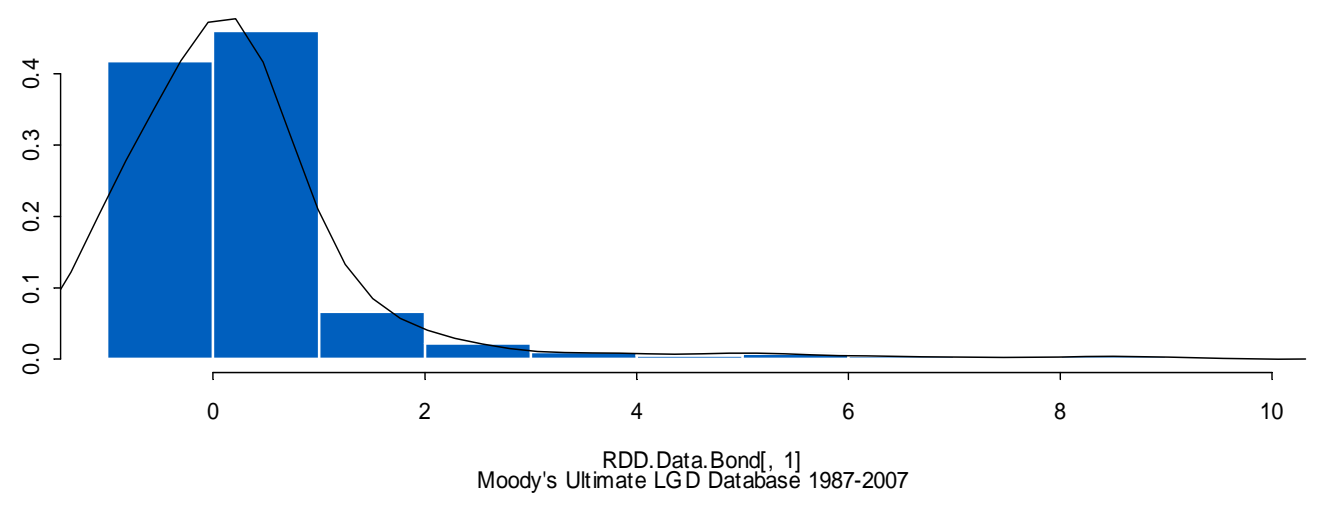

Figure 3.2: Distribution of Return on Defaulted Debt (Loans)

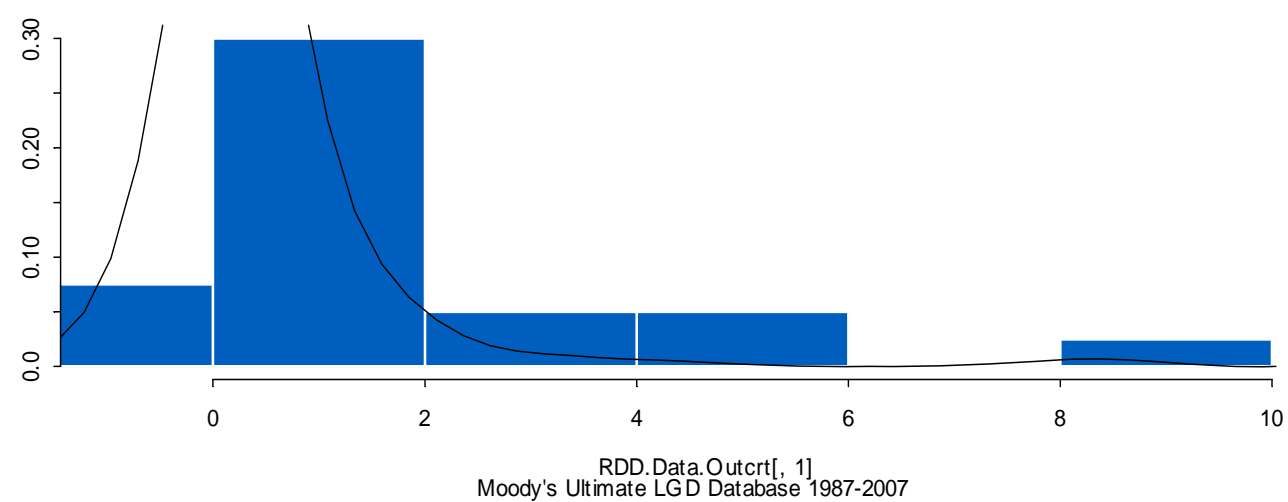




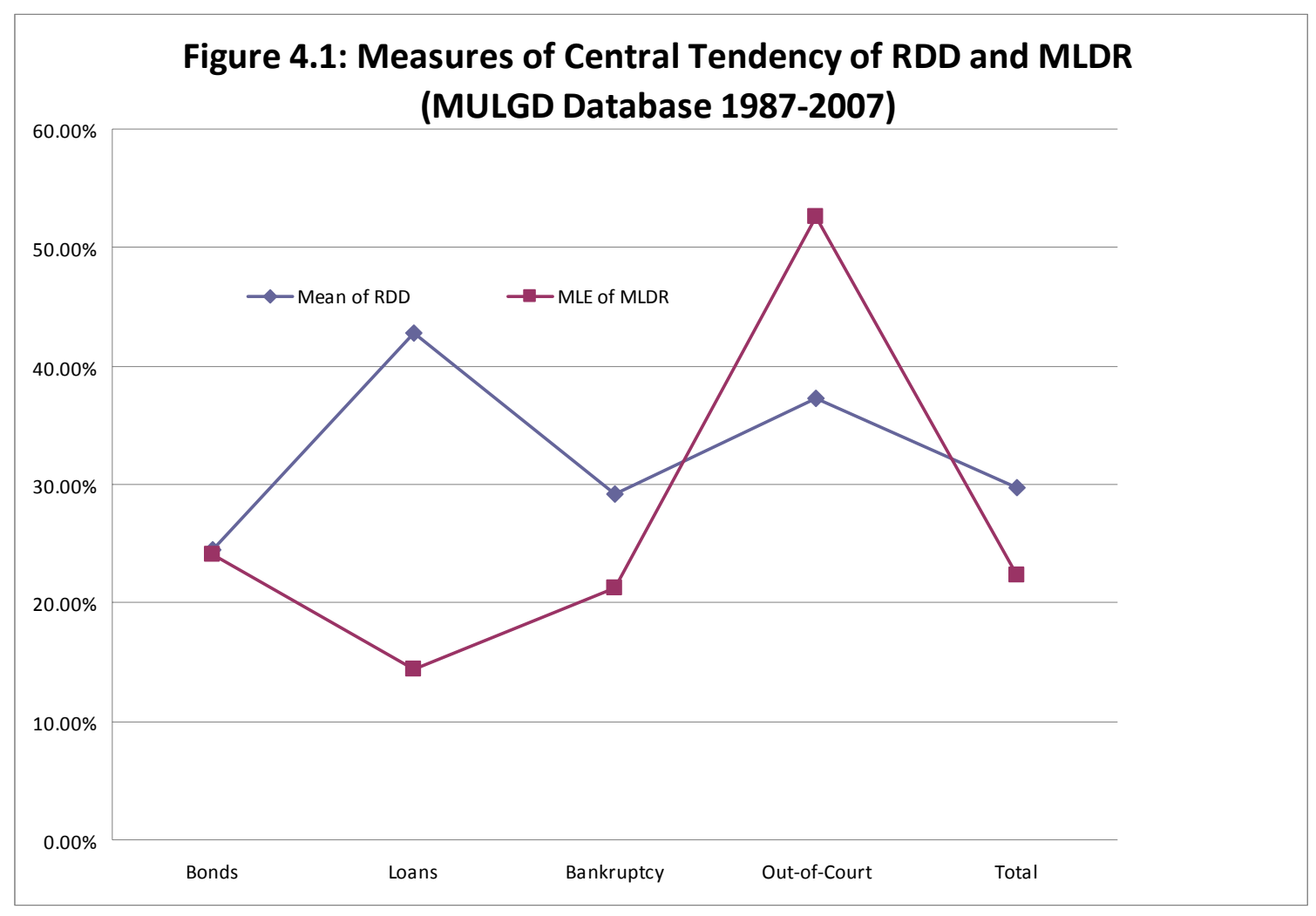

Figure 4.2: Measures of Dispersion of RDD and MLDR (MULGD Database 1987-2007)

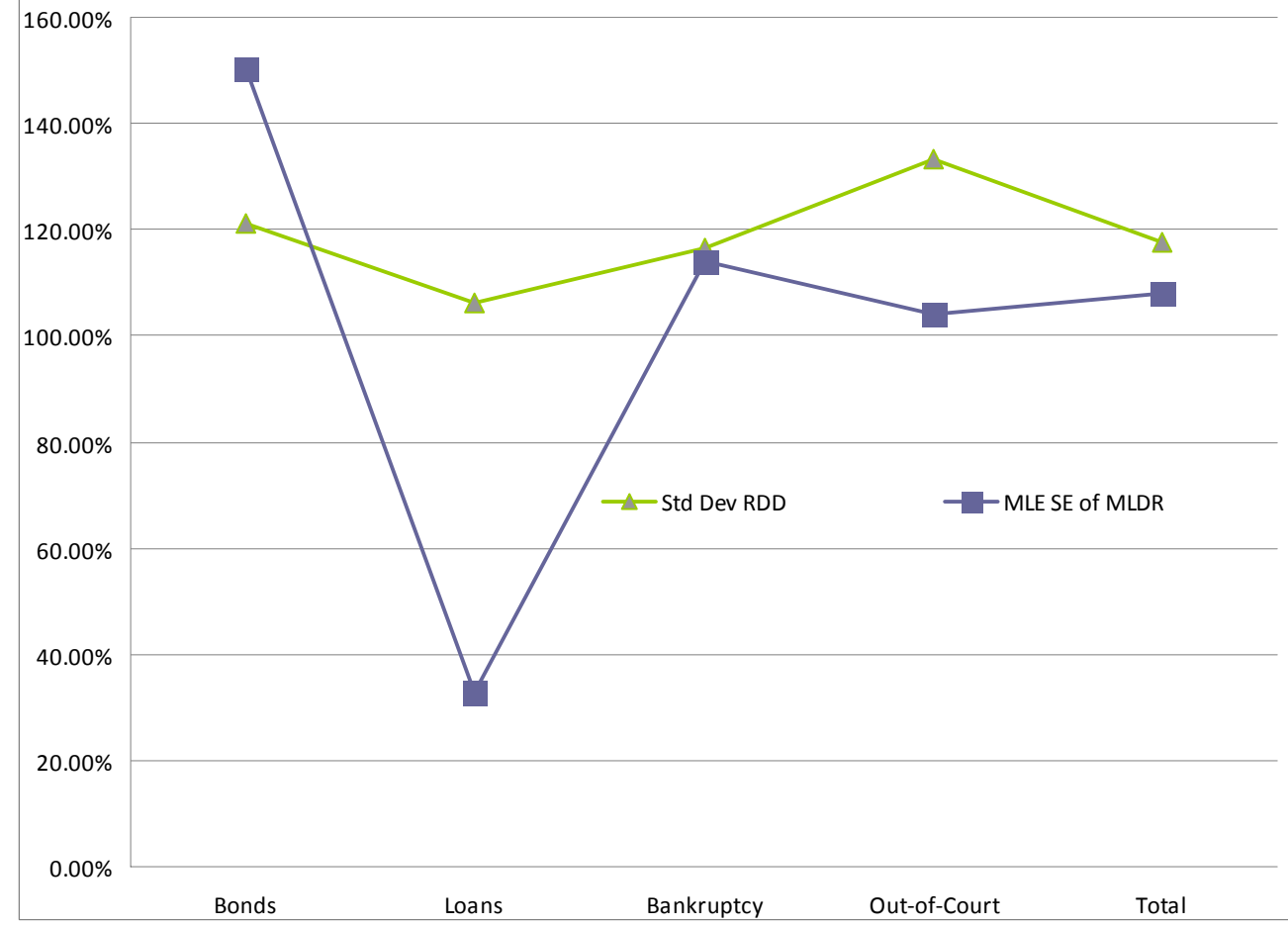



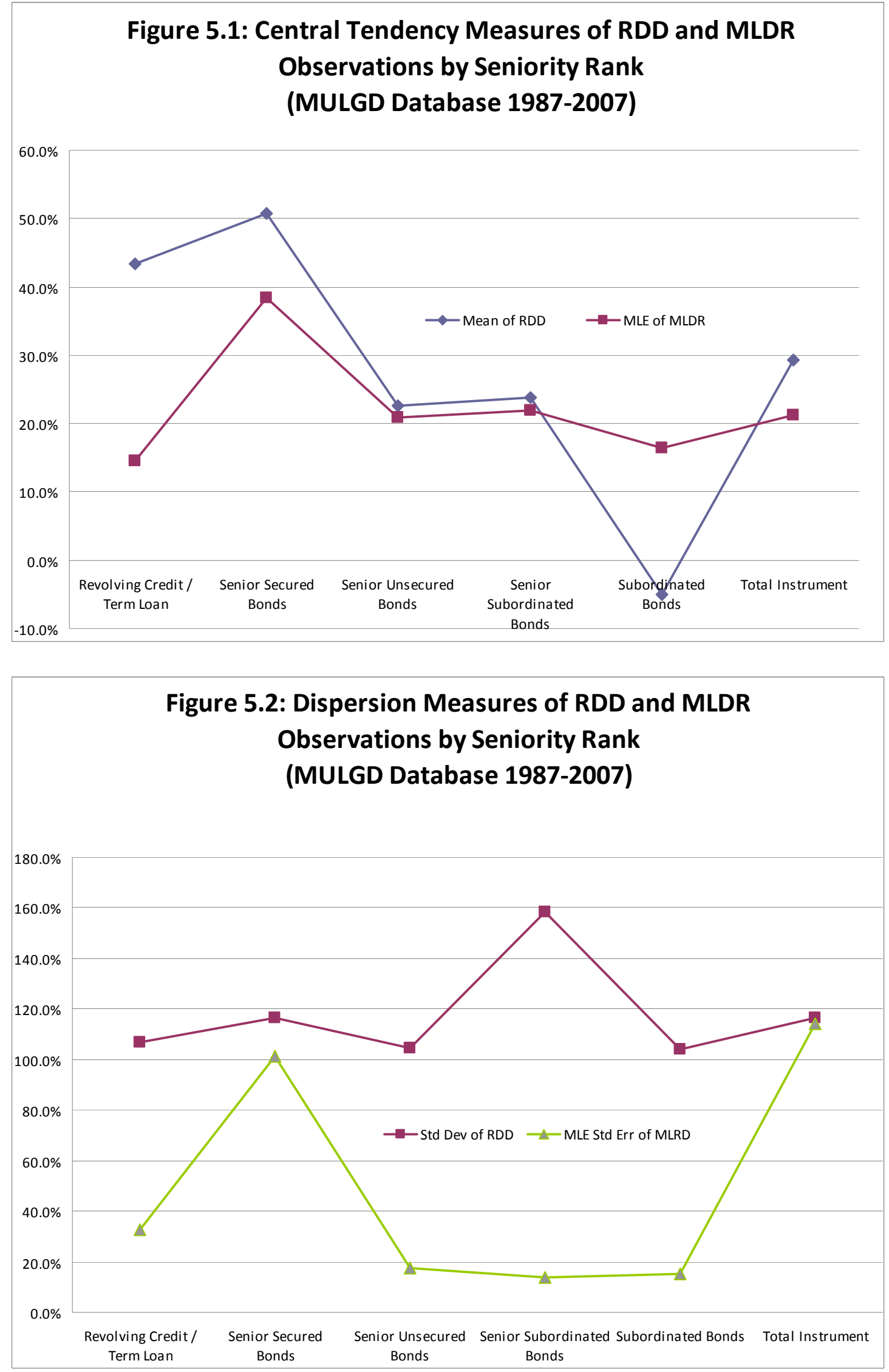

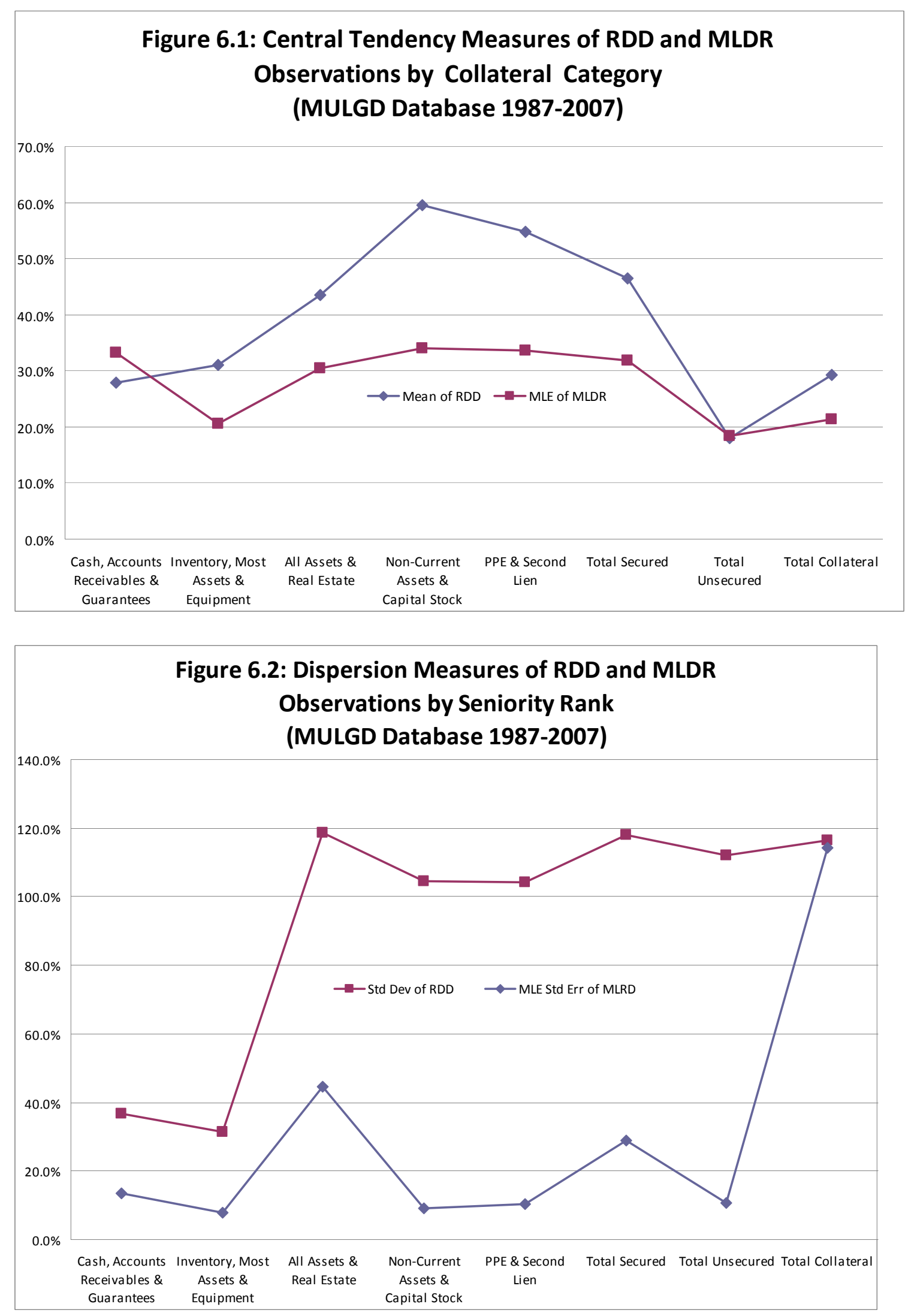


\section{Figure 7.1: Central Tendency Measures of RDD and MLDR}

Observations by Year of Default

(MULGD Database 1987-2007)

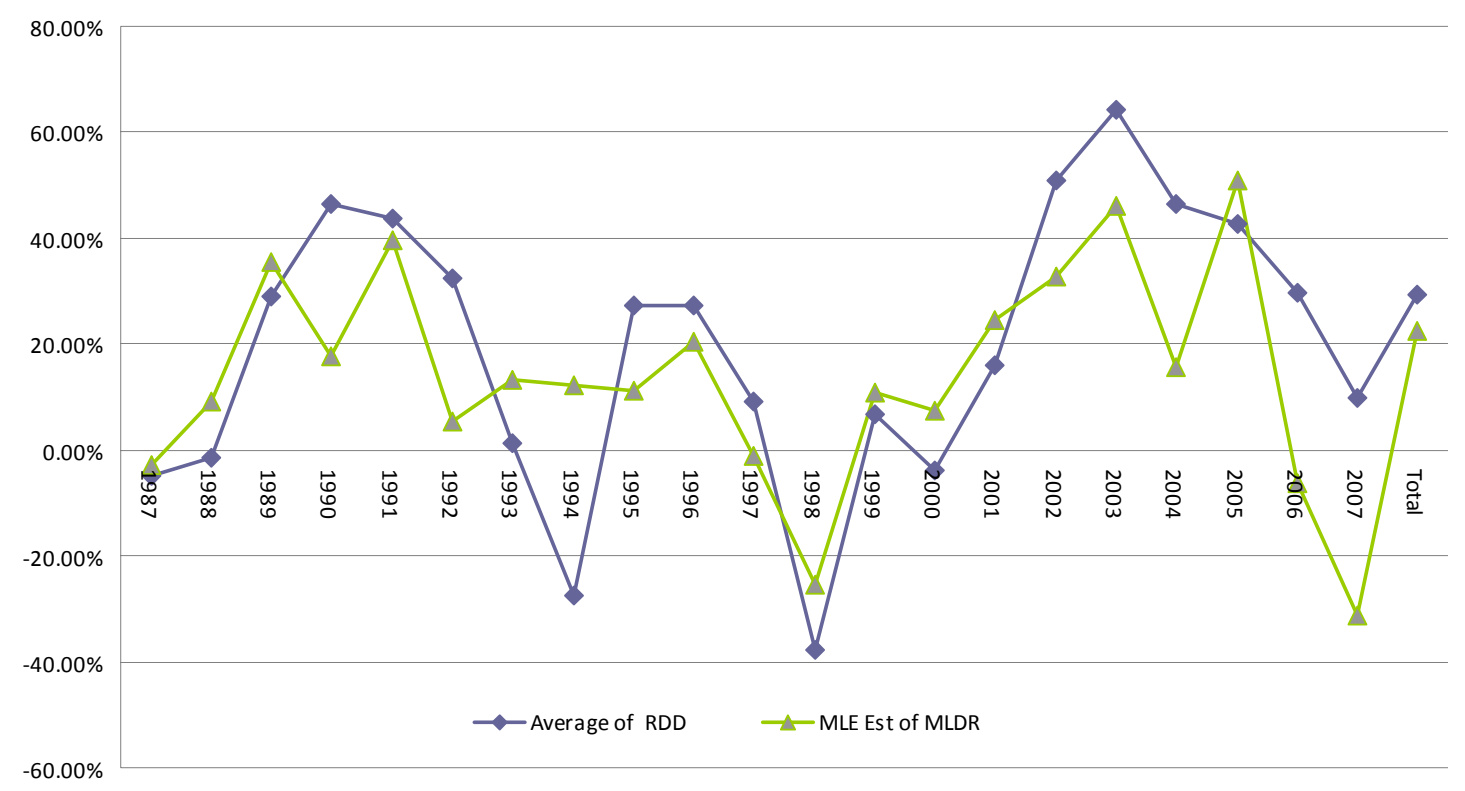

Figure 7.2: Dispersion Measures of RDD and MLDR Observations by Year of Default

(MULGD Database 1987-2007)

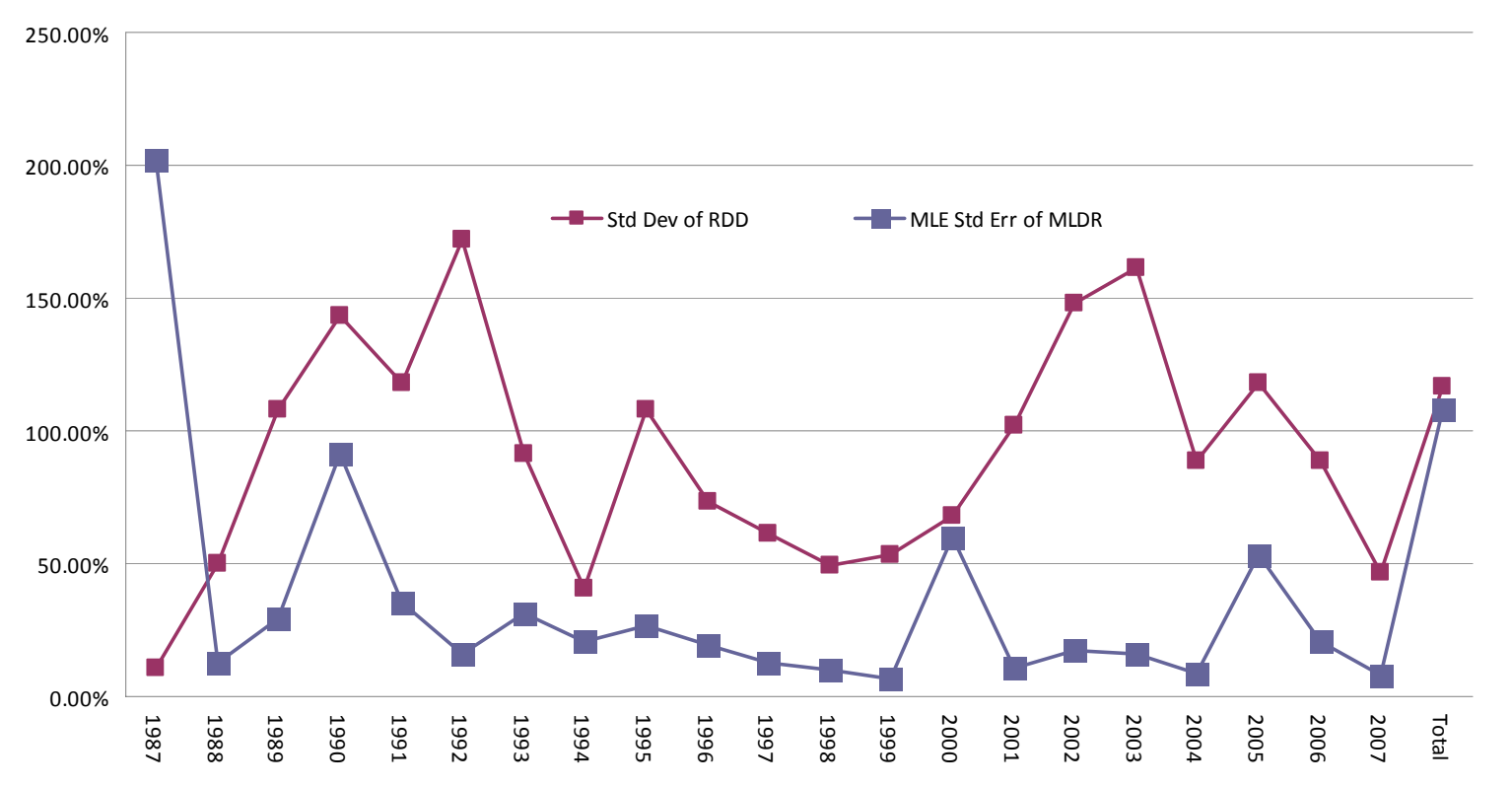




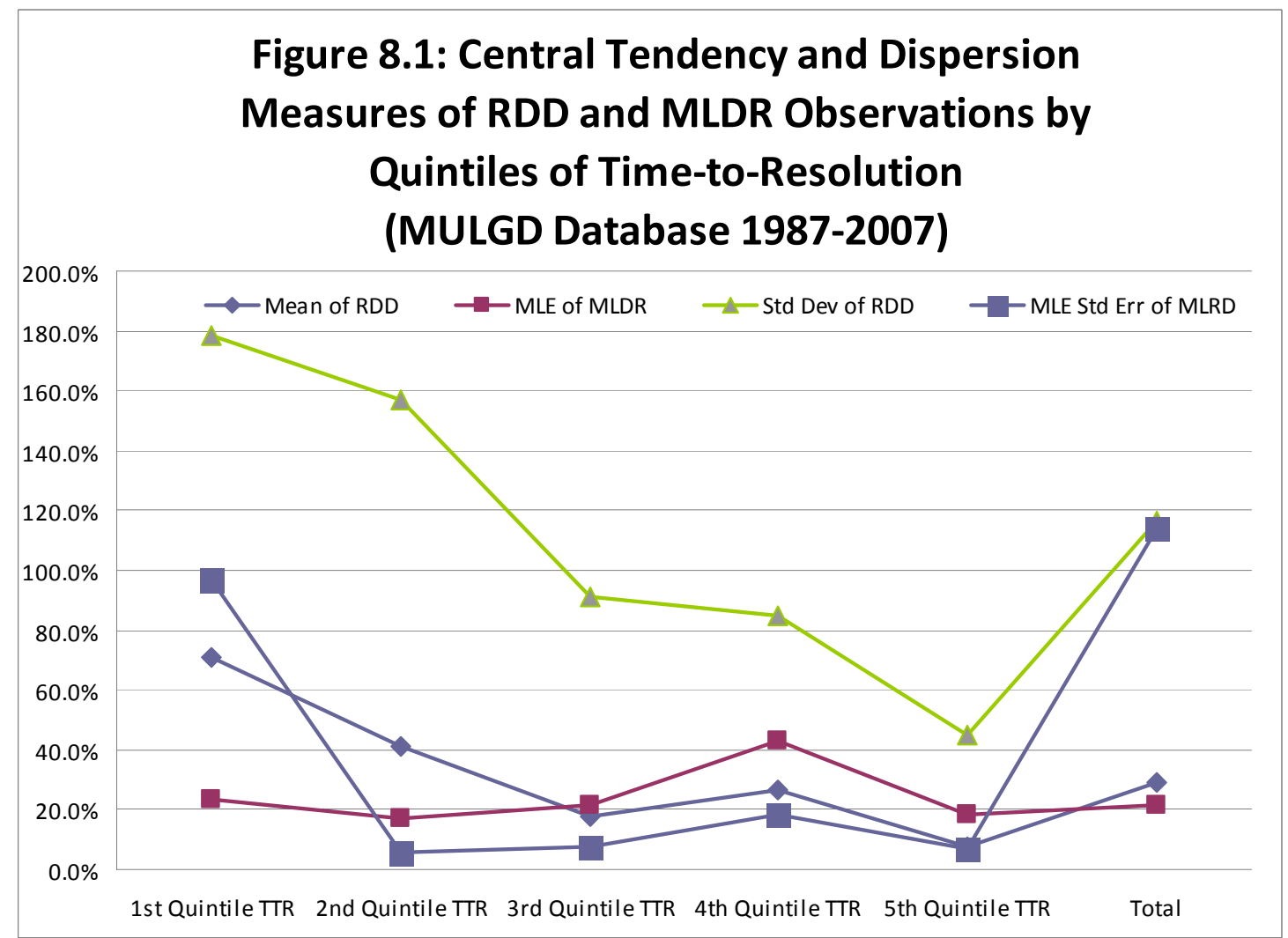

Figure 8.2: Central Tendency and Dispersion

Measures of RDD and MLDR Observations by Quintiles of Time-in-Distress

(MULGD Database 1987-2007)

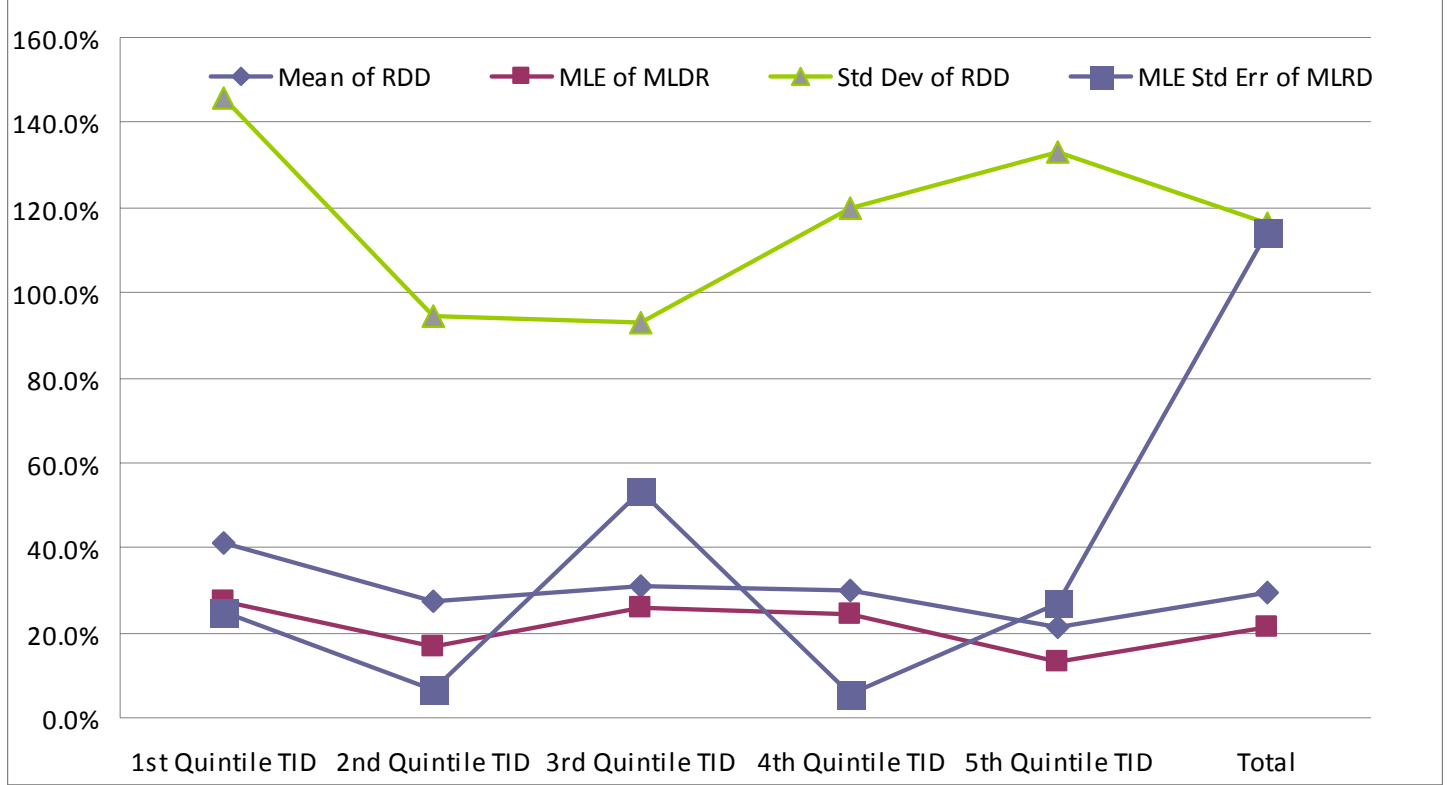


Figure 9.1: Central Tendency Measures of RDD and MLDR Observations by Credit Rating at Origination (MULGD Database 1987-2007)

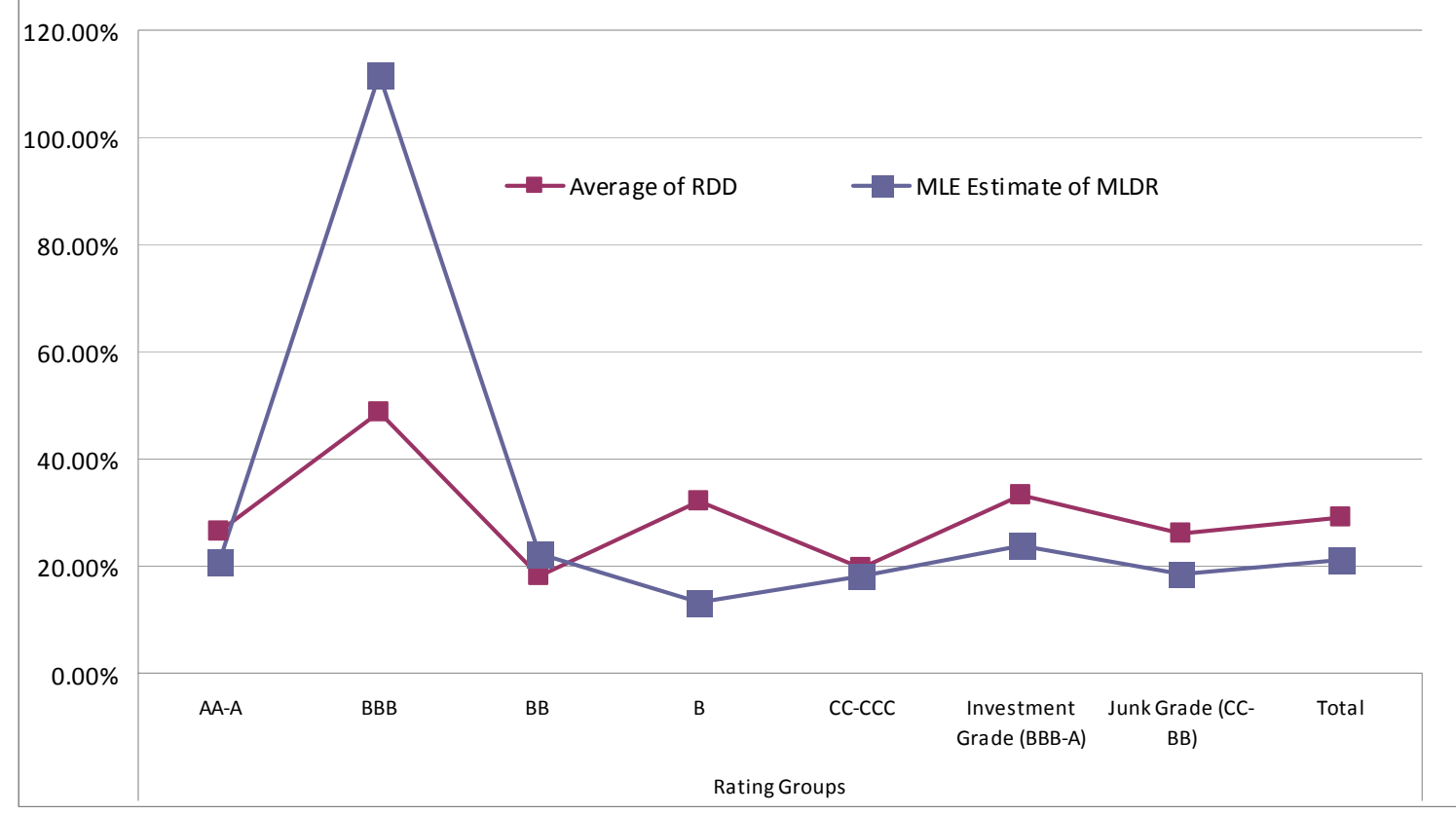

Figure 9.2: Dispersion Measures of RDD and MLDR Observations by Credit Rating at Origination (MULGD Database 1987-2007)

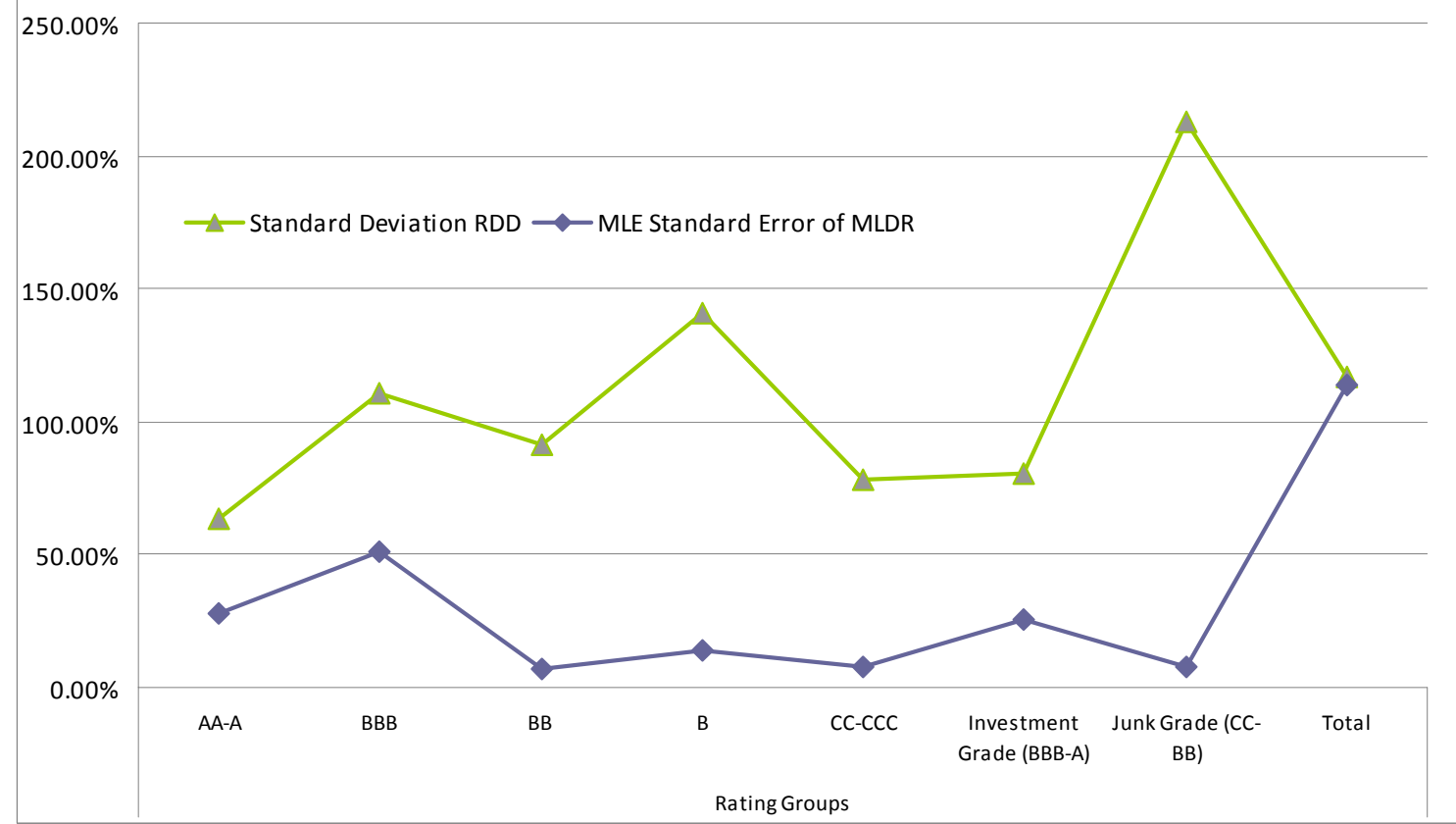




\section{Figure 10.1: Central Tendency Measures of RDD \& MLDR by Tranche Safety Index \& Debt Position Categories}

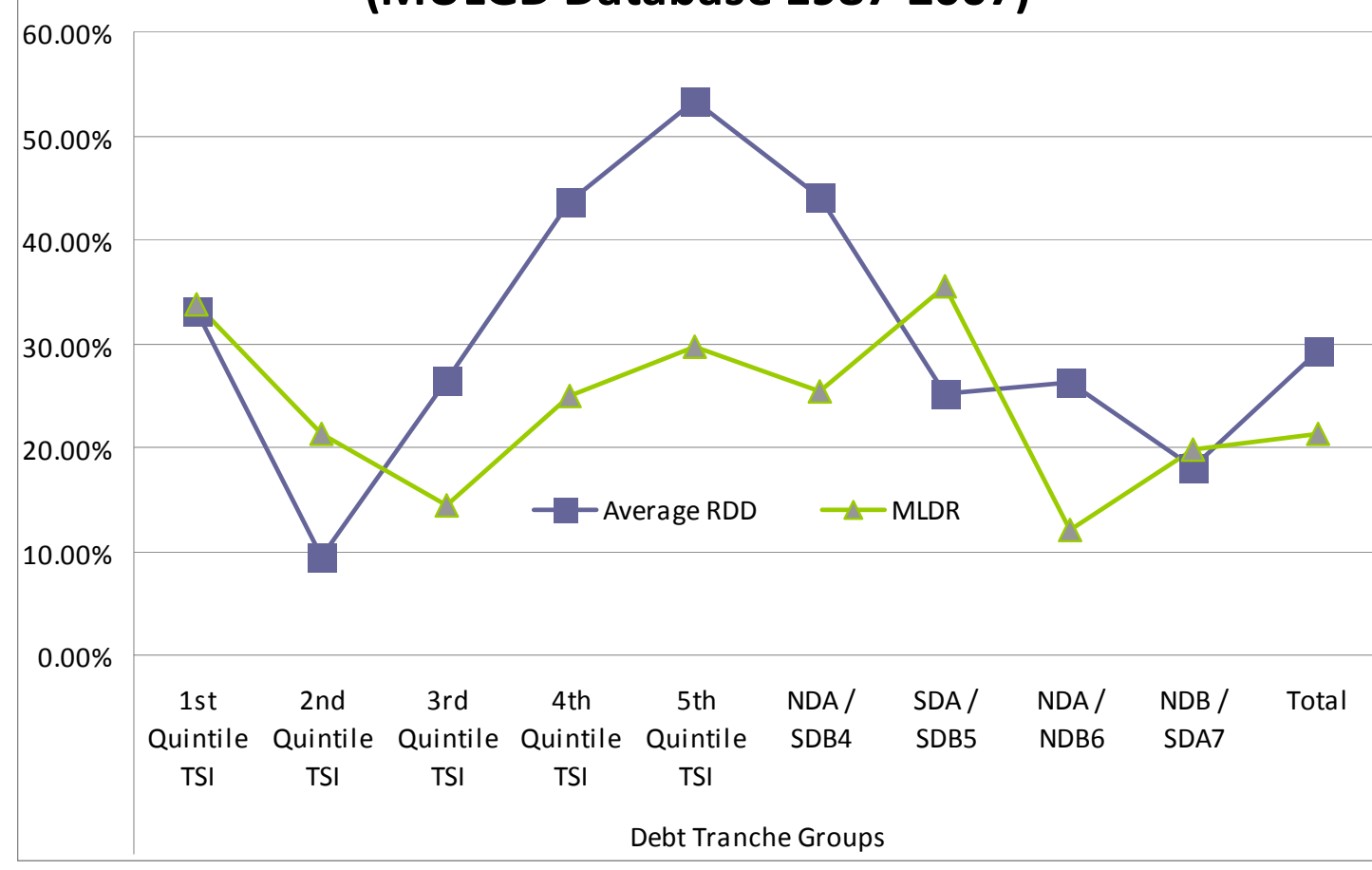

Figure 10.2: Dispersion Measures of RDD \& MLDR by Tranche Safety Index \& Debt Position Categories (MULGD Database 1987-2007)

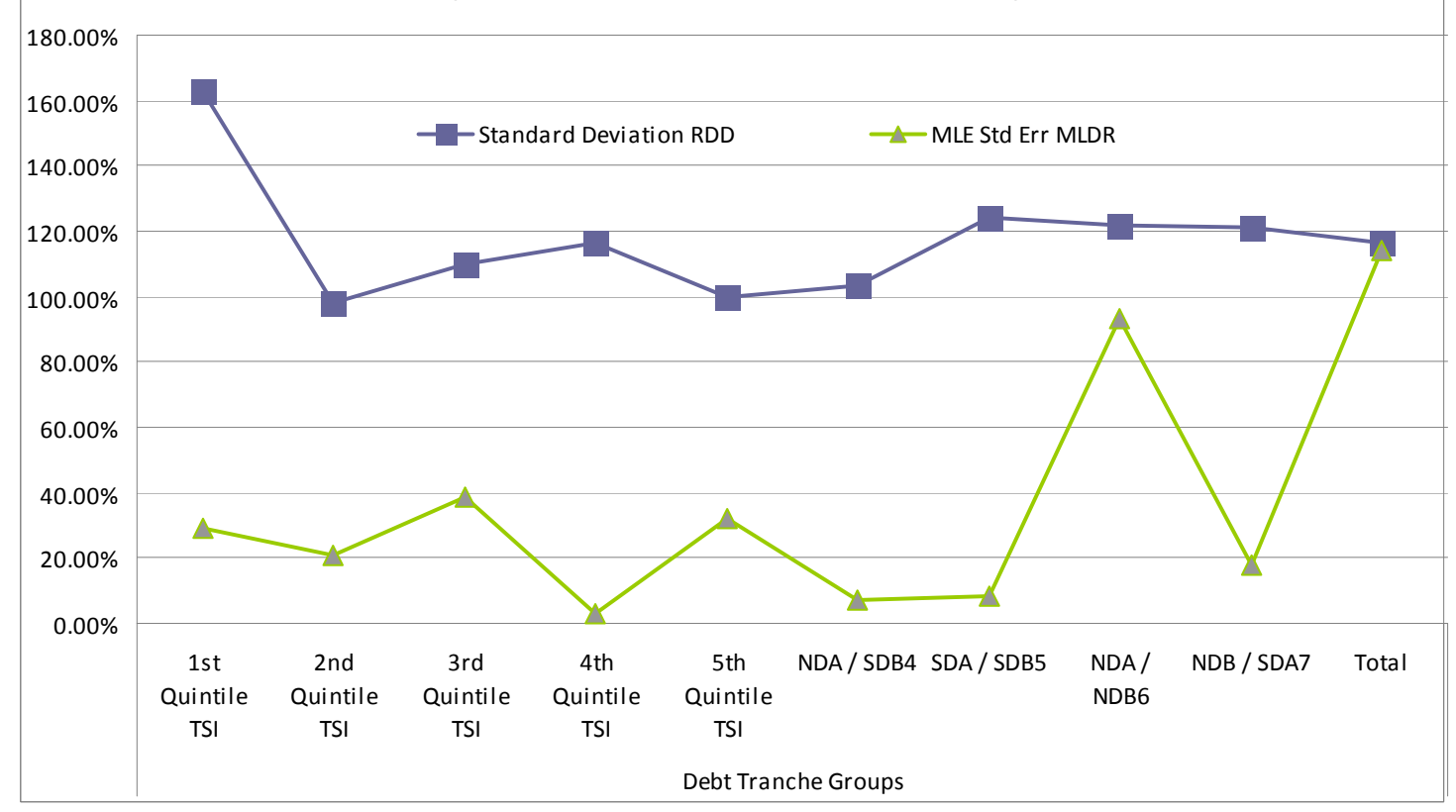



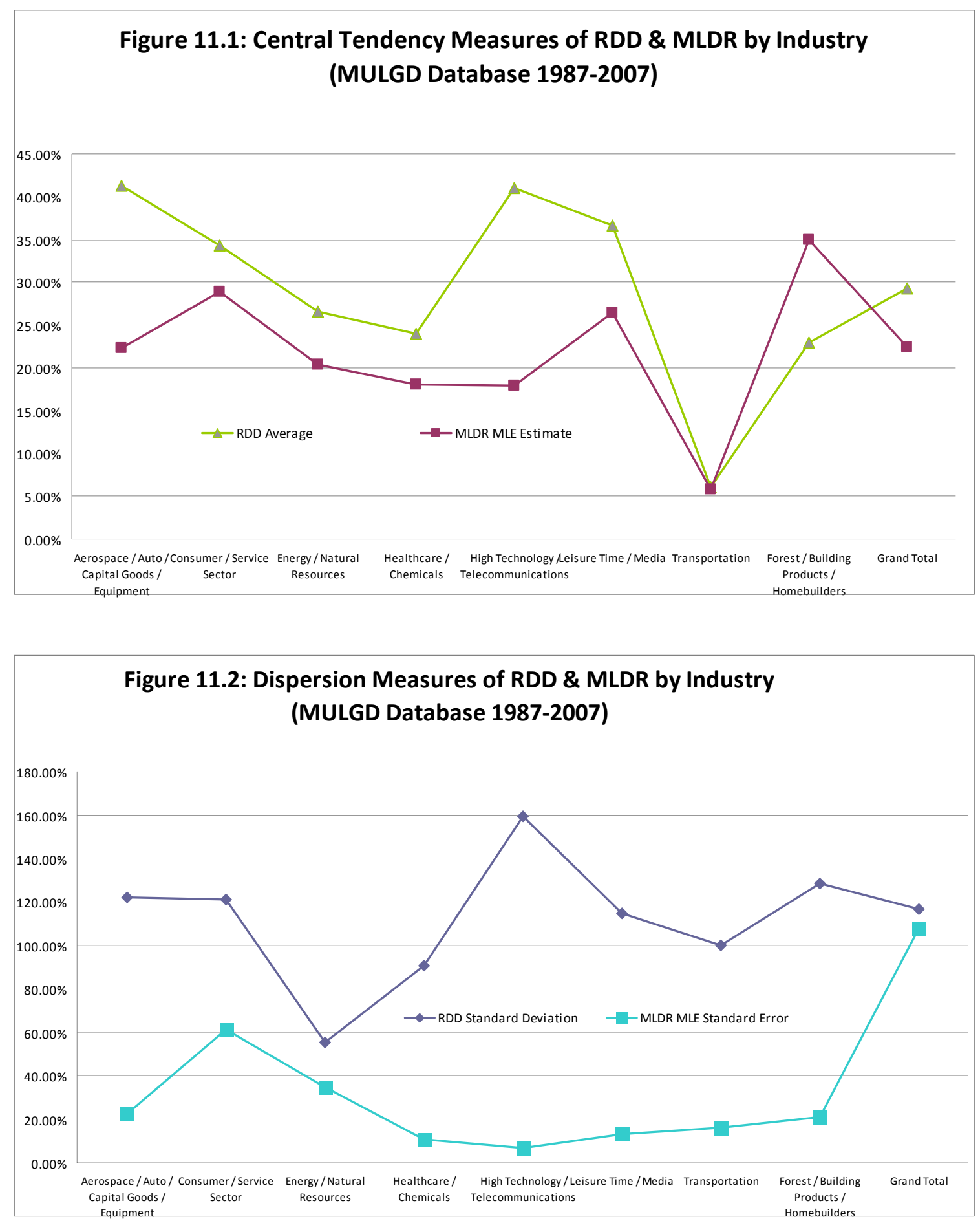
Figure 12.1: Annualized Return on Defaulted Debt vs. Market-to-Book Value (MULGD Database 1987-2007)

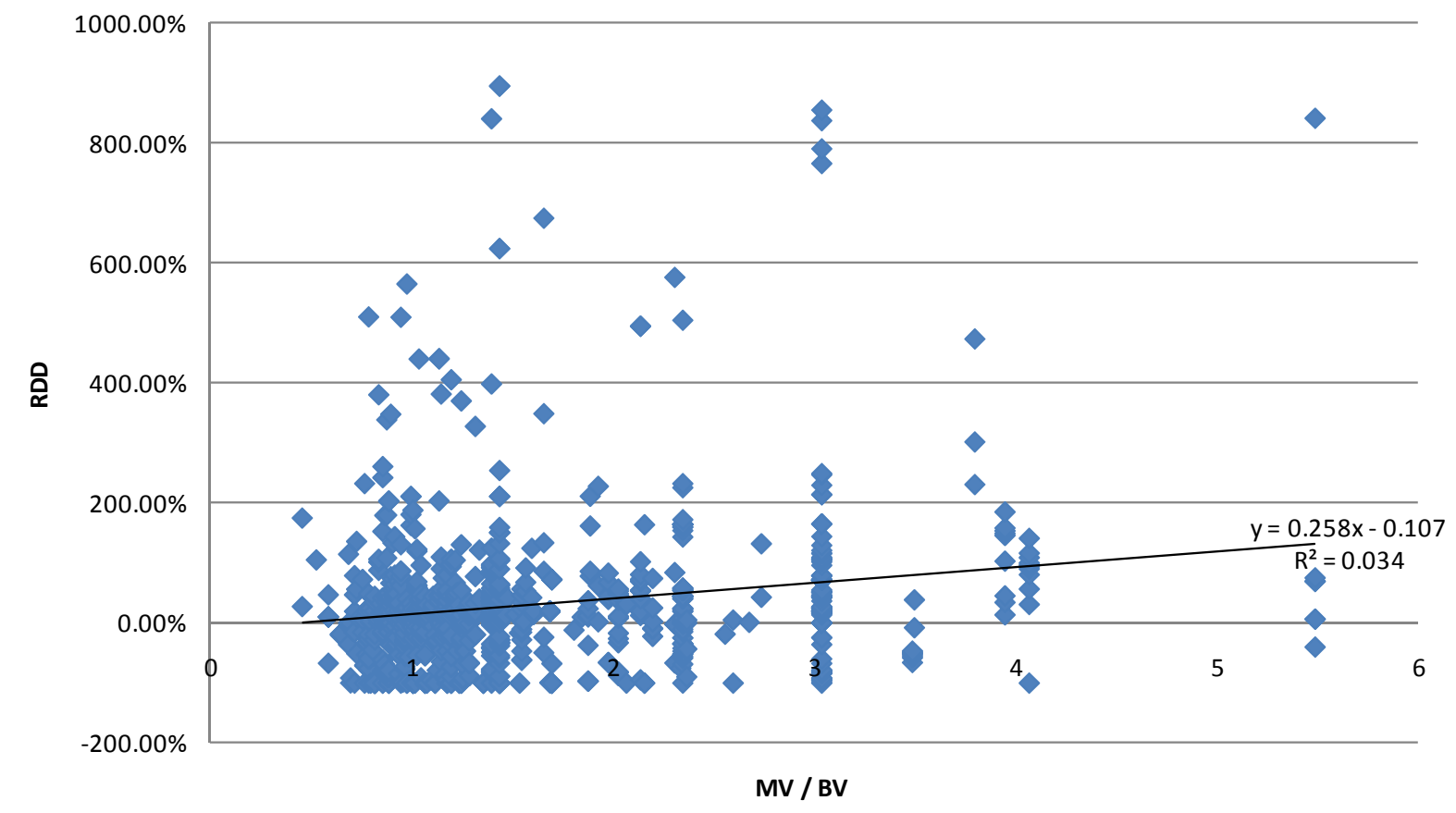

Figure 12.2: Annualized Return on Defaulted Debt vs.

Total Liabilities to Book Value of Assets (MULGD Database 1987-2007)

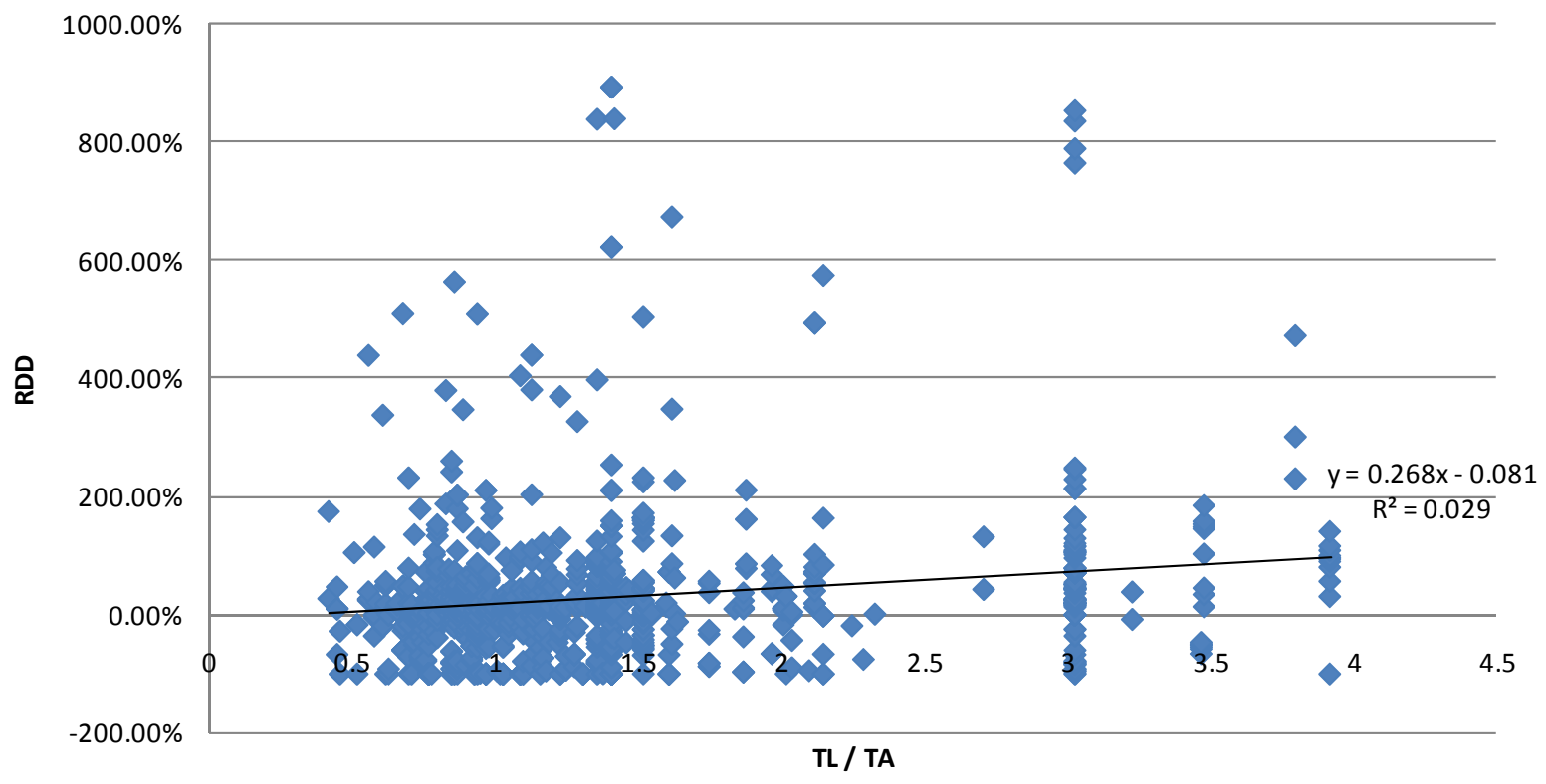




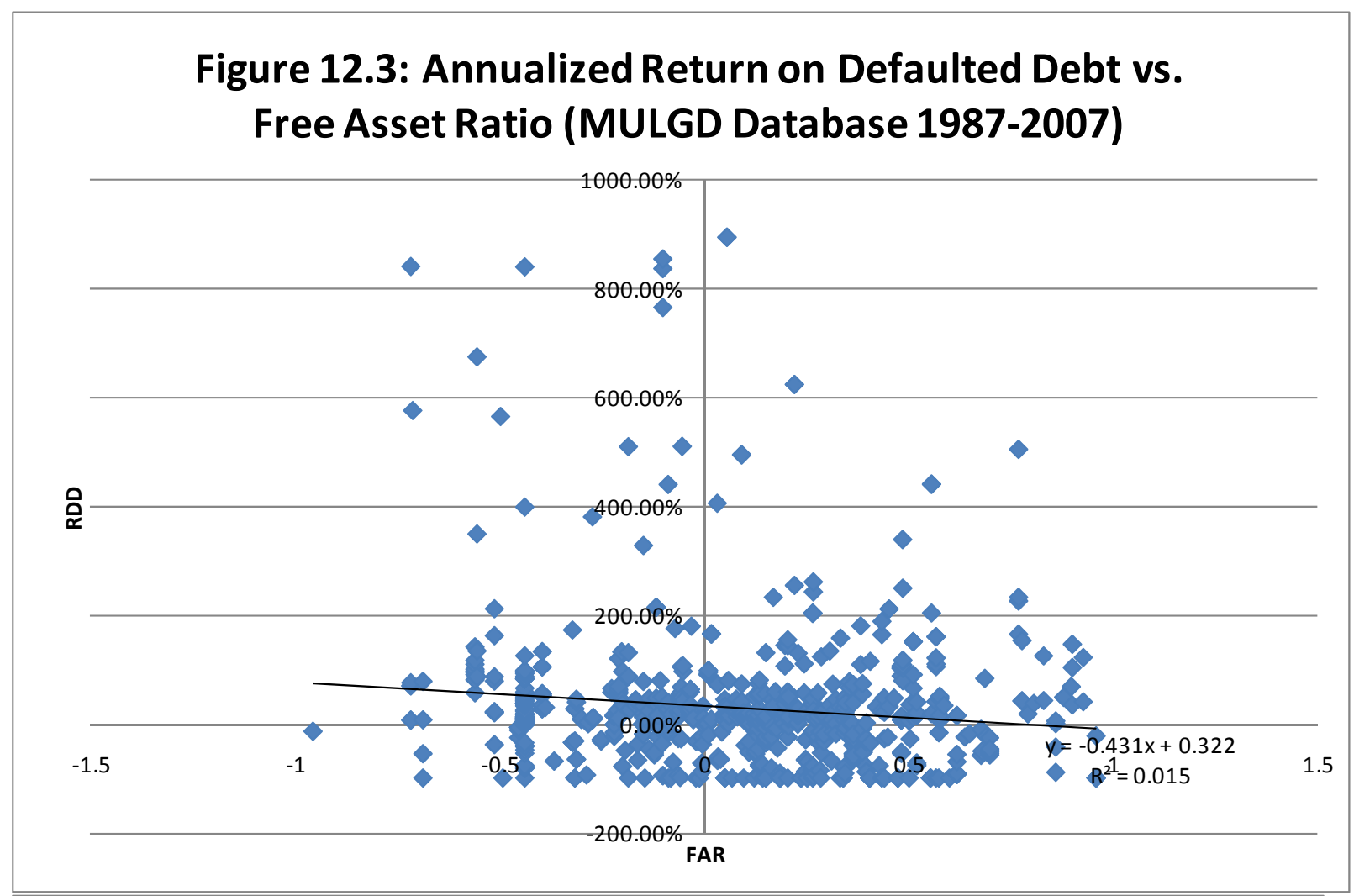

Figure 12.4: Annualized Return on Defaulted Debt vs. Cumulative Abnormal Equity Returns (MULGD Database 1987-2007)

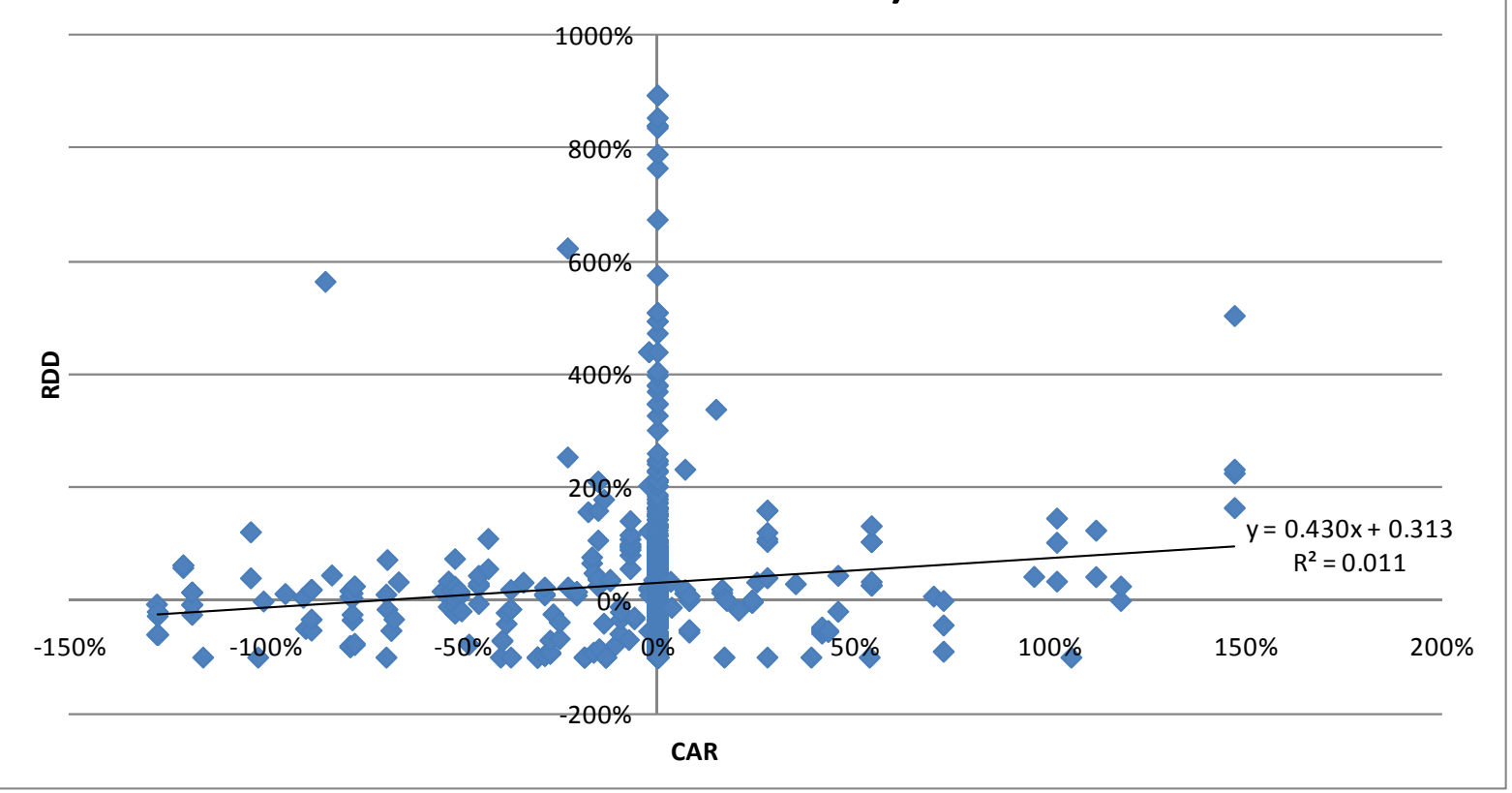



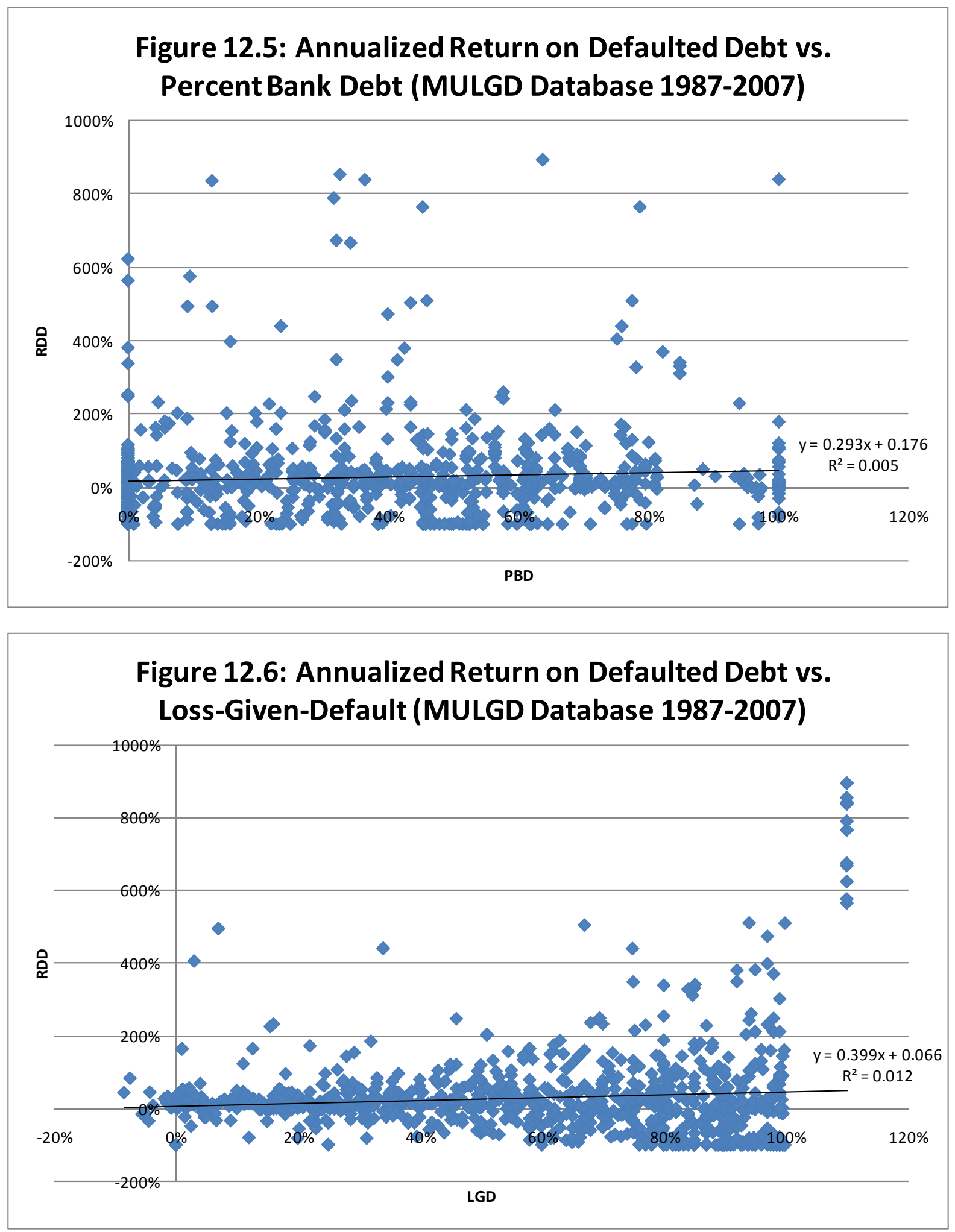

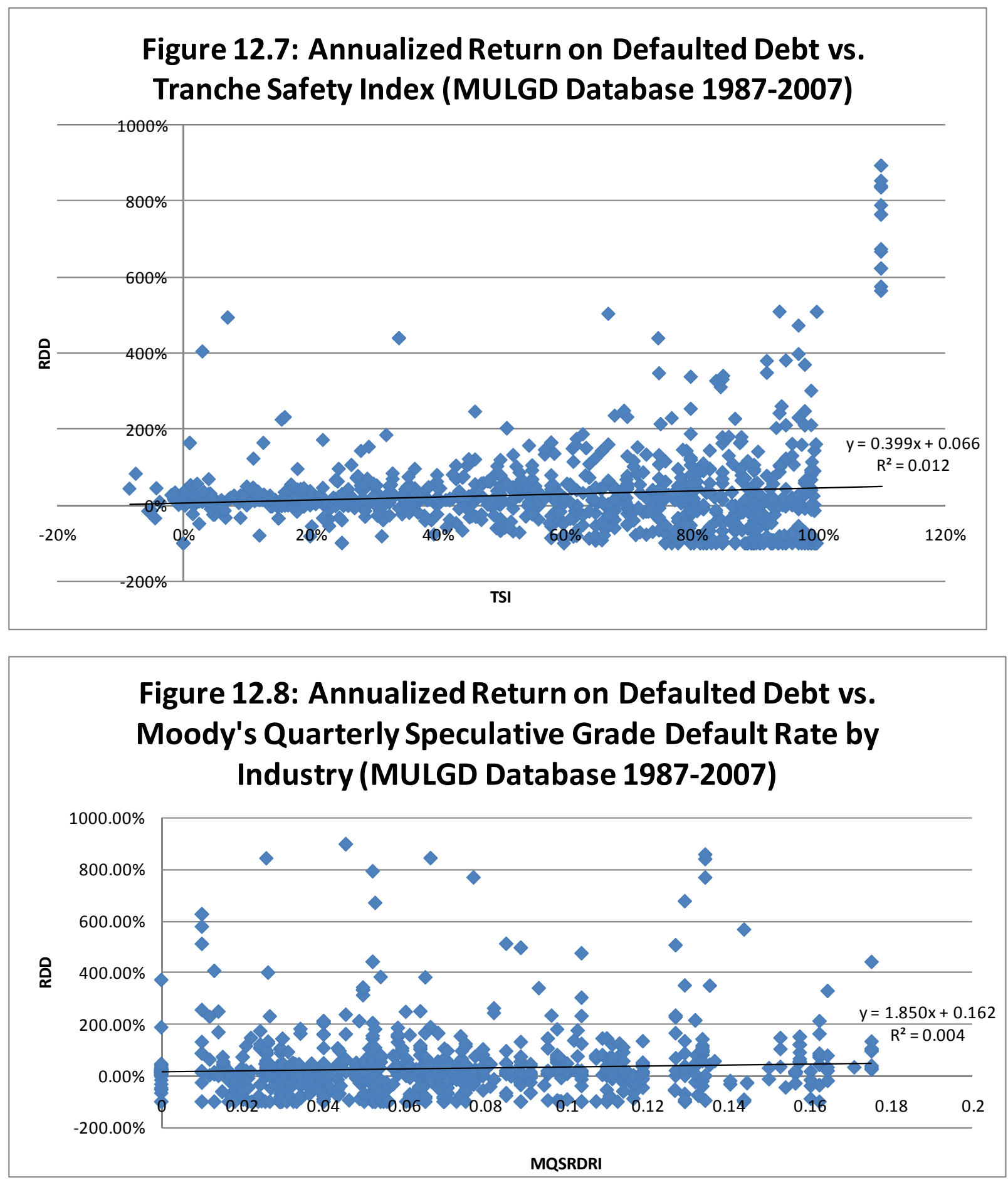

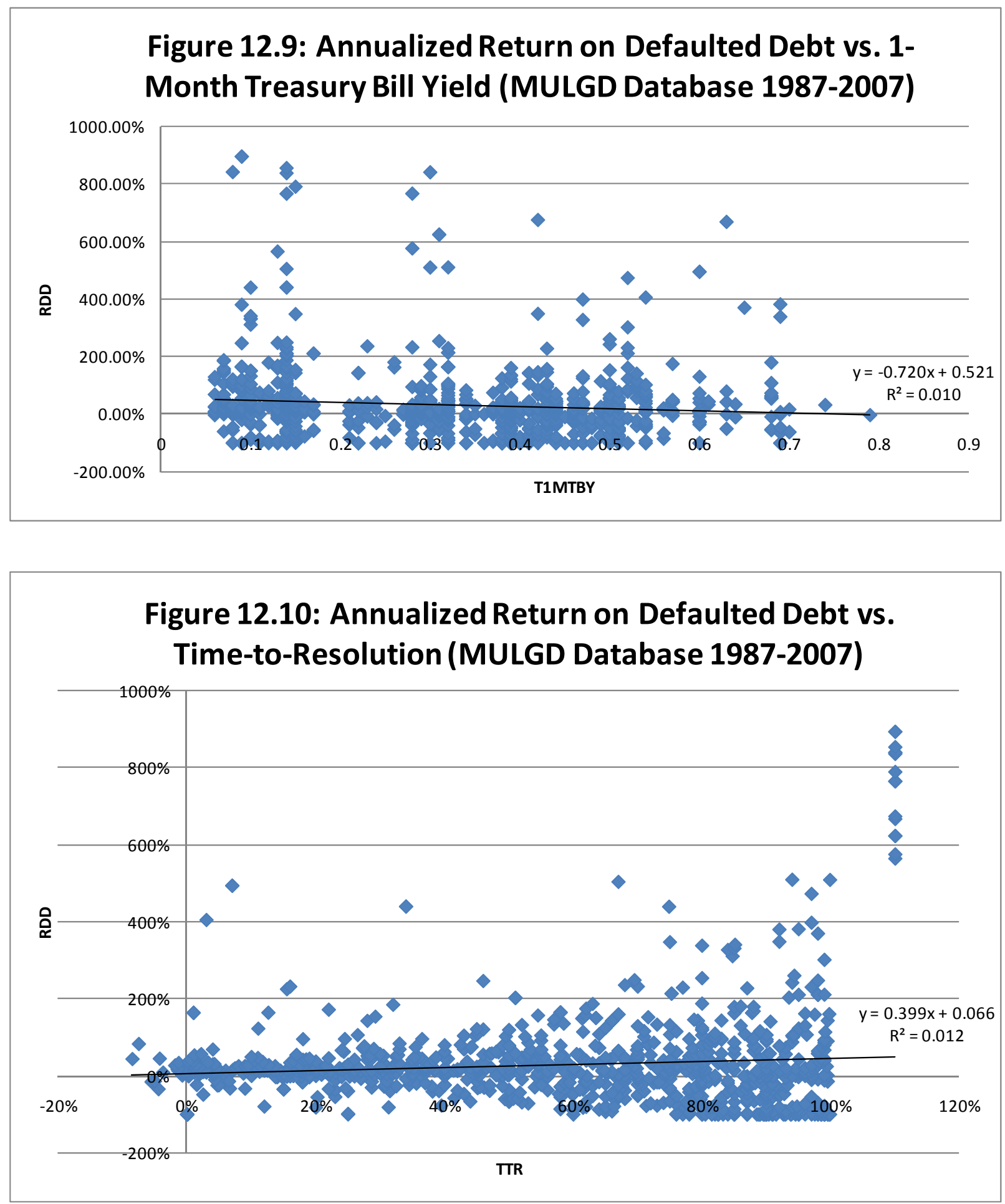


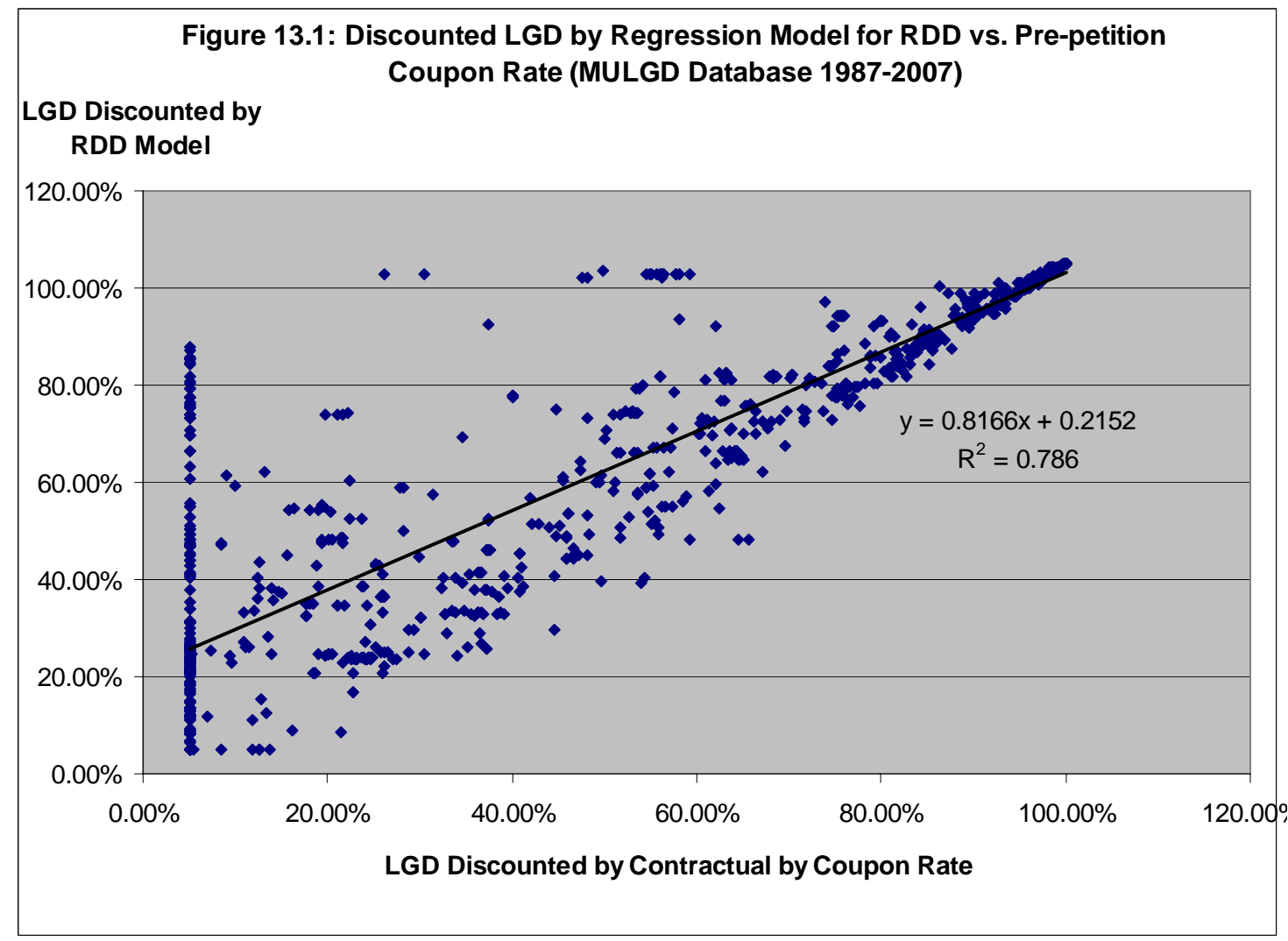

Figure 13.2: Discounted LGD by Regression Model for RDD vs. Punitive Discount Rate (MULGD Database 1987-2007)

\section{LGD Discounted by}

RDD Model

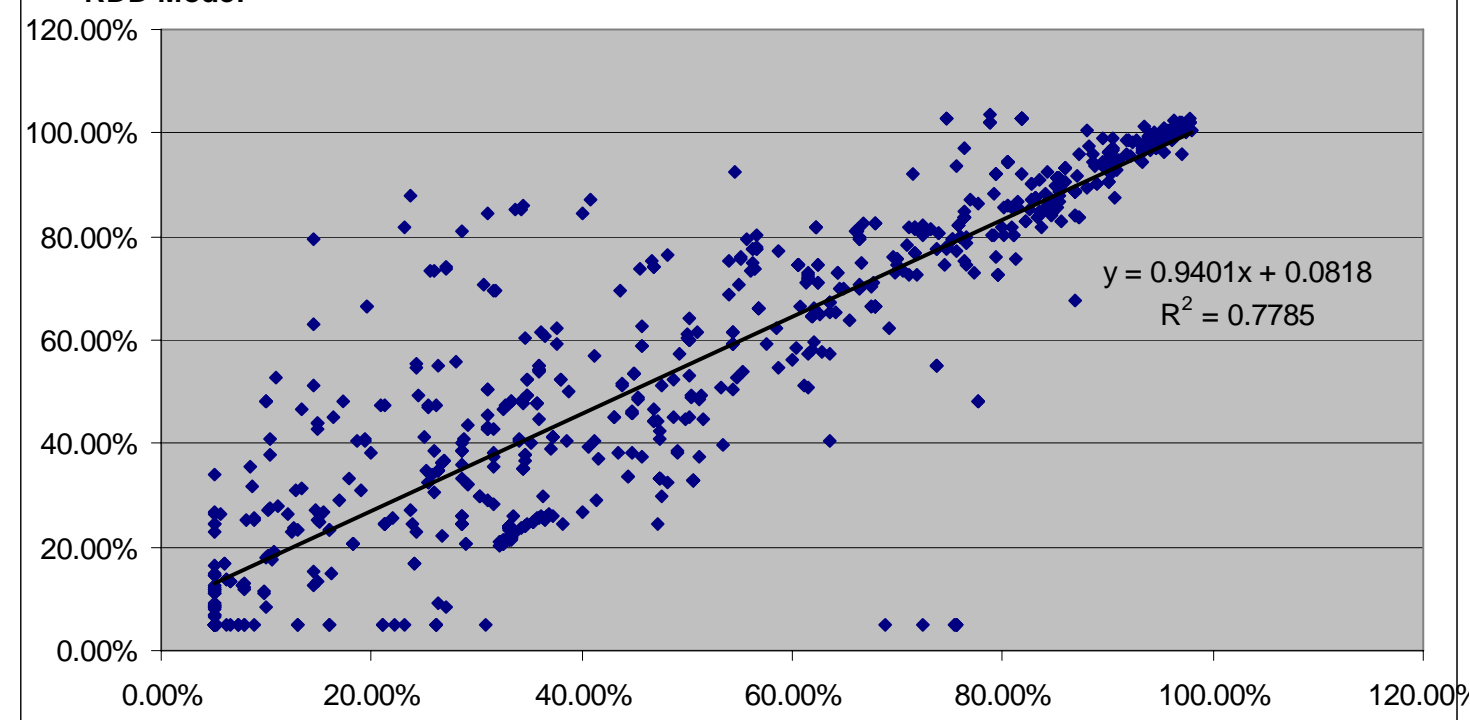

LGD Discounted by Punitive Discount Rate 
Figure 13.3: Densities of LGD Discounted by RDD Model vs. Contract Rate

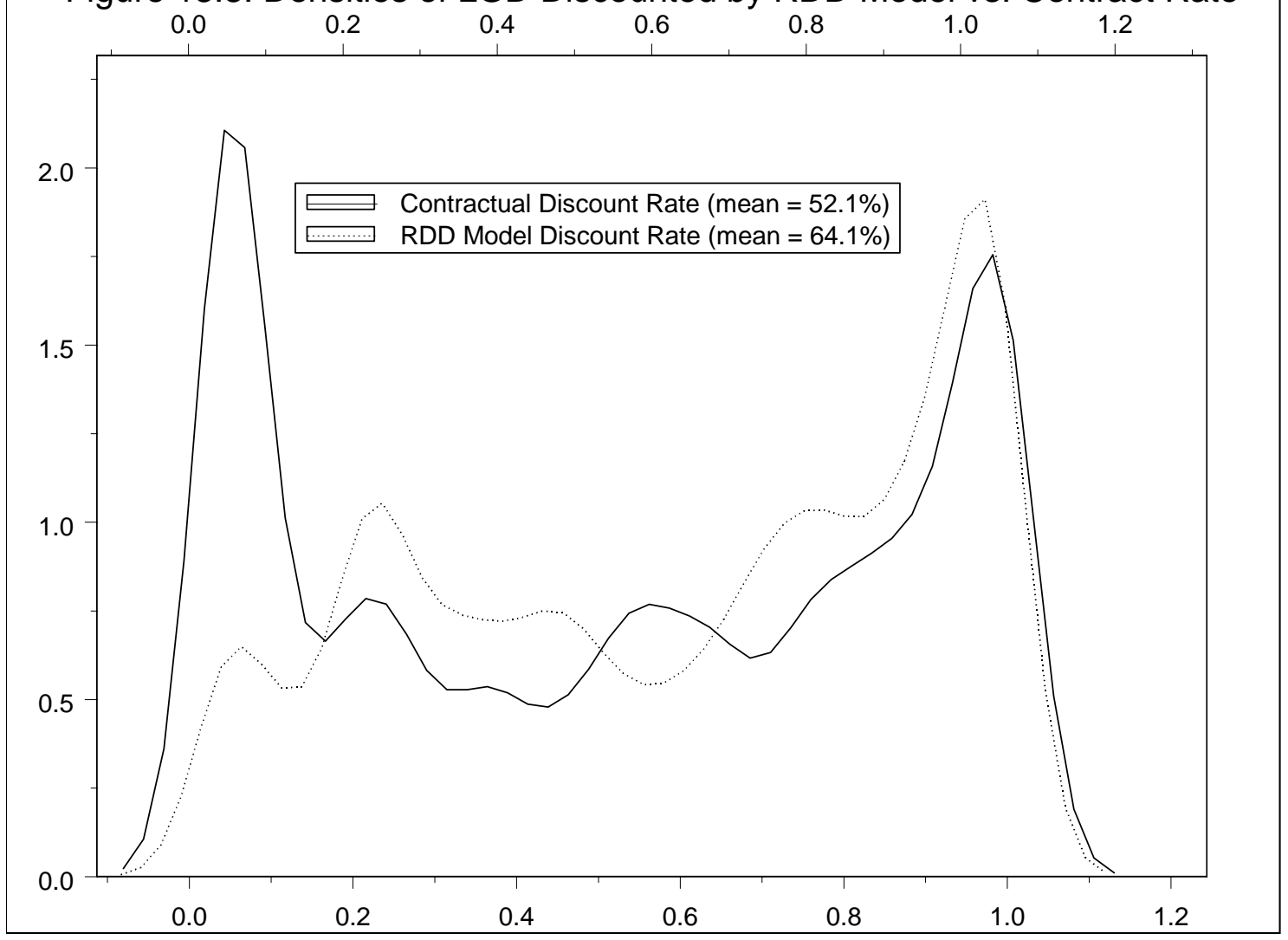

Figure 13.4: Densities of LGD Discounted by RDD Model vs. Punitive Rate

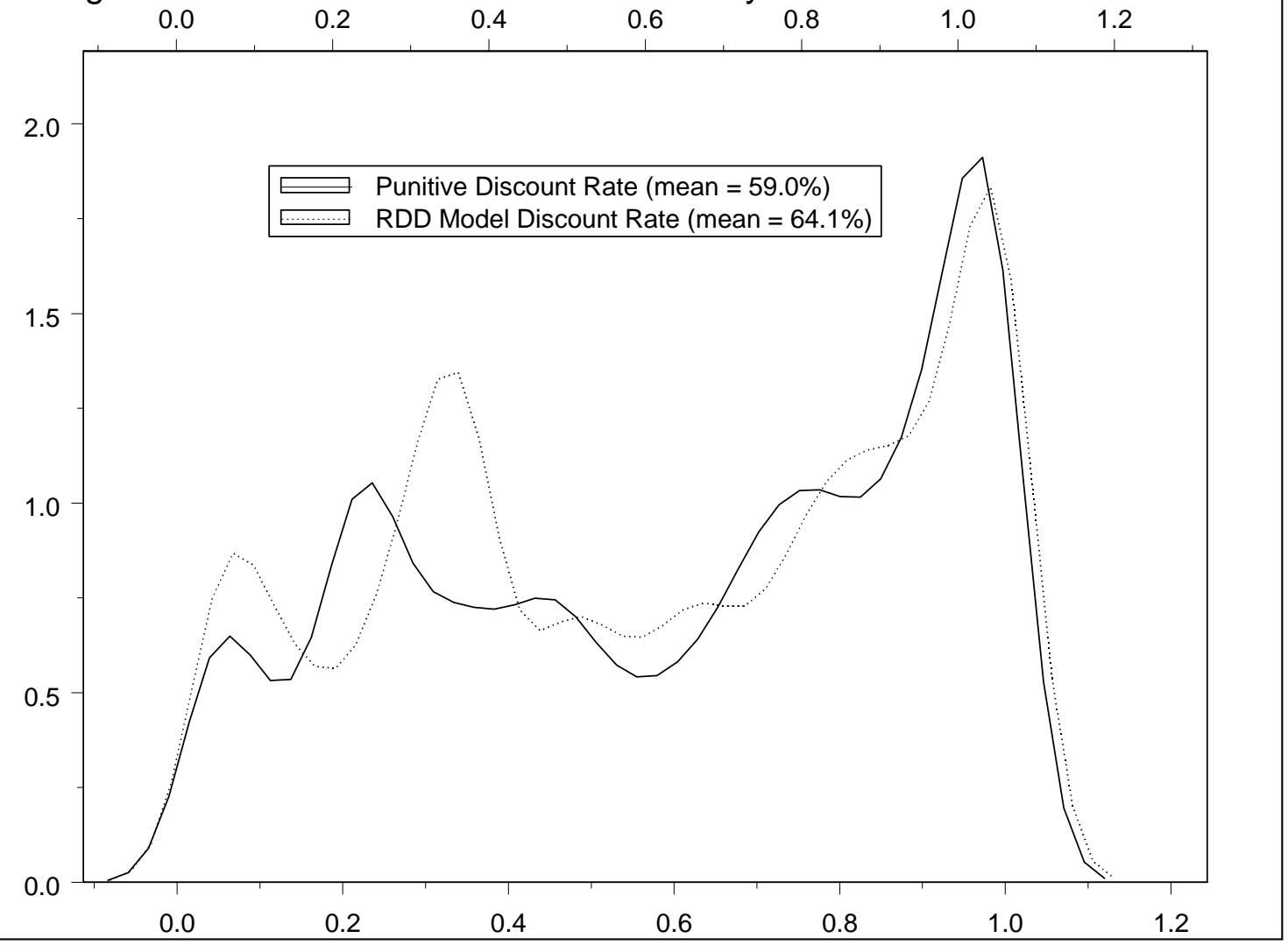


Figure 13.5: Densities of Regulatory Credit Capital (MULGD 1987-2007)

0.0

0.1

0.2

0.3

0.4

$0.5 \quad 0.6$

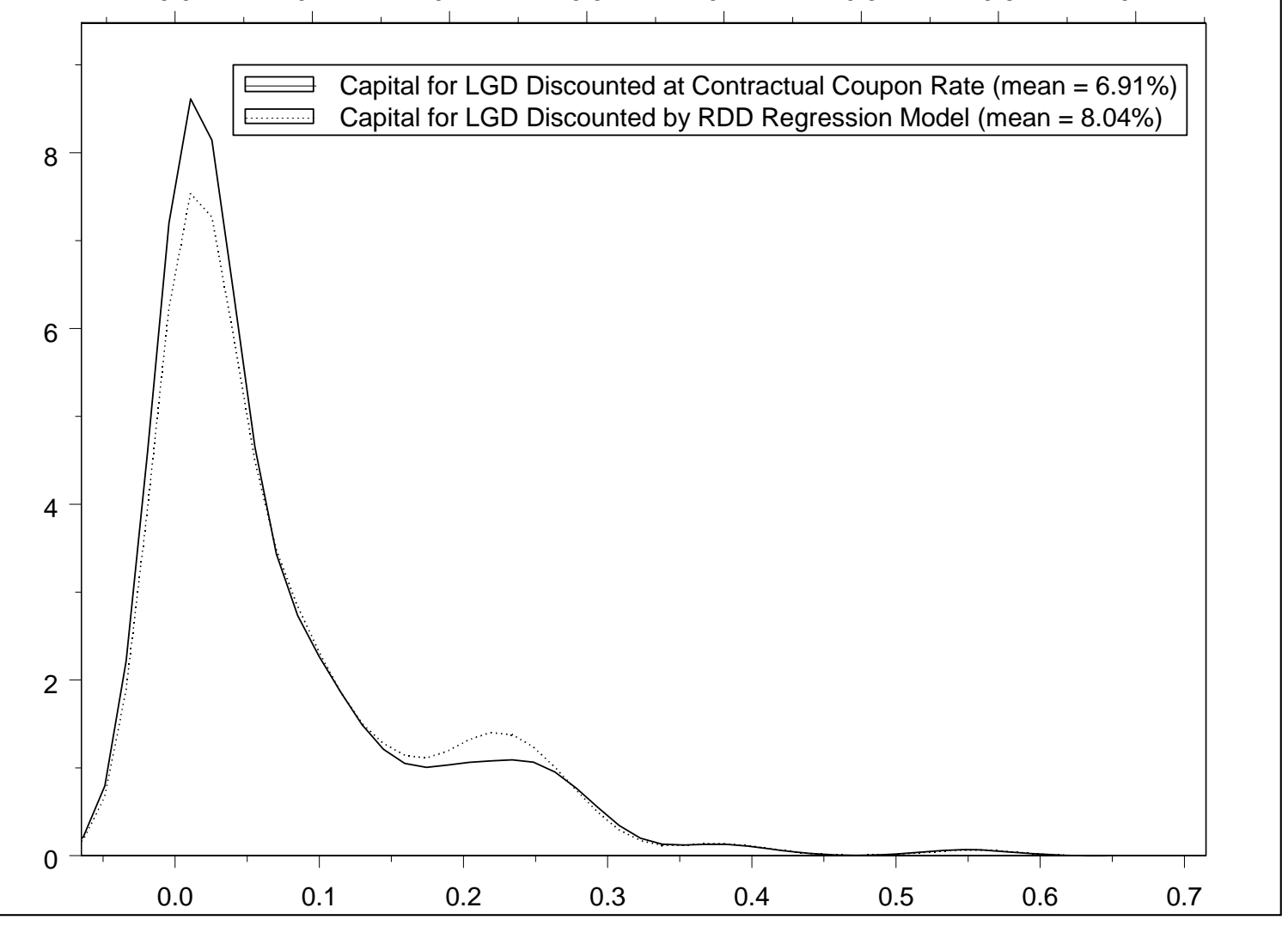

Figure 13.6: Densities of Regulatory Credit Capital (MULGD 1987-2007)

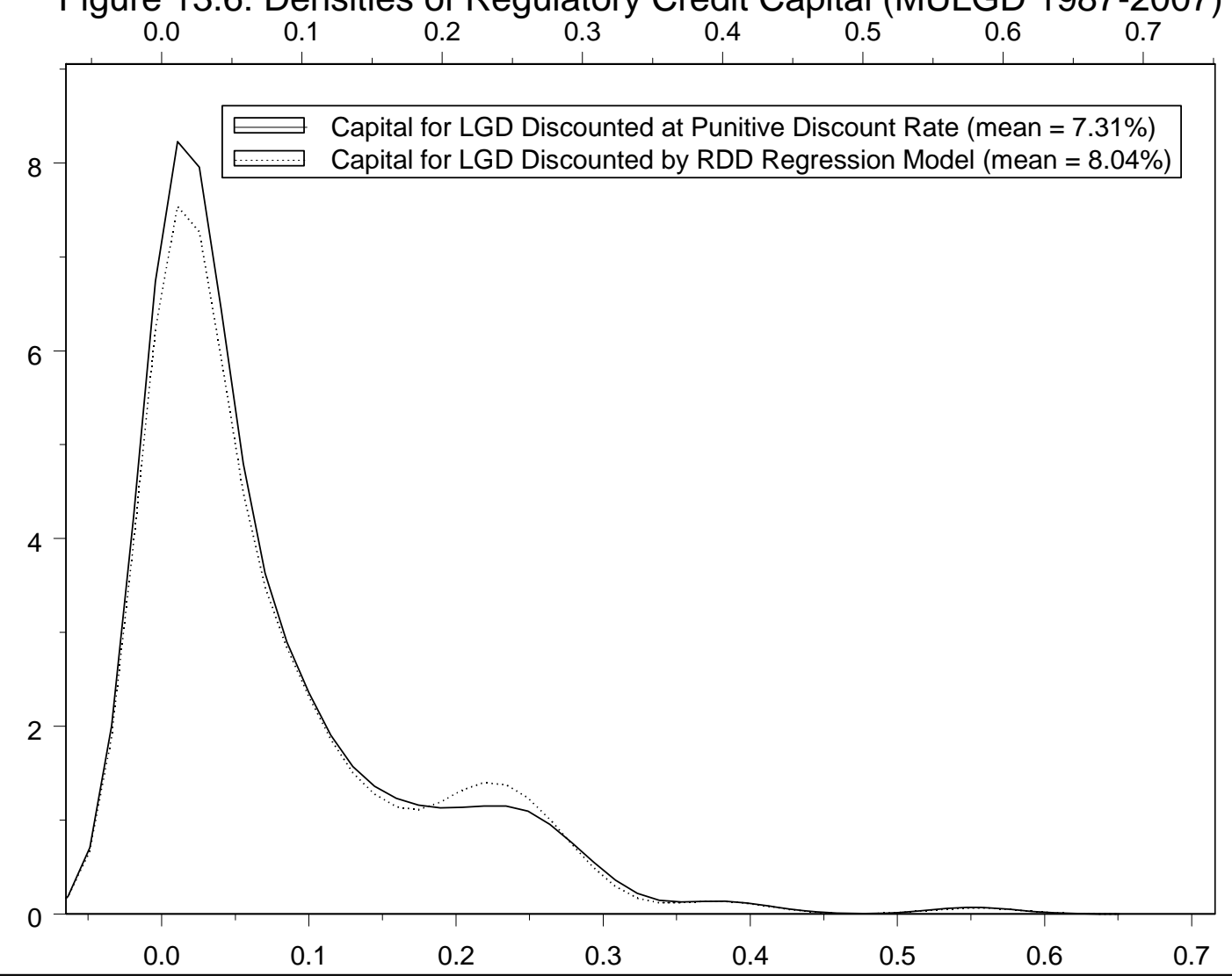




\section{References}

Altman, Edwa rd I., Resti, Andrea and Andrea Sironi, 2001, "Analyzing and Explaining Default Recovery Rates", ISDA Research Report, London, December 2001.

Araten, Michel, J acobs, J r., Mic hael and Peeyush Varshney, Measuring Loss Given Default on Commercial Loans for the J P Morgan Chase Wholesale Bank: An 18 Year Intemal Study, RMA J oumal, May 2004, 28-35.

Asamow, Elliot and David Edwards, 1995, Measuring loss on defaulted bank loans: a 24-yea rstudy, J oumal of Commercial Lending, Vol. 77, No.7, pp. 11-23.

Barco, Michael, 2007, Going downtum, Risk, April, \#\#-\#\#.

Basel Committee on Banking Supervision, 2003, "The New Ba sel Accord", Consultative Document, Bank for Intemational Settlements (BIS), April.

Basel Committee on Bank Regulation, 2004, “Intemational C onvergence on Capital Mea surement and Capital Standards", BIS, J une.

of the Fra mework Doc ument", BIS, J uly. ,2005, "Guidance on Paragraph468

Brady, B., Chang, P., Miu, P., Ozdemir, B and David Schwartz, 2006, Disc ount rate for workout recoveries: an empiric al study, Working Paper.

Carey, Mark and Michael Gordy, 2007, the bank as grim reaper: debt decomposition and recoveries on defaulted debt, Federal Reserve Board, Working Paper.

Carty, Lea and Dana Lieberman, 1996, Default bank loan recoveries, Moody's Investor Services, Special Comment.

Davis, P.O., 2004, “Credit Risk Measurement: Avoiding Unintended Results: Pa rt 3: Disc ount Rates and Loss G iven Defa ult" (J uly-August 2004), RMA J oumal, vol. 86, no. 10, pp. $92-95$

Eales, Robert and Edmond Bosworth, 1998, Severity of loss in the event of default in small business and la rger consumer loans, J ouma I of Lending and C redit Risk Management, pp, 58-65.

Emery, K., Cantor, R., Keisman, D. and Sharon O u, April 2007, Moody's Ultimate Rec overy Database, Special Comment, Moody's Investor Service.

Fama, Eugene F. and Kenneth R. French, 1992. "The Cross-Section of Expected Stock Retums", The J oumal of Fina nce, Vol. XLVII, No. 2. (J une).

Friedman, Craig and Sven Sand ow, 2003, Ultimate recoveries, Risk, 69-73.

Frye, J ohn, 2000a, Collateral da mage, Risk, April, 91-94. 
2000b, "Collateral Damage Detected", Federal reserve Bank of Chic ago, Emerging Issues Series, Oc tober, 1-14.

2000c, Depressing recoveries, Risk, November, 108-111.

2003, A false sense of security, Risk, August, 63-67.

Gordy, Michael, 2000, A compara tive anatomy of credit risk models, J oumal of Banking and Finance, pp. 119-149.

, 2003, A risk-factor model foundation for ratings-based bank c a pita I rules, J oumal of Fina nc ial Intemediation, Vol. 12, pp. 199-232.

Guha, R, 2003, Recovery of face value at default: empirical evidence and implic ations for credit risk pric ing, London Business Sc hool, Working paper.

Gregory Gupton and Roger M. Stein, 2005, “LossC alc TM V2: Dynamic Prediction of LGD", Moody's KMV.

Keisman, David and Karen van de Castle, 2000, Suddenly structure mattered: insights into recoveries of defaulted debt, Corporate Ratings - Commentary, Standard and Poors.

Kupiec, Paul, "Estimating Recovery Disc ount Rates: A Methodological Note," The J oumal of Risk Management in Fina ncial Institutions," Vol. 1, No. 1, 2007.

Maclachlan, I., 2004, "Choosing the Disc ount Factor for Estimating Ec onomic LGD”, (May 2004), Australia and New Zealand Banking Group Ltd, working paper

Maddala, G.S., 1983, Limited Dependent and Qualita tive Variables in Finance (Cambridge University Press, Ca mbridge).

1991, The perspective on the use of limited-dependent and qua lita tive variables models in accounting research, The Accounting Review 66: 788-807.

Mallick, B.K. and A.E. Gelfand, Generalized linear models with unknown link functions, Biometrika 1994 81(2):237-245.

Merton, P., Robert C., 1973, “Theory of Rational O ption Pricing” The Bell J oumal of Economic sand Mana gement Science, Vol. 4, No. 1 (Spring, 1973), pp. 141-183

Miu, P., and B. Ozdemir, 2005, "Practic al and Theoretic al Challenges in Validating Basel Pa rameters: Key Leamings from the Experience of a Canadian Bank" (Fall 2005), J oumal of Credit Risk, vol. 1, no. 4, pp. 89-136

Office of the Comptroller of the Currency / Department of the Trea sury, Federal Reserve System, Office of Thrift Supervision / Department of the Treasury; RiskBased Capital Standards: Advanced Capital Adequacy Framework - Ba sel II, Federal Register Vol. 72 No. 235, December 7, 2007 [“Ba sel II U.S. Final Rule”]. 
Vasicek, O. (1987). "Proba bility of Loss on a Loan Portfolio." Working Paper, KMV, 1987. Published as “Loan Portfolio Value," RISK, December 2002, pp. 160-162. 


\section{Appendix 1: Beta-Link Generalized Linear Model for RDD}

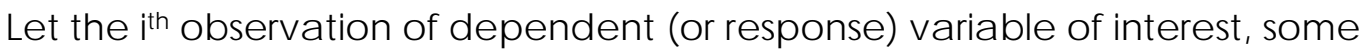
measure of the LGD discount rate be denoted $\varepsilon_{i}$ (e.g., the RDD), be observed independently. The vector of independent (or stimulus) variables correspond ing to bounded random variable $\varepsilon_{i}$ is denoted by $\mathbf{x}_{i}=\left(x_{1 i}, . . x_{p i}\right)^{\mathrm{T}}$. We assume that the conditional expectation of $\varepsilon_{i} \in(l, u) ; l, u \in R$ depends upon a linearfunction $\eta: R^{P} \times R^{P} \rightarrow R$ of the $\mathbf{x}_{i}$ only through a smooth, invertible function $m: R \rightarrow R:$

$$
\begin{gathered}
E_{P}\left[\varepsilon_{i} \mid \mathbf{x}_{i}\right]=\mu=\int_{l}^{u} p\left(\varepsilon_{i} \mid \mathbf{x}_{i}\right) \varepsilon_{i} d v\left(\varepsilon_{i}\right)=m(\eta) \\
\eta=\boldsymbol{\beta}^{T} \mathbf{x}_{i}=m^{-1}(\mu)
\end{gathered}
$$

Where $m^{-1}(.) \equiv \Lambda: R \rightarrow R$ is defined as the link function that maps from the conditional mean of the response variable $\mu$ to the linearfunction $\eta$. In this framework, the distribution of $\varepsilon_{i}$ resides in the exponential fa mily, membership in which implies a probability distribution function of the following form:

$$
\mathrm{p}\left(\varepsilon_{i} \mid \mathbf{x}_{i}, \boldsymbol{\beta}, A_{i}, \zeta\right)=\exp \left[\frac{A_{i}}{\zeta}\left\{\varepsilon_{i} \theta\left(\mathbf{x}_{i} \mid \boldsymbol{\beta}\right)-\gamma\left(\mathbf{x}_{i} \mid \boldsymbol{\beta}\right)\right\}+\tau\left(\varepsilon_{i}, \frac{\zeta}{A_{i}}\right)\right]
$$

Where $\gamma: R \rightarrow R$ and $\tau: R \rightarrow R$ are smooth functions (satisfying certa in regula rity conditions), $A_{i}$ is a known prior weight, $\varsigma \in R^{+}$is a scale parameter (possibly known), and the location function $\theta: R \rightarrow R$ is related to the linearpredictor according to:

$$
\theta\left(\mathbf{x}_{i} \mid \boldsymbol{\beta}\right)=\left(\gamma^{\prime}\right)^{-1}\left(\mu\left(\mathbf{x}_{i}\right)\right)=\left(\gamma^{\prime}\right)^{-1}\left(m\left(\boldsymbol{\beta}^{T} \mathbf{x}_{i}\right)\right)
$$

This framework subsumes many of the models in the literature on the classical linear regression and limited / qua lita tive dependent va riables fra mework.

We consider the case most releva nt for RDD estimation, and that least pursued in the GLM literature. In this context, we a re dealing with a random va riable in a bounded region, with no loss of genera lity we assume to be the unit interval. This most conveniently modelled through employing a beta distribution, in which case if we denote the response percent RDDD rate as $\varepsilon_{i} \in[0,1]$, then the density is given by:

$$
\mathrm{p}\left(\varepsilon_{i} \mid \mathbf{x}_{i}, \boldsymbol{\beta}\right)=\frac{\varepsilon_{i}^{\alpha\left(\boldsymbol{\beta}^{T} \mathbf{x}_{i}\right)-1}\left(1-\varepsilon_{i}\right)^{\beta\left(\boldsymbol{\beta}^{T} \mathbf{x}_{i}\right)-1}}{B\left[\alpha\left(\boldsymbol{\beta}^{T} \mathbf{x}_{i}\right), \beta\left(\boldsymbol{\beta}^{T} \mathbf{x}_{i}\right)\right]} \quad \varepsilon_{i} \in[0,1] ; \alpha, \beta: \mathbb{R} \rightarrow \mathbb{R}^{++}
$$


Where $B[x, y]=\frac{\Gamma(x) \Gamma(y)}{\Gamma(x+y)}=\int_{0}^{1} u^{x-i}(1-u)^{y-1} d u$ in (4.7) is the standard beta function, $\Gamma(x)=x$ ! is the gamma function, and we allow the generalization in which the constant parameters goveming the distribution are replaced by smooth, invertible functions $\alpha(),. \beta($.) of the linear predictors from the real-line to the positive half-plane $\mathbb{R} \rightarrow \mathbb{R}^{++} \times \mathbb{R}^{++}$. See Jacobs et al (2007) for a derivation of the canonical form (4.3) in this case. We follow Mallick and Gelfand (1994), in which the link function is taken as a mixture of cumulative beta distributions, the precise mixture of which being taking the form:

$$
\theta\left(\mathbf{x}_{i} \mid \boldsymbol{\beta}, \boldsymbol{\varphi}, \mathbf{a}, \mathbf{b}\right)=\boldsymbol{\beta}^{T} \mathbf{x}_{i}=\sum_{j=1}^{k} \phi_{j} \int_{u=0}^{l_{i}} \frac{u^{a_{j}-1}(1-u)^{b_{j}-1}}{B\left[a_{j}, b_{j}\right]} d u
$$

Where the parameters $\boldsymbol{\varphi}, \mathbf{a}, \mathbf{b}$ are chosen to match features of the data. In this application, a mixture of 2 beta distributions was found to be sufficient. While in most cases we will not have a closed-fom or even an a nalytic solution, we may a lwa ys estimate the underlying pa rameters $\boldsymbol{\beta}$ consistently and effic iently by maximizing the log-likelihood function:

$$
l\left(\theta\left(\boldsymbol{\beta} \mid \mathbf{x}_{i}\right), \zeta\left(\boldsymbol{\beta} \mid \mathbf{x}_{i}\right), \boldsymbol{\beta} \mid \mathbf{x}_{i}, \varepsilon_{i}, A_{i}\right)=\sum_{i=1}^{n}\left[\frac{A_{i}}{\zeta\left(\boldsymbol{\beta} \mid \mathbf{x}_{i}\right)}\left\{\varepsilon_{i} \theta_{i}\left(\boldsymbol{\beta} \mid \mathbf{x}_{i}\right)-\gamma\left(\boldsymbol{\beta} \mid \mathbf{x}_{i}\right)\right\}+\tau\left(\varepsilon_{i}, \frac{\zeta\left[\boldsymbol{\beta} \mid \mathbf{x}_{i}\right]}{A_{i}}\right)\right]
$$

\section{Appendix 2: Two-Factor Structural Credit Risk Model}

In this appendix we outline the development of the likelihood function for a 2factor extension of the asymptotic single risk factor model (Gordy, 2003), which underlies the Ba sel 2 fra mework for regulatory credit risk ca pital, inc orporating systematic recovery risk. Let us denote asset value for the $i^{\text {th }}$ segment of fims (these can be rating classes) by:

$$
A_{t, r}=\rho_{r} X_{t}+\sqrt{1-\rho_{r}^{2}} Z_{t, r}
$$

where $A_{t, r}$ is the asset value of the representative borrower in rating class $r$ at time $\mathrm{t}, Z_{t, r} \sim N(0,1)$ is the corresponding idiosyncratic risk factor, $X_{t} \sim N(0,1)$ (and independent of $Z_{t, r}$ ) is the systematic risk factorgoveming aggregate default rates at time $t$ and the non-nega tive parameter $\rho_{r}$ is the sensitivity (or loa ding) of assets in class $r$ to the systematic risk factor (and $\rho_{r}^{2}$ is referred to as the asset value correlation). It follows that the conditional probability-of-default (PD) is given by the ubiquitous Va sic ek (1987) fo mula: 


$$
R\left(X_{t} \mid P D_{r}, \rho_{r}\right)=\operatorname{Pr}\left(Z_{t, r}<\frac{\Theta^{-1}\left(P D_{r}\right)-\rho_{r} X_{t}}{\sqrt{1-\rho_{r}^{2}}}\right)=\Theta\left(\frac{\Theta^{-1}\left(P D_{r}\right)-\rho_{r} X_{t}}{\sqrt{1-\rho_{r}^{2}}}\right)
$$

where $R\left(X_{t} \mid P D_{r}, \rho_{r}\right)$ denotes the PD conditional as a function of the systematic risk factor, $P D_{r}$ is the unconditional (or long-run) probability-of-d efault parameter for the $r^{\text {th }}$ rating and $\Phi(z)=\operatorname{Pr}(Z \leq z)=\frac{1}{2 \pi} \int_{-\infty}^{z} e^{-\frac{1}{2} u^{2}} d u$ is the cumulative distribution function for a standard nomal random variable and $\Phi^{-1}(p)=\inf _{z} \operatorname{Pr}(p \leq \Phi(z))$ is the inverse of the distribution (or the quantile function). We can derive the $d$ istribution of the default rate (the realization of the conditionalPD) in yeart for rating class $r, d r_{t, r} \equiv L\left(x_{t} \mid P D_{r}, \rho_{r}\right)$, by a change-of-varia blestechnique, as (15.2) is invertible. The systematic risk factor is:

$$
X_{t}=\frac{\Phi^{-1}\left(P D_{r}\right)-\sqrt{1-\rho_{r}^{2}} \Phi^{-1}\left(d r_{t, r}\right)}{\rho_{r}}
$$

Then, according to the formula

$$
X \sim f_{X}(x), y=g(x) \rightarrow Y \sim f_{Y}(y)=\left|\frac{d g^{-1}(y)}{d y}\right| f_{X}\left(g^{-1}(y)\right)
$$

The distribution of $d r_{t, r}$ :

$$
f_{d r}\left(d r_{t, r} \mid P D_{r}, \rho_{r}\right)=\frac{\sqrt{1-\rho_{r}^{2}}}{\rho_{r} \phi\left(d r_{t, r}\right)} \phi\left(\frac{\Phi^{-1}\left(P D_{r}\right)-\sqrt{1-\rho_{r}^{2}} \Phi^{-1}\left(d r_{t, r}\right)}{\rho_{r}}\right)
$$

Where $\varphi(z)=\frac{1}{2 \pi} e^{-\frac{1}{2} z^{2}}$ is the normal density function.

We model the recovery side analogously, starting with a "loss process" $L_{t, s}$ at time t for senionity class s:

$$
L_{t, s}=\rho_{s} Y_{t}+\sqrt{1-\rho_{s}^{2}} Z_{t, s}
$$

where $Z_{t, s} \sim N(0,1)$ is the corresponding id iosyncratic risk factor, $Y_{t} \sim N(0,1)$ (and independent of $Z_{t, C}$ ) is the systematic risk factor goveming aggregate default rates at time $t$ and the non-negative parameter $\rho_{s}$ is the sensitivity (or loading) of a ssets in seniority class s to the systematic risk factor (and $\rho_{s}^{2}$ is the "loss correlation"). It follows that the conditional loss-given-default (LGD) is given by the ubiquitous Vasicek (1987) formula:

$$
L\left(Y_{t} \mid L G D_{s}, \rho_{s}\right)=\operatorname{Pr}\left(Z_{t, s}<\frac{\Theta^{-1}\left(L G D_{s}\right)-\rho_{s} Y_{t}}{\sqrt{1-\rho_{s}^{2}}}\right)=\Theta\left(\frac{\Theta^{-1}\left(L G D_{s}\right)-\rho_{s} Y_{t}}{\sqrt{1-\rho_{s}^{2}}}\right)
$$


where $L\left(y_{t} \mid L G D_{s}, \rho_{s}\right)$ denotes the LGD conditional as a function of the systematic risk factor $Y, L G D_{c}$ is the unc ond itional (or long-run) loss-givendefault parameter for the $s^{\text {th }}$ senionity class. We can derive the distribution of the loss rate (the rea lization of the conditional LGD) in yeart for seniority class $S$, $l r_{t, s} \equiv L\left(x_{t} \mid P D_{r}, \rho_{r}\right)$, by a change-of-variables technique, as (15.6) is invertible.

The systematic risk factor is:

$$
Y_{t}=\frac{\Phi^{-1}\left(L G D_{s}\right)-\sqrt{1-\rho_{s}^{2}} \Phi^{-1}\left(l r_{t, s}\right)}{\rho_{s}}
$$

Then, according to the (15.3) distribution of $l r_{t, s}$ :

$$
f_{l r}\left(\operatorname{lr}_{t, s} \mid L G D_{s}, \rho_{s}\right)=\frac{\sqrt{1-\rho_{s}^{2}}}{\rho_{s} \phi\left(l r_{t, s}\right)} \phi\left(\frac{\Phi^{-1}\left(L G D_{s}\right)-\sqrt{1-\rho_{s}^{2}} \Phi^{-1}\left(l r_{t, s}\right)}{\rho_{s}}\right)
$$

We now derive the likelihood function for the model parameters. We assume that the systematic risk factors on the PD and LGD sides, $X_{t}$ and $Y_{t}$, are bivariate normal with correlation $r$

$$
\left(X_{t}, Y_{t}\right)^{T} \sim \Phi_{2}\left(\left(\begin{array}{l}
0 \\
0
\end{array}\right),\left(\begin{array}{cc}
1 & r_{X Y} \\
r_{X Y} & 1
\end{array}\right)\right)
$$

where the $\Phi_{2}(x, y \mid \rho)=\frac{1}{2 \pi \sqrt{1-\rho^{2}}} \exp \left(x^{2}-2 \rho x y+y^{2}\right)$ is bivariate standa rd ized normal distribution is for zero-mean and unit variance random variables $\mathrm{x}, \mathrm{y}$ with correlation $\rho$. The likelihood contribution for a representative instrument in $r^{\text {th }}$ rating and $\mathrm{s}^{\text {th }}$ senionity class in yeart has the integral form:

$$
\begin{aligned}
& l\left(d r_{t, r}, d r_{t, s} \mid P D_{r}, \rho_{r}, L G D_{s}, \rho_{s}, r_{X Y}\right)= \\
& \int_{0}^{1} \int_{0}^{1} \frac{\sqrt{1-\rho_{r}^{2}}}{\rho_{r} \phi(u)} \phi\left(\frac{\Phi^{-1}\left(P D_{r}\right)-\sqrt{1-\rho_{r}^{2}} \Phi^{-1}(u)}{\rho_{r}}\right) \frac{\sqrt{1-\rho_{s}^{2}}}{\rho_{s} \phi(v)} \phi\left(\frac{\Phi^{-1}\left(L G D_{s}\right)-\sqrt{1-\rho_{s}^{2}} \Phi^{-1}(v)}{\rho_{s}}\right) \Phi_{2}\left(u, v \mid r_{X Y}\right) d u d v
\end{aligned}
$$

Assuming independence across ratings, seniorities and years, the full loglikelihood is given by:

$$
\begin{aligned}
& \log L\left(\left\{d r_{t, r}, d r_{t, s}\right\}_{t=, \ldots, T ; r=1, ., R ; s=1, . ., S} \mid\left\{P D_{r}, \rho_{r}, L G D_{s}, \rho_{s}\right\}_{t=, . ., T ; r=1, \ldots, R ; s=1, . ., S}, r_{X Y}\right)= \\
= & \sum_{t=1}^{T} \sum_{r=1}^{R} \sum_{s=1}^{S} \log \left[l\left(d r_{t, r}, d r_{t, s} \mid P D_{r}, \rho_{r}, L G D_{s}, \rho_{s}, r_{X Y}\right)\right]
\end{aligned}
$$

